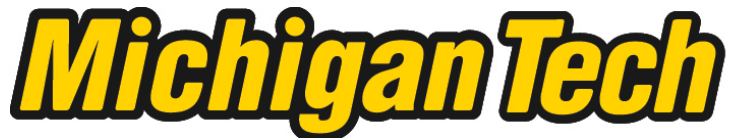 \\ Michigan Technological University Create the Future Digital Commons @ Michigan Tech
}

\section{Land use/cover change using Remote Sensing and Geographic Information Systems : Pic Macaya National Park, Haiti}

Jessie A. Vital

Michigan Technological University

Follow this and additional works at: https://digitalcommons.mtu.edu/etds

Part of the Forest Sciences Commons

Copyright 2008 Jessie A. Vital

\section{Recommended Citation}

Vital, Jessie A., "Land use/cover change using Remote Sensing and Geographic Information Systems : Pic Macaya National Park, Haiti", Master's Thesis, Michigan Technological University, 2008.

https://doi.org/10.37099/mtu.dc.etds/138

Follow this and additional works at: https://digitalcommons.mtu.edu/etds

8 Part of the Forest Sciences Commons 


\title{
Land Use/Cover Change Using Remote Sensing and Geographic Information Systems: Pic Macaya National Park, Haiti
}

By

Jessie A. Vital

\begin{abstract}
A THESIS
Submitted in partial fulfillment of the requirements

For the degree of

MASTER OF SCIENCE IN FOREST ECOLOGY AND MANAGEMENT

MICHIGAN TECHNOLOGICAL UNIVERSITY

2008
\end{abstract}

Copyright @ Jessie A. Vital 2008 
This thesis, "Land Use/Cover Change Using Remote Sensing and Geographic Information Systems: Pic Macaya National Park, Haiti "is hereby approved in partial fulfillment of the requirements for the degree of MASTER OF SCIENCE IN FOREST ECOLOGY AND MANAGEMENT.

School of Forest Resources and Environmental Sciences

Signatures:

Thesis Advisor

Dr. Ann L. Maclean

Dean

Dr. Margaret R. Gale

Date 


\section{ABSTRACT}

A post classification change detection technique based on a hybrid classification approach (unsupervised and supervised) was applied to Landsat Thematic Mapper (TM), Landsat Enhanced Thematic Plus (ETM+), and ASTER images acquired in 1987, 2000 and 2004 respectively to map land use/cover changes in the Pic Macaya National Park in the southern region of Haiti. Each image was classified individually into six land use/cover classes: built-up, agriculture, herbaceous, open pine forest, mixed forest, and barren land using unsupervised ISODATA and maximum likelihood supervised classifiers with the aid of field collected ground truth data collected in the field. Ground truth information, collected in the field in December 2007, and including equalized stratified random points which were visual interpreted were used to assess the accuracy of the classification results. The overall accuracy of the land classification for each image was respectively: 1987 (82\%), 2000 (82\%), 2004 (87\%). A post classification change detection technique was used to produce change images for 1987 to 2000, 1987 to 2004, and 2000 to 2004. It was found that significant changes in the land use/cover occurred over the 17- year period. The results showed increases in built up (from $10 \%$ to 17\%) and herbaceous (from 5\% to 14\%) areas between 1987 and 2004. The increase of herbaceous was mostly caused by the abandonment of exhausted agriculture lands. At the same time, open pine forest and mixed forest areas lost (75\%) and (83\%) of their area to other land use/cover types. Open pine forest (from $20 \%$ to $14 \%$ ) and mixed forest (from18 to $12 \%$ ) were transformed into agriculture area or barren land. This study illustrated the continuing deforestation, land degradation and soil erosion in the region, which in turn is leading to decrease in vegetative cover. The study also showed the importance of Remote Sensing (RS) and Geographic Information System (GIS) technologies to estimate timely changes in the land use/cover, and to evaluate their causes in order to design an ecological based management plan for the park. 


\section{AKNOWLEDGEMENTS}

There are a number of people I would like to acknowledge for their contribution to my thesis research writing and my stay here in Houghton. Foremost, I would like to express my sincere gratitude to my advisor, Dr. Ann Maclean for her guidance, encouragement, approachability, valuable comments and endless patience in improving my writing. Without her, this would not have been possible. I am also grateful to my Committee Members, Drs. Blair Orr, Kathleen E. Halvorsen, Alex Mayer for their insightful suggestions and comments.

I want also to express my thanks to Fulbright and the Graduate School for sponsoring my stay here and the cost of my studies. I want to thank the Dean, the Faculty and the staff from the Graduate School, SFRES, for making my time at Michigan Tech most fruitful. I thank the FW3540 GIS lab students with whom I shared a wonderful teaching and learning experience. I would like to thank colleagues from GIS, and the biometrics and modeling lab: Luke Spaete, Lacey Mason, Sinan Aabood, Clara Anton, Bharat Pokharel, and Chris Miller for their support, laugh and company.

A special thanks to my flatmates Abbygaiel Beggs and Jessica Lynn Koski for their companionships. Sara Fares, Fredline Ilorme, Yeliana Yeliana, Amber Lilly Kenny, Anna Colvin, Jim Shultz, Michel Bourdieu, Dr. Rima B. Carlson and family, and the wonderful Peace Corps Volunteers of Michigan Tech, thank you for your support and all the good times we had together.

I want to thank my field crew Jean Denis Chery and my brother Mackenzie who accompanied me in the field and helped with the fieldnotes. I would also like to thank Despagne family in Macaya for their hospitality during my field visit. Lastly, I am grateful to my dear family and parents, for their love and, particularly my dad, who always encourages me and reminds me that everything is possible through education and efforts. 


\section{TABLE OF CONTENTS}

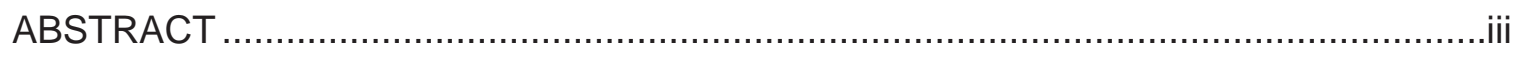

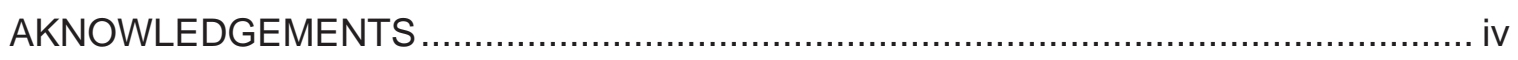

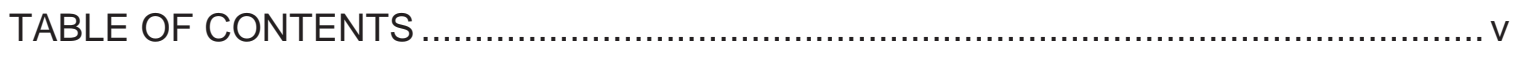

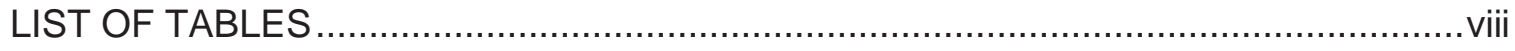

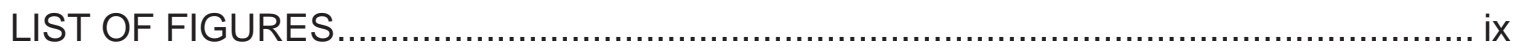

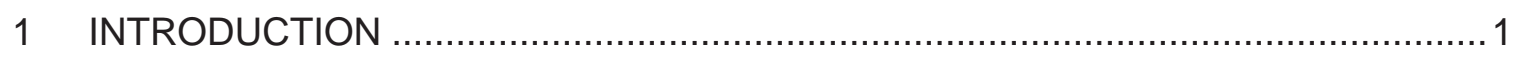

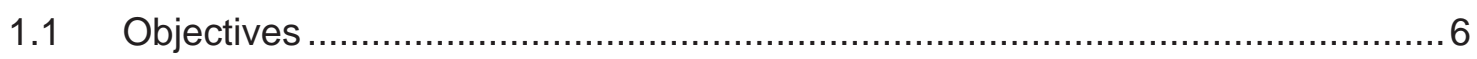

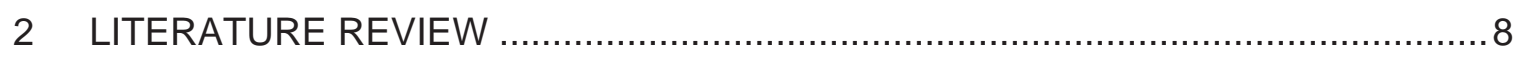

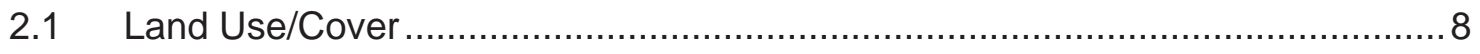

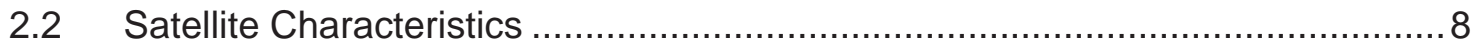

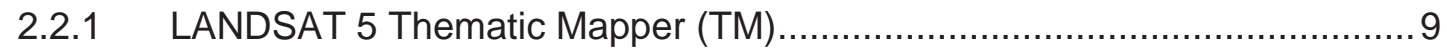

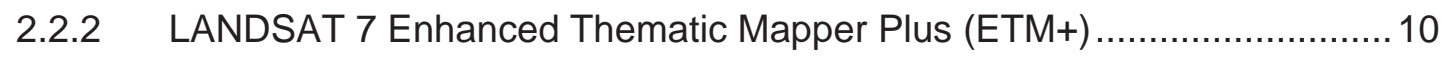

2.2.3 Advanced Spaceborne Thermal Emission and Reflection Radiometer

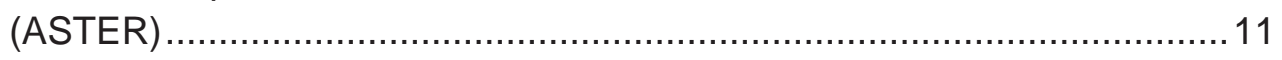

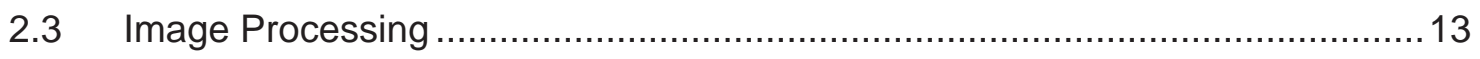

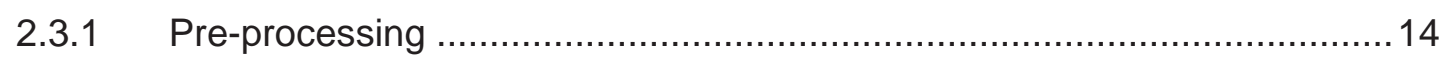

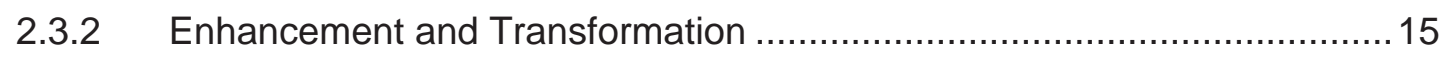

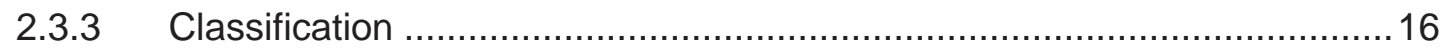

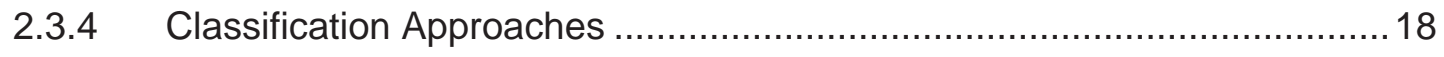

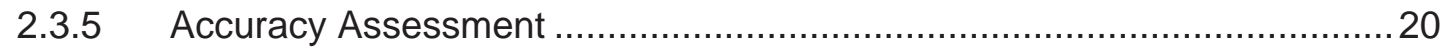

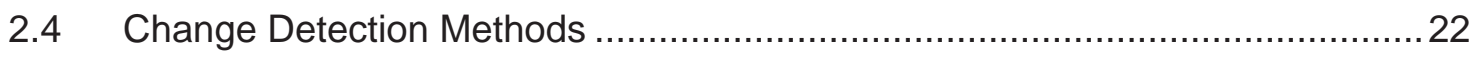


3 DESCRIPTION AND METHODOLOGY OF THE STUDY SITE

3.1 Location and Characteristics of the Study Site ........................................... 24

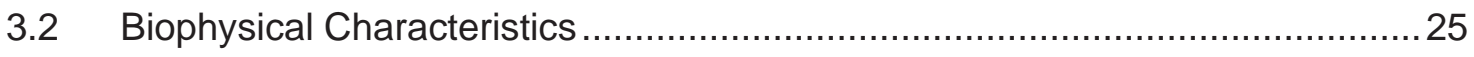

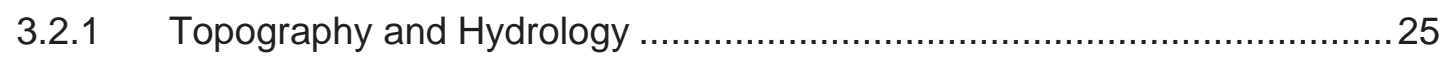

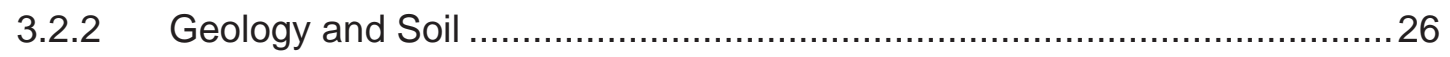

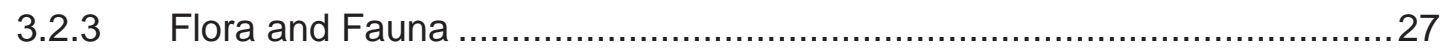

3.2.4 Population and economic activities .............................................. 29

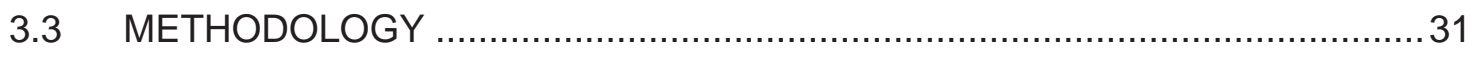

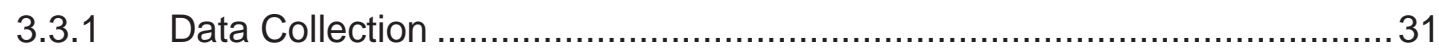

3.3.2 Satellite Imagery and Characteristics .................................................... 32

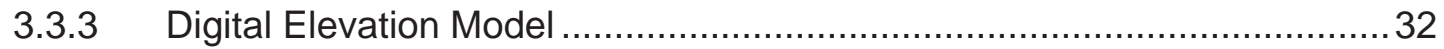

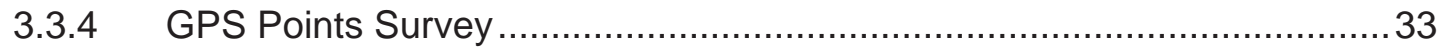

3.3.5 Software Packages Utilized ............................................................... 33

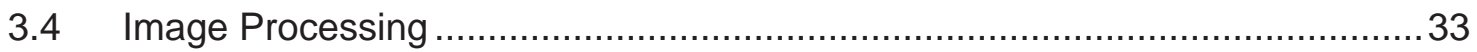

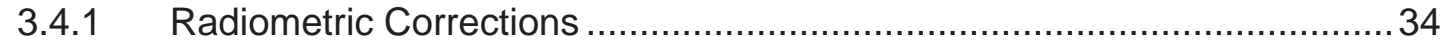

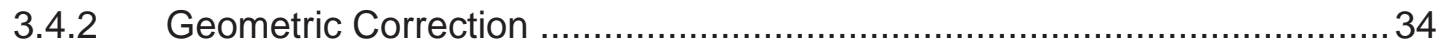

3.5 Image Classification and Accuracy Assessment .......................................... 40

3.5.1 Classification scheme and information classes' characteristics ............... 40

3.5.2 Hybrid classification and Accuracy Assessment processes .................... 48

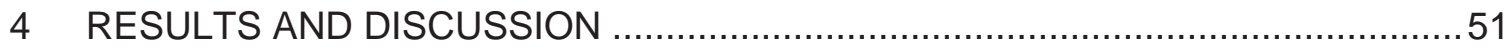

4.1 Spectral separability among the classes land use/cover $(1987,2000,2004) \ldots 51$

4.2 Classification Maps and Accuracy Results of the Landsat TM, Landsat ETM+, and ASTER Images

4.2.1 Accuracy Assessment and land use/cover Map of the Landsat TM (1987)54

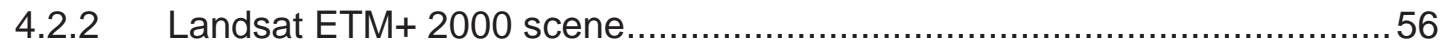

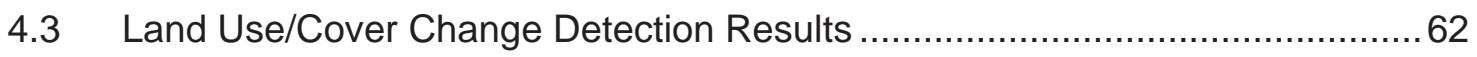


4.3.1 Change map between 1987 and 2000 classifications .............................. 62

4.3.2 Change map between 1987 and 2004 classifications .............................66

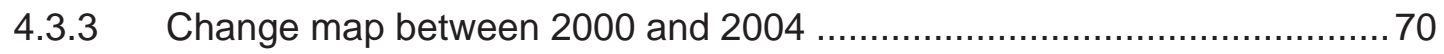

4.3.4 Change map between 1987 and 2004 classifications ............................75

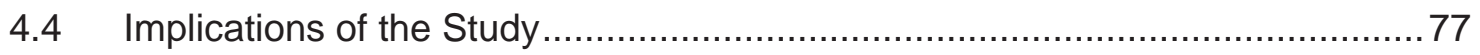

4.4.1 Causes of land use/cover change in the Macaya area............................77

4.4.2 Consequences of land use/cover change in the Macaya area .................. 80

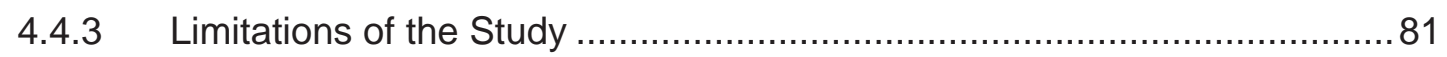

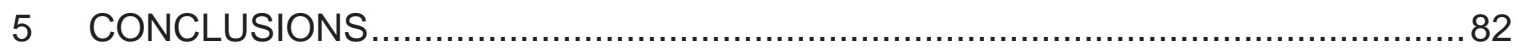

APPENDIX A: Principal Components Statistics and Analysis................................... 85

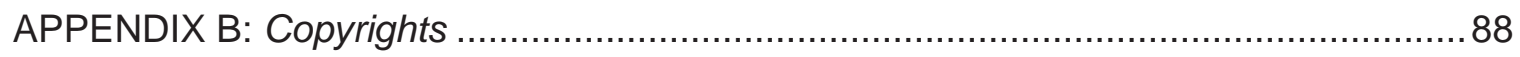

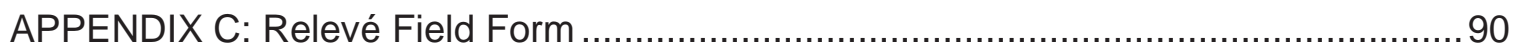

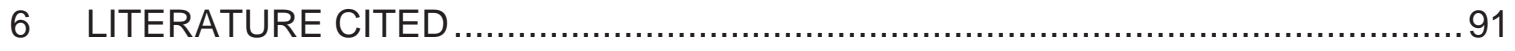




\section{LIST OF TABLES}

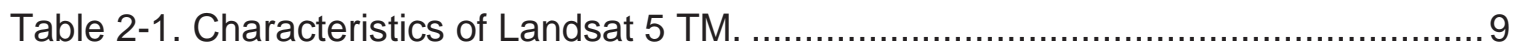

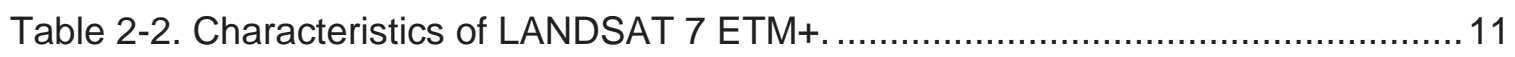

Table 2-3. Characteristics of ASTER data ....................................................... 12

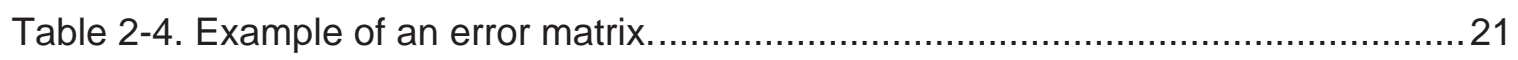

Table 3-1. Characteristics of the satellite imagery utilized..................................... 32

Table 3-2. Classification scheme designed for the study ......................................... 41

Table 4-1. Summary of land use/cover accuracies (\%) for 1987, 2000, and 2004........53

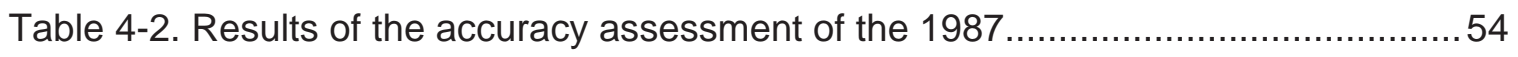

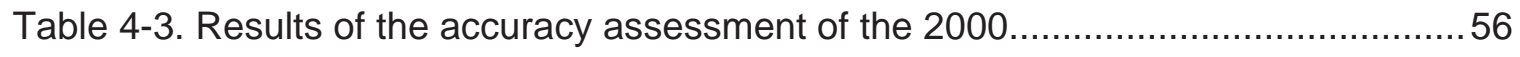

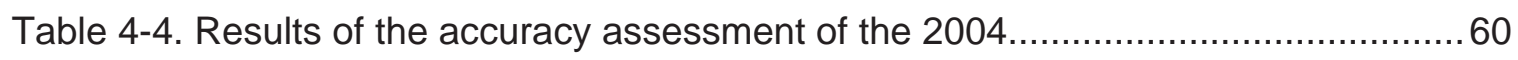

Table 4-5. Comparison of areas (ha) and rates of change between 1987 and 2000..... 62

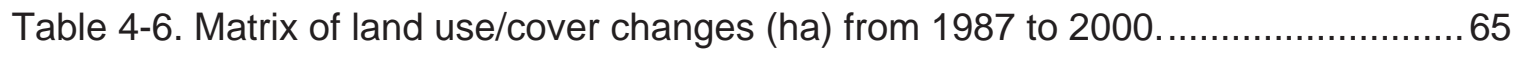

Table 4-7. Comparison of areas (ha) and rates of change between 1987 and $2004 \ldots . . .66$

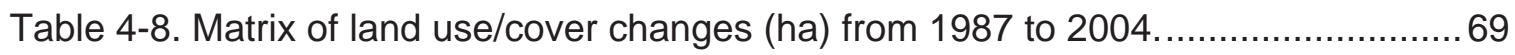

Table 4-9. Comparison of areas (ha) and rates of change between 2000 and $2004 \ldots . . .70$

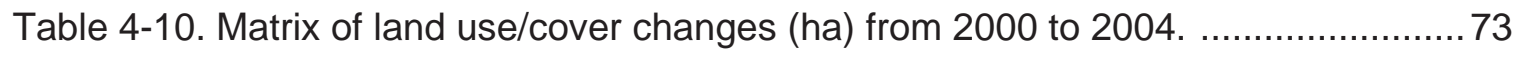

Table 4-11. Comparison of areas (ha) and rates of change between 1987, 2000,2004. 


\section{LIST OF FIGURES}

Figure 1-1. Location of the three National Reserves in Haiti.

Figure 2-1. Example of a spectral pattern recognition classification using spectral classes.

Figure 3-1. Location of Pic Macaya National Park, Haiti surrounded by two major Mountains--Pic Formon and Pic Macaya.

Figure 3-2. False color composite of ETM+ band 4-3-2 (RGB) in the Macaya Region.

Figure 3-3. Gully erosion on the plain and hilly mountains..

Figure 3-4. Illustrations of Pinus Occidentalis.

Figure 3-5. Haitian Solenodon (upper left) and White-winged Warbler (upper right) White-winged Crossbill or Hispaniolan Crossbill (Loxia megaplaga), and Black-capped Petrel (Pterodroma hasitata).

Figure 3-6. Economic activities of the population living in/around the park Macaya.

Figure 3-7. General Methodology

Figure 3-8. Preprocessing flowchart

Figure 3-9. Landsat ETM+ after radiometric corrections (right).

Figure 3-10. False color composite of bands 4, 3, 2 (rgb) of Landsat ETM+ 2000.

Figure 3-11: False color composite of bands 7, 4, and 2 (rgb) of Landsat ETM+scene .

Figure 3-12. True color composite of bands 3, 2, 1 (rgb) of Landsat ETM+.

Figure 3-13. Landsat ETM+ PCs 1-2-3 displayed as red, green, blue.

Figure 3-14. Flowchart of image classification and accuracy assessment

Figure 3-15. Illustrations of built-up areas.

Figure 3-16. Illustrations of Agricultural land--active cropping and fallow lands.

Figure 3-17. Illustrations of Herbaceous land types 
Figure 3-18. Illustrations of open pine forest in Pic Macaya National Park. 45

Figure 3-19. Varying compositions of mixed degraded forest. 46

Figure 3-20. Examples of barren land class 47

Figure 4-1. Spectral separability for land use/cover classes of the Landsat TM 1987.

Figure 4-2. Spectral separability for land use/cover classes of the Landsat ETM+ 2000.

Figure 4-3. Spectral separability for land use/cover classes of the ASTER $2004 . \quad 52$

Figure 4-4. Land use/cover map of the Landsat TM (1987) image. 55

Figure 4-5. Land use/cover map of the Landsat ETM+ (2000) image. 59

Figure 4-6. Land use/cover map of the ASTER (2004) image. 61

Figure 4-7. Comparison of the land use/cover changes between 1987 and $2004 . \quad 63$

Figure 4-8. Comparison of the land use/cover changes between 1987 and $2004 \quad 67$

Figure 4-9. Comparison of the land use/cover changes between 2000 and 2004 classifications.

Figure 4-10. Comparison of the land use/cover changes between the 1987, 2000, and 2004 classifications. 


\section{INTRODUCTION}

Tropical forest resources, specifically Haitian forest resources, are strongly impacted by natural and anthropogenic forces. Many mountainous regions, in particular Haiti, are subjected to hurricanes and other severe weather events every year, which contribute to fallen trees and soil erosion. Furthermore, the demands of increasing human populations place additional pressure on these natural resources (Allen and Barnes 1985; Zurick 1995; Gong and Xu 2003). Munasinghe (1993) revealed that 2.5 million hectares of forest are cleared yearly in Central America for livestock production such as cattle. Demands for wood fuel (the main source of energy for cooking and heating for 1.5 billion people living in developing countries), timber, and recreation result in overutilization and degradation of these forests (Stein et al. 1999).

Tropical regions have experienced a rapid change in the spatial distribution and characteristics of their forests, especially the conversion from forest to non-forest. Large tracts of tropical forests have been converted to agriculture because of increasing population and lack of economic opportunities for this population (Laurance et al. 2006). Consequently, deforestation has been the focus of many global change studies (Riebsame et al. 1994). According to Myers et al., (2000) the Caribbean region is one of the "hottest hotspots" with large numbers of threatened and endangered endemic plants and vertebrate species. To reduce the loss of biological diversity in the region and to protect the environment, in 2007 with the support of the United Nations Environment Programme (UNEP), Cuba, Haiti, and the Dominican Republic signed an agreement to create the first biological corridor in the Caribbean zone (UNEP 2007). 
However, conservation efforts are described as very challenging in the Greater Antilles for countries like Haiti, the Dominican Republic, and Jamaica (Paryski et al. 1988). The struggle to maintain biodiversity and to manage natural resources sustainably is more visible in Haiti than any of the Caribbean Islands. Haiti is classified as a very poor, overpopulated and an environmentally degraded country (Paryski et al. 1988). Strauss (2000) pointed out that Haiti has only $1.44 \%$ of its original forest coverage. These remnants are distributed on less than 200 square kilometers among three National Reserves (Figure 1-1): La Visite National Park, Pic Macaya National Park, and National History Park - Citadel, Sans Souci, Ramiers (Paryski et al. 1988; UNEP-WCMC 1997).

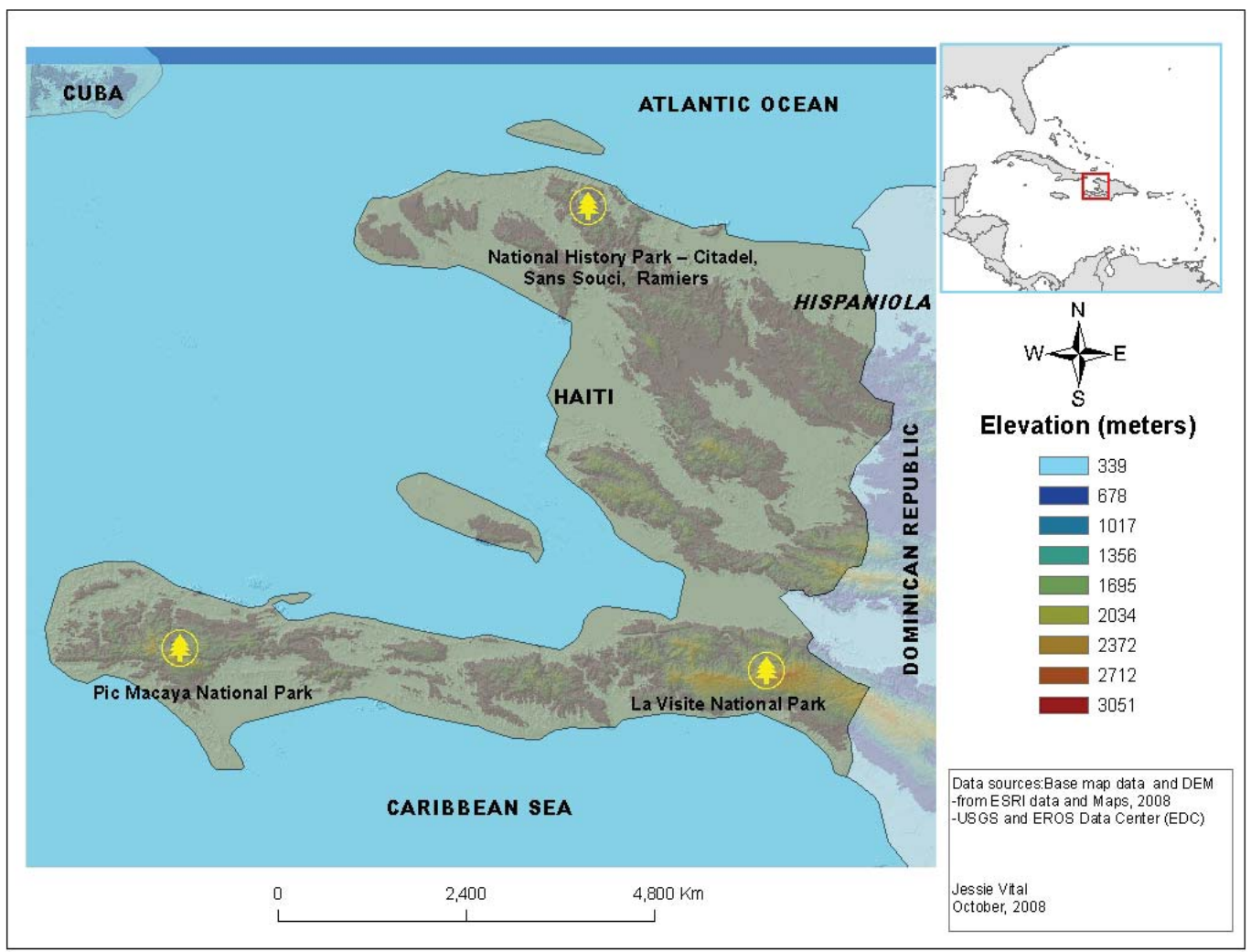

Figure 1-1. Location of the three National Reserves in Haiti. 
According to many researchers, deforestation in Haiti is rooted in the lack of an all encompassing long-term forest management, the lack of well-defined and adopted policies for natural resources management, and the complexity of land tenure (PierreLouis 1989). Additional contributing factors include lack of economic incentives such as off-farm activities for peasants and farmers other than agricultural or charcoal production, illegal forest harvesting (Dolisca et al. 2007a), and an uncontrolled increase in population. In a recent census, the Haitian Institute of Statistics (IHSI) estimated the Haitian population at 8.4 million. The population density is close to 300 people per square kilometer in the capital, Port-au-Prince, which is the highest in the Caribbean region (IHSI 2003).

This study looks at land use/cover changes occurring within and adjacent to the Pic Macaya National Park. The Macaya region shelters a distinctive flora with many endemic species and contains the headwaters of five rivers. Deforestation within fragile watershed areas is jeopardizing the region's unique ecosystem (Olson et al. 1996). Thus, in the last two decades there have been many initiatives such as reforestation and soil conservation projects to protect the 5500 hectares of mesic forest of Pic Macaya National Park from degradation. For instance, the World Bank, the United States Agency for International Development (USAID), NGOs and a team of researchers from the University of Florida have worked and contributed in many ways to document and conserve the biodiversity of Pic Macaya National Park. However, political instability has shortened the life cycle of projects; and the severe poverty of the people living in or around the area has facilitated the continuing trend of deforestation. 
Moreover, managers and governmental institutions monitoring the parks are located far away. Remote, rugged terrain and hazardous roads make the park access difficult.

This study uses Remote Sensing (RS) and Geographic Information Systems (GIS) technologies to detect, delineate and quantify the rate of land cover change that has occurred in Pic Macaya National Park for a 17-year window from 1987 to 2004. Since the early 1970 s with the beginning of the Landsat program, satellite remote sensing has provided the capability to manipulate and analyze satellite imagery at different scales by using computer-based image processing software. RS and GIS software, such as ERDAS Imagine and ESRI ArcGIS software packages, offer an array of tools that facilitate data processing, data analysis and classification of earth surface features such as forest cover, soils, and land use/cover to produce thematic maps (Van Lynden and Mantel 2001; Jensen 2005; Leica Geospatial Imaging 2005; Chang 2006; Lillesand et al. 2008).

$R S$ is the process of gaining information about the Earth's surface by using an instrument at a distance to measure and/or record emitted or reflected electromagnetic energy (Lillesand et al. 2008). RS systems are capable of detecting, measuring and assessing scene variables based on the sensor response to reflected or emitted radiation from the target features. The acquisition of remote sensing data and its interpretation through GIS are cost effective according to many researchers (Campbell 2007; Hayes and Cohen 2007; Shalaby and Tateishi 2007; Lillesand et al. 2008). 
GIS is a computer based information system that has the capacity to store, manage, query, and update spatial information. GIS excels in its capacity to create new information from existing data (Chang 2006). GIS as well as RS play an important role in the decision making process for land management. The use of GIS has become crucial to public policy due to its facility to combine and then analyze geographic data from diverse sources (e.g. national population and housing census statistics data, and natural resources data). For example, researchers, policy makers use GIS maps in public meeting in order to visualize problems and to increase projects transparency. Also GIS products help to inform donors about specific situations and to involve the public impacted by the decisions in public policy (Haklay 2003; Sieber 2003).

RS and GIS provide an economical and viable approach to the challenges of monitoring land use/cover in remote, mountainous areas, as compared to field surveys or aerial photography (Hayes and Sader, 2001). In the case of Haiti, many parameters related to the bio-physical environment, lack of infrastructure, and drastic political-socio-economic conditions have contributed to make data gathering via field-based surveys and aerial photography difficult. Moreover, without spatial data and RS technology, monitoring dynamic changes that are happening at a global or regional scale is a challenging task. Remotely sensed imagery obtained from satellites, such as Landsat, has helped to surmount these issues. 
Land use/cover represents a basic thematic layer utilized by GIS and RS. Anderson et al. (1976) considered land use to be the changes made by humans on the land and land cover as the natural state of the land. Current information on land use/cover is vital to many applications. Foody (2002) considered land use/cover classification and change detection as the most practical application provided by the use of remotely sensed data to produce thematic maps. The thematic map provides land managers with information on the spatial and temporal changes that have occurred across the landscape. RS and GIS technologies are widely used by many researchers to study changes in diverse tropical and arid regions. For mapping and monitoring land use/cover changes in the northwestern coastal zone of Egypt, Shalaby and Tateishi (2007) used RS and GIS. Hartter et al. (2008) used RS to detect tropical dry forest succession in a shifting cultivation mosaic of the Yucatan Peninsula in Mexico. In general, monitoring change detection of land use/cover involves the following steps: a) detecting changes that have occurred; b) identifying the nature of the change; c) measuring the areal extent of the change; d) assessing the spatial pattern of the change (Macleod and Congalton 1998).

\subsection{Objectives}

The objectives of this research are summarized below:

- Determine the rate of land use/cover change and where the change is taking place in Pic Macaya National Park;

- Evaluate which digital image processing classification techniques provide the best change detection information;

- Provide an improved understanding of the process of changes in land use/cover 
patterns within the park to develop policies that can generate sustainable land use/cover management practices and help develop alternative economic incentives to the population living in and adjacent to the park.

Based on these objectives, this study seeks to answer the following questions:

1. Can land use/cover change be detected utilizing TM, ETM+, and ASTER remotely sensed imagery?

2. Which classification approach will yield the best results in detecting the change in land use/cover?

3. What kinds of changes in vegetation composition and distribution have taken place over a 17-year window (1987-2004) within the Macaya Park?

4. Which areas need urgent soil conservation and reforestation intervention?

5. What is the trend of deforestation in the area over time? Are human activities or natural events the main cause of these changes? 


\section{LITERATURE REVIEW}

\subsection{Land Use/Cover}

Land use is a common term used in the remote sensing literature. Meyer (1995) described land use as anthropogenic changes exerted on the natural land cover such as the conversion of wild land into urban or agriculture. Meyer (1995) also defined land cover as the physical state of the land surface with its natural feature type such as water, vegetation, soils, karsts, barren land or forest. One of the problems of mapping land use/cover with remotely sensed data is the capacity to produce a map that depicts, with a high degree of accuracy, the feature present on the land surface. To overcome this, many scientists simultaneously use remotely sensed data, field data and ancillary data in order to produce better and more accurate maps (Anderson and Martinez-Meyer 2004; Currit 2005).

\subsection{Satellite Characteristics}

Satellite remote sensing data with multi-temporal resolution has become a crucial tool for monitoring land use/cover change (Güler et al. 2006). Satellite-based land observation sensors offer reliable and consistent digital data with different ranges of spectral, spatial radiometric and temporal resolutions.

Spectral resolution is defined as the number and spectral width of the bands in the electromagnetic spectrum of a satellite sensor (Jensen 2005). A band is composed of pixels, and each pixel has a digital number (DN) or brightness value (BV). DN or BV is the relative reflectance of the electromagnetic spectrum for the target area or "foot print. 
Spatial resolution refers to the capability of the sensor to depict, measure, and record objects on the ground. The spatial resolution varies among sensors and satellites. The smaller the spatial resolution the greater the detail in the satellite image.

Sensor sensitivity to record changes in the electromagnetic is referred as the radiometric resolution. Different sensors record different reflectance or emittance levels of radiation intensities ranging from 6 bit (Landsat MSS), 8 bit (Landsat TM, ETM+ ASTER VNIRSWIR) and 12 bit (ASTER-TIR). The higher the radiometric resolution, the finer the capacity to detect changes in reflectance or emittance.

Temporal resolution refers to the time of repeat coverage for a specific geographic location (Jensen 2005; Lillesand et al. 2008). Temporal coverage varies also between sensors.

\subsubsection{LANDSAT 5 Thematic Mapper (TM)}

The Landsat program is the oldest digital satellite imaging system of the Earth's surface (Lillesand et al. 2008). The Landsat 5 Thematic Mapper (TM) was launched in March 1, 1984 with two sensors: the Multi Spectral Scanner (MSS) and the Thematic Mapper (TM). The TM sensor was designed to significantly improve the spatial and spectral resolutions, geometric and radiometric accuracies compared to Landsat 1-3 MSS sensor. Additional mid-IR bands and a thermal channel were added in order to achieve improved spectral resolution than the MSS sensor. The TM sensor simultaneously acquires data in seven spectral bands (Table 2-1). 
Table 2-1. Characteristics of Landsat 5 TM.

\begin{tabular}{|c|c|c|c|c|}
\hline Band & $\begin{array}{c}\text { Spectral } \\
\text { Resolution } \\
(\mu \mathrm{m})\end{array}$ & $\begin{array}{c}\text { Spatial } \\
\text { Resolution } \\
\left(\mathrm{m}^{2}\right)\end{array}$ & $\begin{array}{c}\text { Radiometric } \\
\text { Resolution } \\
\text { (bits) }\end{array}$ & $\begin{array}{l}\text { Temporal } \\
\text { Resolution } \\
\text { (days) }\end{array}$ \\
\hline 1 & $0.45-0.52$ & 30 & \multirow{7}{*}{8} & \multirow{7}{*}{16} \\
\hline 2 & $0.52-0.60$ & 30 & & \\
\hline 3 & $0.63-0.69$ & 30 & & \\
\hline 4 & $0.76-0.90$ & 30 & & \\
\hline 5 & $1.55-1.75$ & 30 & & \\
\hline 6 & $10.40-12.50$ & 120 & & \\
\hline 7 & $2.08-2.35$ & 30 & & \\
\hline
\end{tabular}

\subsubsection{LANDSAT 7 Enhanced Thematic Mapper Plus (ETM+)}

The Landsat 7 ETM+ was launched in April 15, 1999 following the failure of Landsat 6 $\mathrm{ETM}+$ to achieve orbit. The earth observing instrument on Landsat-7, the Enhanced Thematic Mapper Plus (ETM+), offers an enhanced version of the TM sensor and provides continuity of the Landsat 5 sensors. Compared to the TM, the ETM+ instrument provides a full aperture $5 \%$ absolute radiometric calibration, a panchromatic band with a higher spatial resolution of 15 meters, and a thermal IR band with $60 \mathrm{~m}$ spatial resolution (NASA Landsat 7 2004) (Table 2-2). 
Table 2-2. Characteristics of LANDSAT 7 ETM+ (Lillesand et al. 2008).

\begin{tabular}{|c|c|c|c|c|}
\hline Band & $\begin{array}{c}\text { Spectral } \\
\text { Resolution } \\
(\mu \mathrm{m})\end{array}$ & $\begin{array}{c}\text { Spatial } \\
\text { Resolution } \\
\left(\mathrm{m}^{2}\right)\end{array}$ & $\begin{array}{c}\text { Radiometric } \\
\text { Resolution } \\
\text { (bits) }\end{array}$ & $\begin{array}{l}\text { Temporal } \\
\text { Resolution } \\
\text { (days) }\end{array}$ \\
\hline 1 & $0.45-0.52$ & 30 & \multirow{8}{*}{8} & \multirow{8}{*}{16} \\
\hline 2 & $0.52-0.60$ & 30 & & \\
\hline 3 & $0.63-0.69$ & 30 & & \\
\hline 4 & $0.76-0.90$ & 30 & & \\
\hline 5 & $1.55-1.75$ & 30 & & \\
\hline 6 & $10.40-12.50$ & 60 & & \\
\hline 7 & $2.08-2.35$ & 30 & & \\
\hline 8 & $0.52-0.90$ & 15 & & \\
\hline
\end{tabular}

\subsubsection{Advanced Spaceborne Thermal Emission and Reflection Radiometer (ASTER)}

ASTER is one of several instruments found aboard the Terra satellite, launched in December 1999 as part of NASA's Earth Observing System (EOS). The Terra satellite has a polar, sun synchronous orbit with an altitude of approximately $704 \mathrm{~km}$ and a revisit cycle of 16 days. It is the product of a consortium between NASA, Japan's Ministry of Economy, Trade and Industry (METI), and Japan's Earth Remote Sensing Data Analysis Center (ERSDAC). ASTER provides detailed data on land surface climatology, hydrology, and elevation. Moreover, ASTER is the only high spatial resolution sensor on Terra that can be used to study land use/cover changes, monitor natural disasters, cloud covers, glaciers, vegetations and ecosystems dynamics at varying spatial resolutions from 15 to 90 m spatial resolution (Abrams et al. 2004; Gillespie et al. 2005).

ASTER collects high spatial resolution data in 14 spectral bands; from the visible through the thermal infrared wavelengths. The sensor has three subsystems to capture data from different regions of the electromagnetic spectrum: the Visible and Near 
Infrared (VNIR), the Shortwave Infrared (SWIR), and the Thermal Infrared (TIR). ASTER imagery can be used in conjunction with Landsat TM and ETM+ data for a number of reasons. ASTER's spectral resolution is similar to that of Landsat TM and ETM+ data. The three $15 \mathrm{~m}$ spatial resolution VNIR spectral bands correspond to the blue, green, red, and NIR bands of Landsat 7. The SWIR bands 4 through 9 (with $30 \mathrm{~m}$ spatial resolution) correspond to Landsat bands 5 and 7 . The TIR bands correspond to the Landsat thermal band 6. Furthermore, ASTER and Landsat TM and ETM+ sensors have the same temporal resolution of 16 days (Feldpausch et al. 2006; Heiskanen 2006; Wulder et al. 2008) (Table 2-3).

Table 2-3. Characteristics of ASTER data- adapted from (National Aeronautics and Space Administration (NASA) 1999).

\begin{tabular}{|c|c|c|c|c|}
\hline Subsystem & Band No. & $\begin{array}{c}\text { Spectral } \\
\text { Range }(\mu \mathrm{m})\end{array}$ & $\begin{array}{c}\text { Spatial } \\
\text { Resolution } \\
\left(\mathrm{m}^{2}\right)\end{array}$ & $\begin{array}{l}\text { Radiometric } \\
\text { (bits) }\end{array}$ \\
\hline \multirow{4}{*}{$\begin{array}{l}\text { Very-Near } \\
\text { Infrared } \\
\text { (VNIR) }\end{array}$} & 1 & $0.52-0.60$ & \multirow{4}{*}{15} & \multirow{4}{*}{8} \\
\hline & 2 & $0.63-0.69$ & & \\
\hline & $3 \mathrm{~N}$ & $0.76-0.86$ & & \\
\hline & $3 B$ & $0.76-0.86$ & & \\
\hline \multirow{6}{*}{$\begin{array}{c}\text { Short Wave } \\
\text { Infrared } \\
\text { (SWIR) }\end{array}$} & 4 & $1.6-1.70$ & \multirow{6}{*}{30} & \multirow{6}{*}{8} \\
\hline & 5 & $2.145-2.185$ & & \\
\hline & 6 & $2.185-2.225$ & & \\
\hline & 7 & $2.235-2.285$ & & \\
\hline & 8 & $2.295-2.365$ & & \\
\hline & 9 & $2.360-2.430$ & & \\
\hline \multirow{5}{*}{$\begin{array}{c}\text { Thermal } \\
\text { Infrared } \\
(\mathrm{TIR})\end{array}$} & 10 & $8.125-8.475$ & \multirow{5}{*}{90} & \multirow{5}{*}{12} \\
\hline & 11 & $8.475-8.825$ & & \\
\hline & 12 & $8.925-9.275$ & & \\
\hline & 13 & $10.25-10.95$ & & \\
\hline & 14 & $10.95-11.65$ & & \\
\hline
\end{tabular}




\subsection{Image Processing}

Image processing is manipulating and processing of remotely sensed digital data to create an end product, such as a change detection map. It includes four major components: pre-processing, classification, accuracy assessment, and change detection techniques. Change detection can be quantified by using data from a single sensor as well as from multiple sensors at different acquisition dates. Various images obtained from the same sensor such as Landsat-5 TM do not require much pre-processing since they have the same spectral, spatial, and radiometric resolutions (Read and Lam 2002).

Furthermore, Landsat' s spatial, spectral, temporal resolutions, its extensive and historical archive, and its accessibility have facilitated its use for monitoring land use/cover activities (Franklin and Wulder 2001; Cohen and Goward 2004). Helmer et al., (2002) have used Landsat TM satellite imagery to map 21 forest formations and land cover in Puerto-Rico. However, recent sensor problems with the Landsat ETM+ along with limited availability of Landsat-5 TM imagery have lead researchers and land managers to seek other remote sensed data sources for monitoring land use/cover change (Cohen and Goward 2004; Wulder et al. 2008). ASTER imagery is helping to fill the gap caused by the Landsat discontinuity (Abrams et al. 2004). Many researchers have begun using ASTER imagery for forest monitoring programs along with Landsat (Feldpausch et al. 2006; Heiskanen 2006).

In order to study change detection among multi-temporal images from different sensors, researchers are challenged by many factors. Systematic errors from the sensors (geometric errors) and variation in the radiance $\left(L_{\lambda}\right)$ values (radiometric errors) can 
create confusion between the changes associated with land use/cover and those related to variations in solar illumination, atmospheric conditions, seasonal phenology and/or error due to sensor malfunction (Chavez 1996; Bruzzone and Prieto 2000; Kaufmann and Seto 2001; Bruzzone et al. 2002; Read and Lam 2002; Richards and Xiuping 2006; Castellana et al. 2007; Nangendo et al. 2007). These issues need to be addressed to minimize the risk of misinformation and to guarantee the accuracy of the results (Song et al. 2001).

\subsubsection{Pre-processing}

Pre-processing is important to normalize the raw digital data for analysis. Campbell (2007) the pre-processing into four main functions: radiometric corrections, geometric corrections, enhancement and transformation.

Radiometric correction is the process of converting the DN from the sensor into units of absolute reflectance (Lillesand et al. 2008). This correction reduces sensor noise and decreases the impact of atmospheric components and topographic shadows. Sensor noise can be caused by sensor malfunction and/or errors in data collection and transmission. Atmospheric errors are usually the result of haze, clouds or particles present in the atmosphere where the energy is back-scattered to the satellite sensor. Topographic shadows represent a common problem in mountainous environments. The recorded DN value is influenced by the slope, aspect and reflectance of the feature on the ground. According to the literature, in the northern hemisphere south facing slopes receive more annual radiation per unit area than and are drier than north facing slopes 
because of the angle of the Earth surface relative to the sun (Chavez 1988; Civco et al. 2002; Lillesand et al. 2008). A number of methods have been recommended and developed to remove or reduce radiometric effects (Vincent 1972; Moran et al. 1992; Chavez 1996).

Geometric correction adjusts distortion effects caused by the Earth's rotation and curvature, sensor motion and platform vibration. This process also allows georeferencing the imagery to a geographic or planar coordinate system (Lillesand et al. 2008).

\subsubsection{Enhancement and Transformation}

Enhancement is a procedure applied to the original image to improve the contrast between features by modifying the range of DNs for easier visual interpretation. Linear and nonlinear contrast enhancements procedures are widely used to extend or "stretch" the range of DNs from 0 to 255 (the full range of values for 8-bit data). However, enhancement procedures have major drawbacks. They alter the statistical structure of the data in such way that it is not recommended to use the enhanced image for automated classification (Jensen 2005).

As opposed to enhancement procedures, transformation procedures, such as Principal Component Analysis (PCA) reduces redundancy between inter-band correlations, increases the computational capacity, improves the visual appearance of the scene, while maintaining the statistical integrity of the image. 
A transformation may also help to discern which combination of bands or components that display unique information (Jensen 2005).

\subsubsection{Classification}

Image classification is the process of grouping and labeling each pixel within the original image to a land use/cover information class (Song et al. 2001; Shrivastava and Gebelein 2007). The resulting classified image becomes a mosaic of pixels regrouped into a thematic map. Two technical expressions are repeatedly found in land use/cover classification: information classes and spectral classes. Information classes differ from spectral classes in that they are defined within a classification scheme by the analyst as the class of interest, based on the objectives of the study and the characteristics of the study area (Jensen 2005).

For instance, adopted the Anderson classification systems use a hierarchical land use/cover classification system with four different levels that characterize the information class for land cover locally, regionally, or globally. These information classes included Forest, Urban, Agriculture, Rangeland, Open Water, Rock, etc. (Anderson et al. 1976). The establishment of a classification scheme is a necessary step for delineating sites from the satellite imagery. Spectral classes comprise a group of pixels, which have similar DNs in one or more bands. This grouping of DN's forms the spectral information class, which is used by the digital image classification algorithm to classify each pixel based on its spectral similarities. The spectral classes are then grouped into information classes by the analyst (Jensen 2005). 
This type of classification, called spectral pattern recognition, is widely used to classify land use/cover. Figure 2-1 shows the process of a spectral classification. Further details are given in point 2.3.3 classification approach.

DN values per pixel

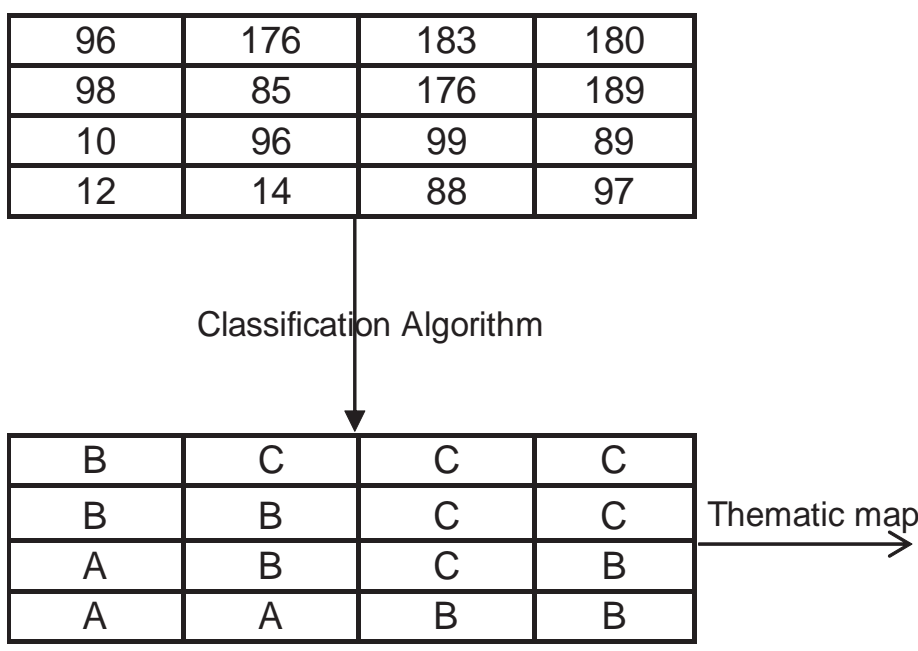

\begin{tabular}{|c|c|}
\hline Spectral Classes & \\
\hline $\mathrm{DN}=0-50>=\mathbf{A}$ & \\
\hline$D N=51-100>=B$ & \\
\hline$D N=101-200>=C$ & Г \\
\hline Information Classes & $\bar{z}$ \\
\hline $\mathrm{A}=$ Water & \\
\hline $\mathrm{B}=$ Forest & \\
\hline $\mathbf{C}=$ Karst Barren & \\
\hline
\end{tabular}

Spectral classes

Figure 2-1. Example of a spectral pattern recognition classification using spectral classes.

Accurately delineating land use/cover classes for regions with complex topography, variation in climate, soils, and ecological zones is difficult. The spectral signatures of many forest species in many Caribbean countries are not distinct and well defined. Their distribution and ecological classification are usually mapped based on climatic zone, geology, elevation and rainfall distribution (Helmer et. al., 2002). Holdridge (1965) classifies the vegetation of Hispaniola based on bioclimatic characteristics. $\mathrm{He}$ determined the regional vegetation type and life zones based on temperature and rainfall. Three major types of vegetation for the Caribbean region were found in his 
classification system: tropical lowland dry forests, highland and mesic pine forest and coastal mangrove swamps. Tasaico (1967.) used the Holdridge system to map potential vegetation for the Dominican Republic. Howard (1973) inventoried the vegetation of the Antilles and also used climatic data and trees species to map the land cover.

Recently, a working group, named the Caribbean Vegetation Ecology Working Group, published a standardized classification system for Caribbean vegetation types (ArecesMallea et al. 1999). It was established based on the classification scheme of Anderson/United States Geological Survey (Anderson et al. 1976). This study utilized a Level I and Level II classification system dependent on the individual land cover classes. The study took into account the land cover class information developed by the University of Florida (Judd 1987), incorporated collateral ground truth data and significant a priori knowledge of the area.

\subsubsection{Classification Approaches}

As noted previously, spectral pattern classification was used in this study to classify the land cover. It is based on the univariate and multivariate statistics associated with each individual pixel for each band. Three types of classification are described: unsupervised, supervised, and hybrid classification schemes (Jensen 2005).

The unsupervised classification approach uses the Iterative Self-Organizing Data Analysis (ISODATA) algorithm to group pixels in the image according to their reflectance values (Jensen 2005). Pixels with spectral similarities are grouped into clusters by the 
algorithm (Duda et al. 2001) with a high degree of objectivity since the process is done with little analyst input initially. Once the clusters are defined, the analyst must assign information class labels (land cover classes) to each cluster. Unsupervised classification methods represent the best choice when extensive fieldwork is not possible as the algorithm insures all spectrally similar pixels are clustered together (Bruzzone et al. 2004).

Supervised classification relies on a priori knowledge of the study area. This knowledge can be obtained from fieldwork, aerial photography, maps and extensive personal experience (Bruzzone et al. 2004). Training sites are developed by drawing polygons around an area of interest (AOI) which represents a spectral class. This spectral class should have a low standard deviation. A seed algorithm may also be used to collect spectrally similar training sets. An original pixel at $\mathrm{x}, \mathrm{y}$ location is selected (seeded) on the image. The neighboring pixels are then evaluated within all bands to locate pixels with similar spectral characteristics of the original seed pixel. Univariate and multivariate statistics are calculated for every training site (mean, standard deviation, covariance and correlation) (Foody 2002; Jensen 2005).

Often better results are achieved by capitalizing on both unsupervised and supervised methods, commonly referred to as hybrid classification. An unsupervised cluster is done to generate spectrally homogenous classes. Then, using visual interpretation and ground truth data, each cluster is labeled and analyzed statistically to determine the spectral separability. This method is particularly vital for the region of our study where 
there is a lack of ground information for each spectral class due to site inaccessibility. Hybrid classifications approaches are cost-effective and successful in producing land use/cover maps with high accuracy from satellite images (Lo and Choi 2004; Güler et al. 2006).

\subsubsection{Accuracy Assessment}

Accuracy assessment is the process of validating the classified land use/cover thematic map. This helps quantify how well the resultant land used/cover map corresponds to the actual land cover. Accuracy assessment is useful for checking the validity of the classification approach for evaluating errors. Two sources of information are then compared: the classified map and the ground reference test information. The relationship between the classified map and the reference data is summarized in an error matrix, called also a confusion matrix or a contingency table (Jensen 2005; Lillesand et al. 2008).

The accuracy report includes an error matrix, producer's and user's accuracy for each information class, an overall accuracy, and Kappa statistics. The error matrix below shows the comparison of each reference point to the classified pixel at the same geographic position (Table 2-4). 
Table 2-4. Example of an error matrix (Congalton and Green 1999).

\begin{tabular}{|l|l|l|l|l|l|l|}
\hline \multicolumn{7}{|c|}{ Reference data } \\
\hline $\begin{array}{c}\text { Land cover } \\
\text { classes }\end{array}$ & Deciduous & Coniferous & Agriculture & Shrub & Row total & $\begin{array}{c}\text { User's } \\
\text { Accuracy } \\
\text { in \% }\end{array}$ \\
\hline Deciduous & $\mathbf{6 5}$ & 4 & 22 & 24 & 115 & $65 / 115=57$ \\
\hline Coniferous & 6 & 81 & 5 & 8 & 100 & $81 / 100=81$ \\
\hline Agriculture & 0 & 11 & $\mathbf{8 5}$ & 19 & 115 & $85 / 115=74$ \\
\hline Shrub & 4 & 7 & 3 & $\mathbf{9 0}$ & 104 & $90 / 104=87$ \\
\hline $\begin{array}{l}\text { Column } \\
\text { total }\end{array}$ & 75 & 103 & 115 & 141 & 434 & \\
\hline $\begin{array}{l}\text { Producer's } \\
\text { Accuracy } \\
(\%)\end{array}$ & $65 / 75=87$ & $81 / 103=79$ & $85 / 115=74$ & $\begin{array}{l}90 / 14 \\
1=64\end{array}$ & & \\
\hline Overall Accuracy in \% $=(65+81+85+90) / 434=74$ & & & \\
\hline
\end{tabular}

The pixels or polygons that were correctly assigned to each information class are represented in the diagonal cells of the matrix (in bold). The off-diagonal cells display the errors in the classification given the ground reference information. Producer's and user's accuracies measure the correctness of each information class with respect to omission and commission errors.

Producer's accuracy is obtained by dividing the number of correctly classified pixels of a class by the column total of reference points within the class in question (see producer's accuracy row in Table 2-4). It tells how well the analyst has classified a certain area in the land surface. A low producer's accuracy implies a high error of omission. Omission errors occur when a classified pixel is excluded from the class that it really belongs to. User's accuracy is calculated by dividing the number of correctly classified pixels by the row total of pixels of the assessed class (far right column of the error matrix in Table 2-4). As a user of the produced map, the user's accuracy of a class indicates what percentage of a particular land cover type on the map is really that land cover type on 
the ground. A low user's accuracy represents a high error of commission. Commission error occurs when a land cover class is included in an incorrect class category. Overall accuracy is the number of correctly classified reference point (the diagonal points in the table) divided by the total number of reference points (Congalton and Green 1999).

The Kappa statistic (Khat) compares two datasets to see if they differ significantly. It looks at the agreement or accuracy between the classified map and the reference data. The Kappa statistic utilizes all the data in the matrix rather than just the diagonal data in the error matrix. The Kappa statistic ranges from 0 to 1 . A value close to 1 indicates a high agreement between the two datasets (Congalton and Green 1999).

\subsection{Change Detection Methods}

Change detection is the process of observing and comparing two multi-temporal images acquired of the same geographical area at different anniversary dates in order to map and analyze spatial patterns of change (Jensen 2000). The choice of a change detection algorithm dictates the type of change results.

Image algebra (band differencing and ratioing) and post classification comparison (PCC) are among the algorithms widely used to create land cover change map. Image algebra techniques evaluate and compare pixel by pixel the multi-date images to reveal changes between acquisition dates. It is divided into two different methods: image differencing and image ratios. Image differencing is performed by subtracting the DN value of one image for a particular band from the DN value of the corresponding pixel in the same 
band of the second image. Image ratios are executed by dividing the DN of one image from a particular band by the DN of the corresponding pixel of the same band of the second image (Singh, 1989).

Post Classification Comparison (PCC) is considered the simplest approach to assess change detection. Land cover maps for a least two different times using the same spectral information classes are required (Jensen 2005). Each image is classified independently and then compared through cross-tabulation to produce a change "fromto" image. When compared to the image algebra technique, PCC can produce information on the type of transition change. The method chosen depends on the nature of the study and the type of imagery available. Based on the scope of this study, the PCC method is preferred, and has been broadly accepted in RS to identify change among multi-temporal data (Hayes and Cohen 2007; Shalaby and Tateishi 2007). 


\section{DESCRIPTION AND METHODOLOGY OF THE STUDY SITE}

\subsection{Location and Characteristics of the Study Site}

Pic Macaya National Park is located in southwest Haiti, approximately $36 \mathrm{~km}$ North West of Les Cayes and $195 \mathrm{~km}$ South West of Port-au-Prince. Its geographic position lies between $1821^{\prime} \mathrm{N}$ latitude and 74 01' W longitude. Pic Macaya National Park is situated within the Massif de la Hotte, which ranges from 1,270 to 2,255 meters in elevation (Figure 3-1).

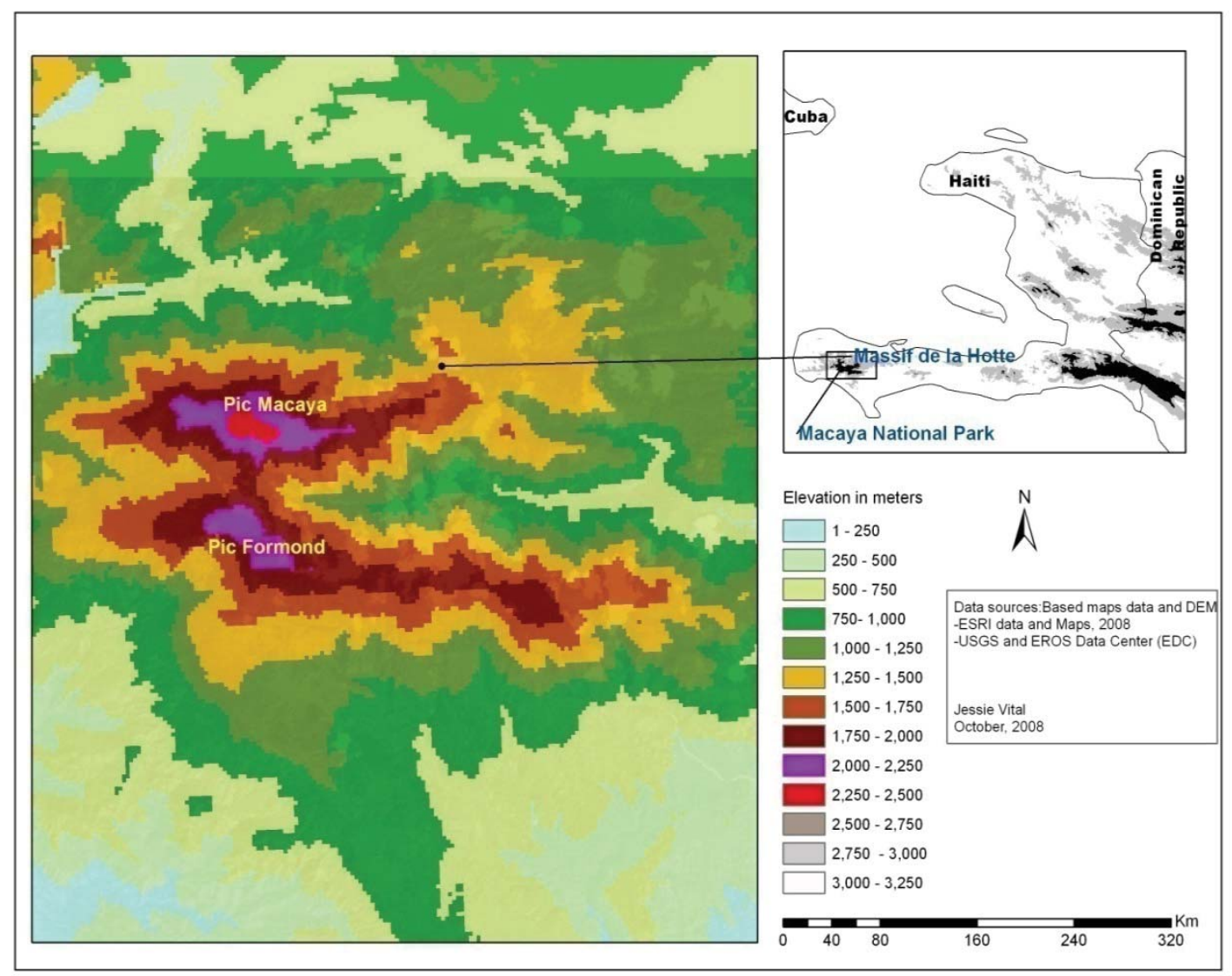

Figure 3-1. Location of Pic Macaya National Park, Haiti surrounded by two major Mountains--Pic Formon and Pic Macaya (ESRI data source, GLCF). 


\subsection{Biophysical Characteristics}

\subsubsection{Topography and Hydrology}

The topography of the Pic Macaya National Park is extremely rugged (Figure 3-2). The Park's boundary is located around two dominant mountains in the region, Pic Formon $(2,250$ meters or $7,381 \mathrm{ft})$ in the east, and Pic Macaya in the west $(2,347$ meters or 7,700 ft) (Figure 3-1). The plains and the rocky hills south of Pic Formond are included in the park's boundary. The park area is the headwaters of five main rivers: Grande Ravine du Sud, Roseaux, Port-à-Piment, l'Acul, and Guinaudée (Woods, 1987). Temperatures range from $20^{\circ} \mathrm{C}$ to $0^{\circ} \mathrm{C}$. The region is influenced by moist air, winds and sea breezes blowing from north to south. This results in frequent rainfall at higher elevations. The region receives an annual rainfall of more than 3,000-5,000 mm yearly.

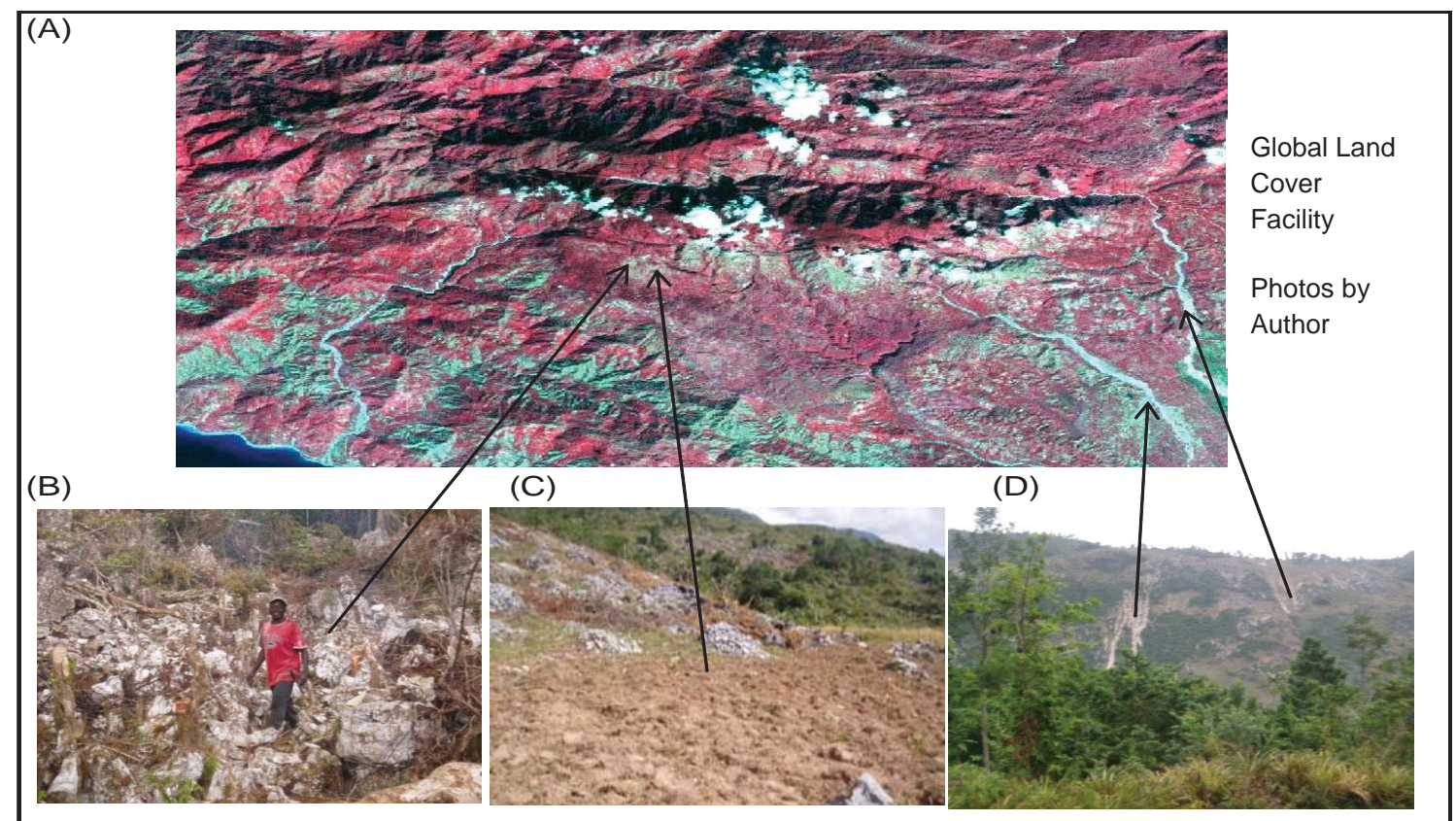

Figure 3-2. A- False color composite of ETM+ band 4-3-2 (RGB) in the Macaya Region. Major typical vegetation covers are pine forest (dark red) and broadleaf shrubs light red; barren land and agriculture are shown in shades of brown and pink; the light green represents karsts rock and the blue represents urban areas. (B) karsts, (C) barren land, and (D) mountain erosion. 


\subsubsection{Geology and Soil}

The geology of the area is described as complex, and consists of uplifted limestone, basaltic volcanic rock, and siliceous sandstone and was formed around 70 to 80 million years ago. The geological formation influences the soils type. The soils are predominantly oxisols and ultisols characterized by a low $\mathrm{pH}$, acidic and neutral composition. In the upper hills area, the soils are thin and very erodible and lose fertility rapidly when cultivated (Sergile et al. 1992). Gully erosion is frequent in the lower hills and plains. Deforestation, high hurricane winds, and heavy rainfall increase erosion risks. The lower hills and the plains are covered respectively with red clays and alluvial soils (Figure $3-3$ ).

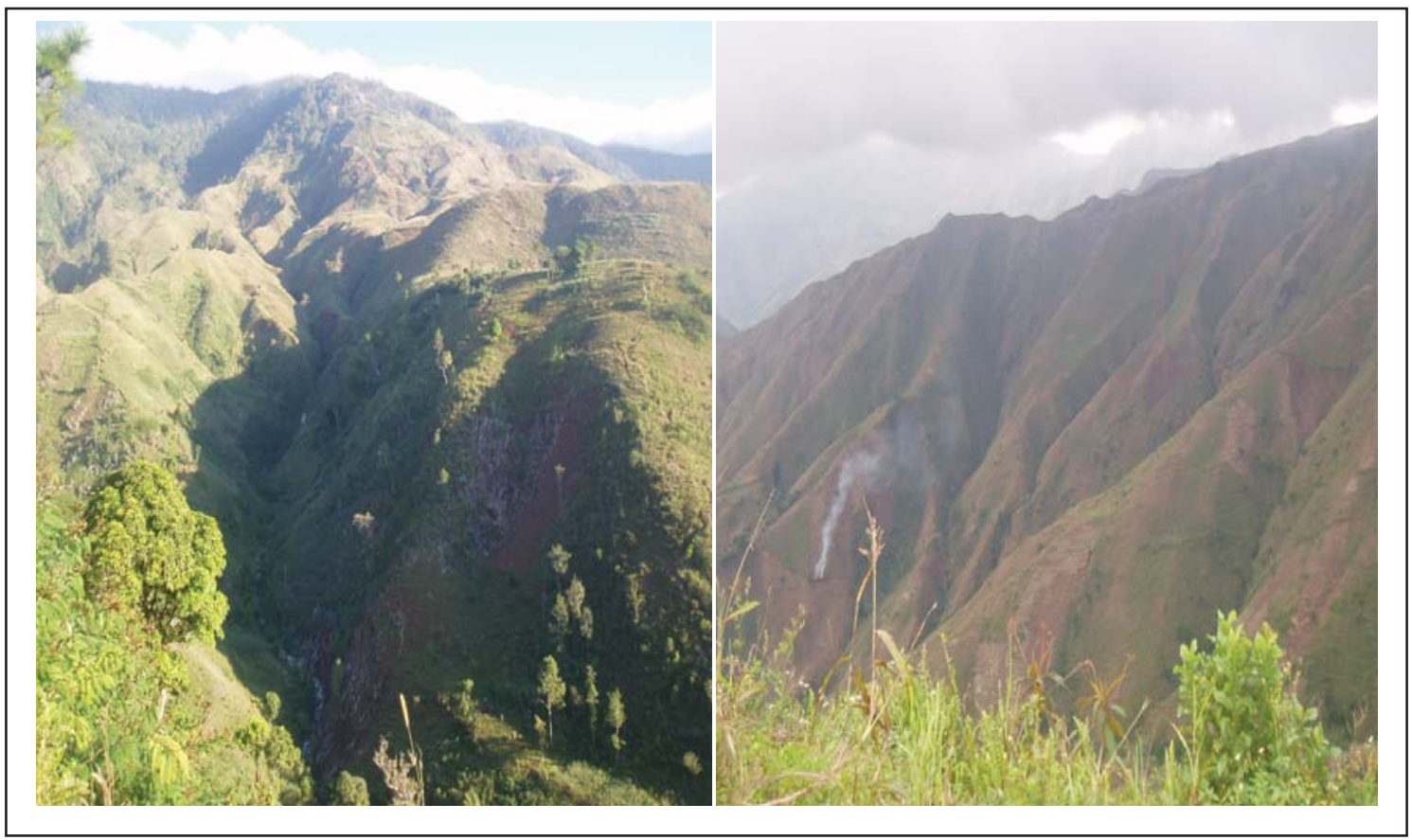

Figure 3-3. Gully erosion on the plain and hilly mountains. Photos by author. 


\subsubsection{Flora and Fauna}

The region of the Massif de la Hotte including the park area is dominated by needleleave forest, such as Pinus Occidentalis or "Bois Pin", the only endemic conifer in the Island (Holdridge 1942). These pines can reach 40 meters in height and approximately two meters in diameter (Holdridge 1947) (Figure 3-4).

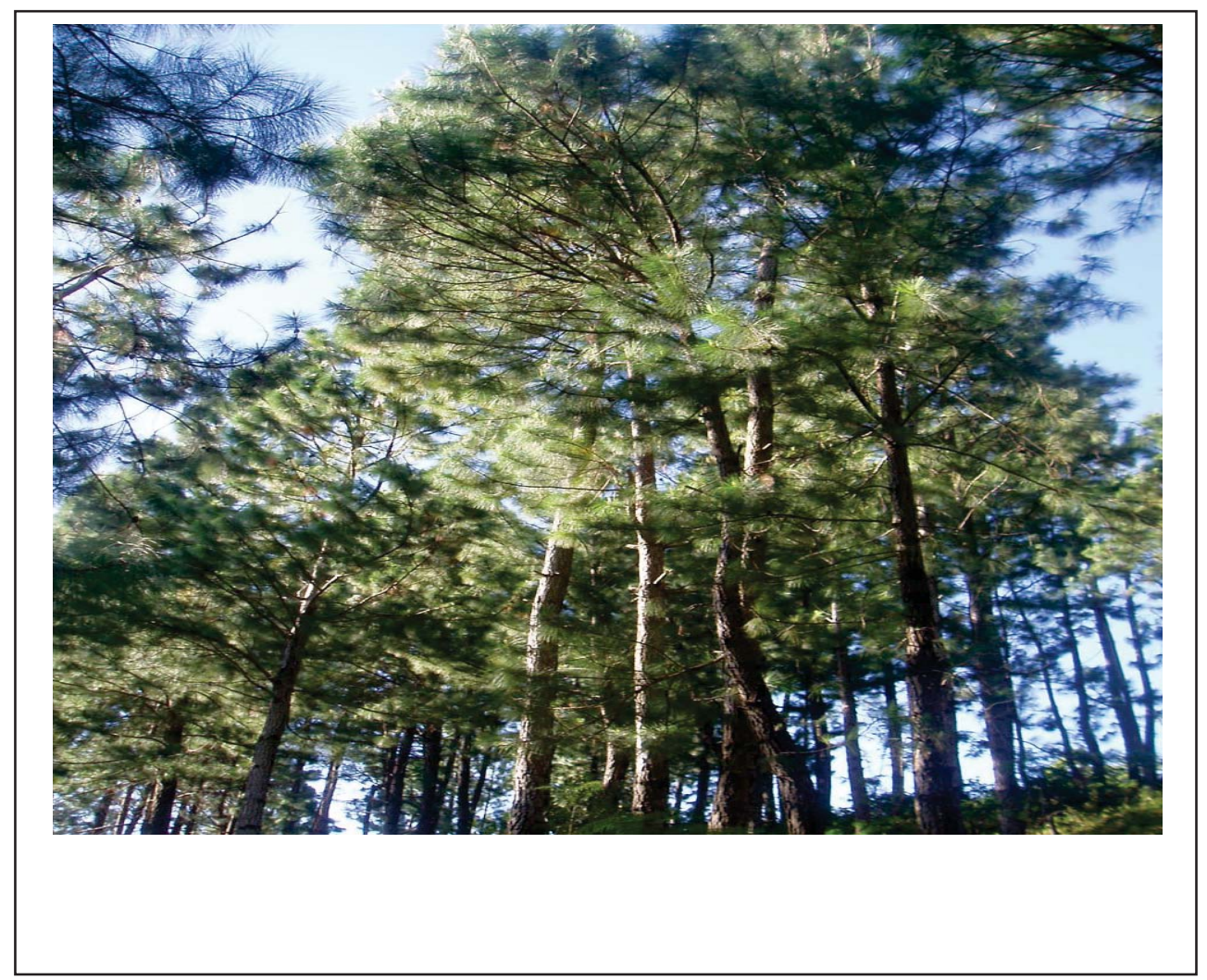

Figure 3-4. Illustrations of Pinus Occidentalis $\odot$ author.

In general, vegetation types in the park and adjacent areas include montane cloud and wet forests, pine forest, and lower montane wet forests find at elevations of $850 \mathrm{~m}$ to $2300 \mathrm{~m}(2,788-7,545$ feet). One out of 10 plant species is endemic to the park. 
There are more than 500 species of vascular plants, with 130 endemic to the island. Thirty four percent of flowering plants are endemic to the park (Judd 1987; Timyan 2000). The park also provides habitat for many mammalian species, migratory birds and amphibians (Figure 3-5). One endangered mammalian species, the Haitian Solenodon (Rhizoplagiodontia lemkei), is endemic to the park. Numerous birds have been observed in the park. Three are vulnerable to extinction: the White-winged Warbler (Xenoligea montana) and the White-winged Crossbill or Hispaniolan Crossbill (Loxia megaplaga), and Black-capped Petrel (Pterodroma hasitata) (Judd 1987; Paryski et al. 1988; Olson et al. 1996; International Union for Conservation of Nature 2008).

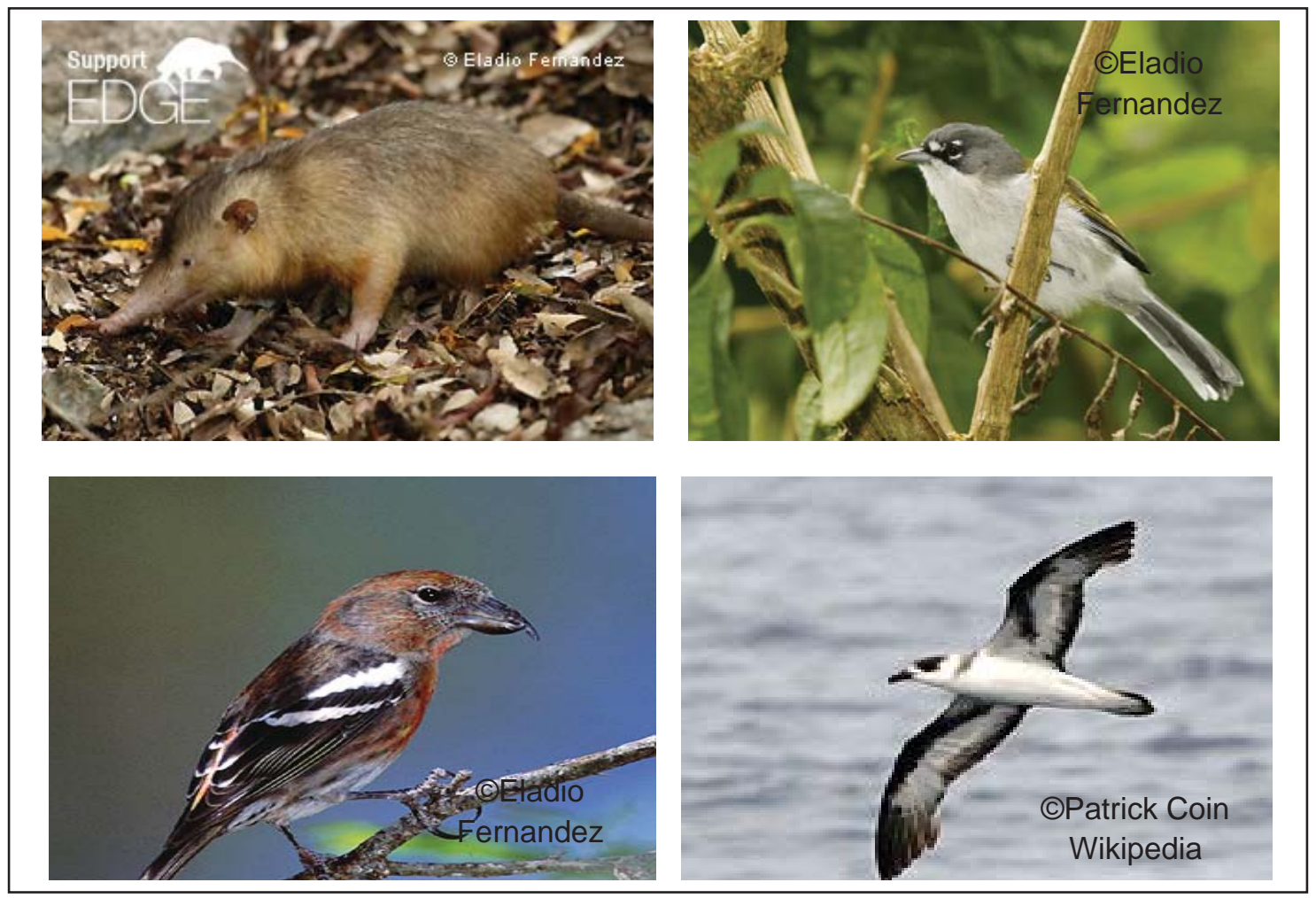

Figure 3-5. Haitian Solenodon (upper left) and White-winged Warbler (upper right) White-winged Crossbill or Hispaniolan Crossbill (Loxia megaplaga), and Black-capped Petrel (Pterodroma hasitata). Pictures: Courtesy of Mr. Eladio Fernandez and Mr. Patrick Coin. Printed with permission. 


\subsubsection{Population and economic activities}

The population living within, or adjacent to, the park has seen a dramatic increase in the last 20 years. Compounding the rapid population increase is the seasonal flow of migrant farmers who access the area during the growing season (November-March) to exploit tree resources for charcoal production and clearing land for seasonal crops production (Organization for the Rehabilitation of the Environment 2001). The main economic activity of people living adjacent to the park area is agriculture including cropping and livestock production (Figure 3-6).

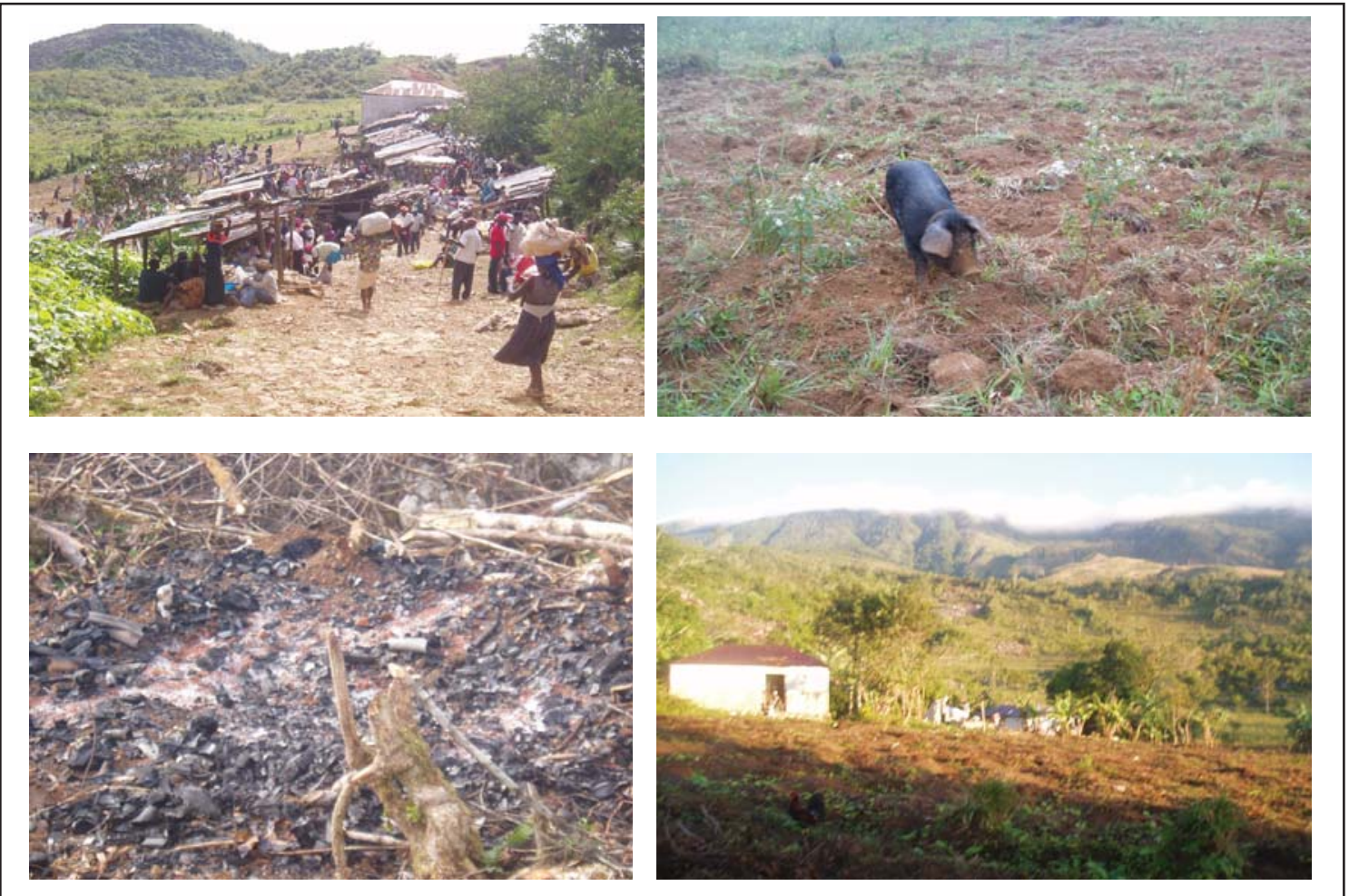

Figure 3-6. Economic activities of the population living in/around the park Macaya. 
The main income source of the inhabitants of the plaine des Cayes and surrounding communal section is agriculture. There are hectares of rice, beans, bananas, and vegetable gardens whose main irrigation depends on the rivers coming from the park. The local cropping calendar starts with clearing in November and December. From January to February, men and women are actively planting their gardens with yams, manioc, and sweet potatoes. Crops such as black beans are intercropped with corn and roots. From April to June, Macaya local residents rely on the marketplace for food. Livestock includes cattle, goats, sheep, Haitian pigs, and poultry raised for market and are the emergency financial support for the family as shown in the Figure 3-6. The harvesting season starts in May and continues to July.

Additional income is generated from illegal timber harvesting and land clearing within the Park. Large deciduous trees such as Bois Tremble (Didymopanax tremulum) are utilized for charcoal production. Pine trees are cut down for housing construction. The cleared areas are converted into gardens for fast growing, cash crops such as beans.

Intense deforestation in the park areas threatens the stability and the hydrologic cycle of these rivers, as well as the rich agricultural lands below. Pic Macaya National Park serves the double roles of conserving and protecting numerous endemic species of plants and animals and also of providing irrigation for the population downstream. 


\subsection{METHODOLOGY}

\subsubsection{Data Collection}

Imagery from a single satellite for the study area with the same temporal coverage over time with cloud coverage less than $20 \%$ was not available. Data from different sensors were chosen: Landsat-5 TM, Landsat-7 ETM+, and ASTER. All the images were located within path 010/ row 047 of the Landsat Worldwide Reference System (Figure 3-7).

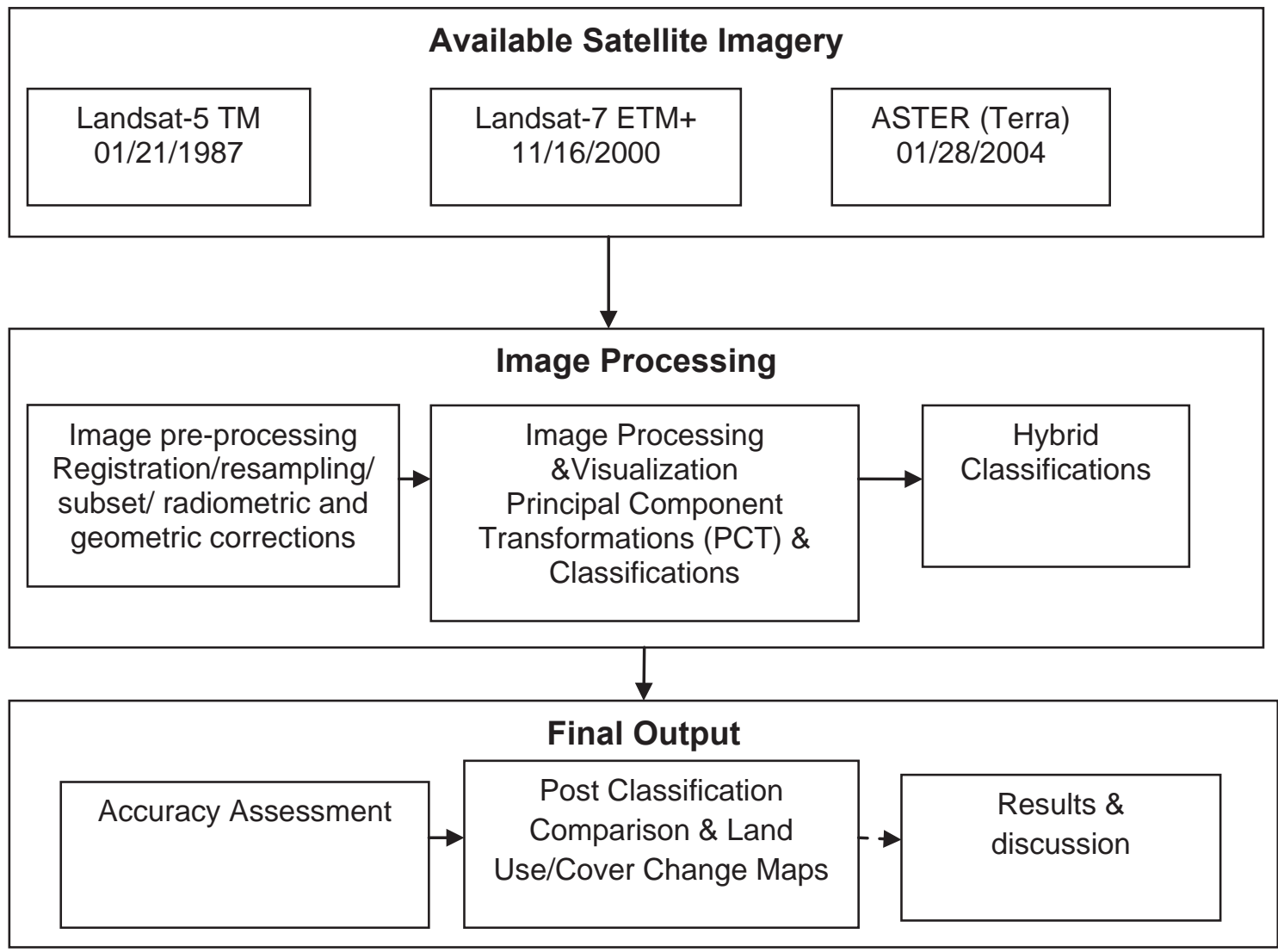

Figure 3-7. General Methodology.

Land use/cover maps, at scales of 1:1,971,021, available for Haiti and the Dominican Republic were consulted to gain an understanding of the type and distribution of the vegetation. These small scale maps cover a large area on the ground and provide only 
general information on the type of vegetation and its location. A Shuttle Radar Topography Mission (SRTM) Digital Elevation Model (DEM) was used. Field data were collected in December 2007.

\subsubsection{Satellite Imagery and Characteristics}

The characteristics of the remotely sensed image used for this study are given in the Table 3-1. They represent the best scenes available from the cited sources.

Table 3-1. Characteristics of the satellite imagery utilized.

\begin{tabular}{|c|c|c|c|c|c|}
\hline SATELLITE & SENSOR & $\begin{array}{l}\text { PIXEL } \\
\text { SIZE }\end{array}$ & PATH/ROW & $\begin{array}{c}\text { ACQUISITION } \\
\text { DATE }\end{array}$ & SOURCE \\
\hline Landsat 5 & TM & 30 & \multirow[b]{3}{*}{ 010/047 } & $1987 / 01 / 21$ & \multirow{3}{*}{$\begin{array}{l}\text { Global Land } \\
\text { Cover Facility } \\
\text { www.glcf.umiacs. } \\
\text { umd.edu }\end{array}$} \\
\hline Landsat 7 & ETM+ & 30 & & $2000 / 11 / 16$ & \\
\hline Terra & $\begin{array}{l}\text { ASTER } \\
\text { (VNIR+ } \\
\text { SWIR) }\end{array}$ & 15 & & $2004 / 01 / 28$ & \\
\hline
\end{tabular}

\subsubsection{Digital Elevation Model}

A 3-arc-second Digital Elevation Model (DEM) of 90 meter was used in this study. This DEM is a product of the Shuttle Radar Topography Mission (SRTM), a joint project overseen by NASA and the National Geospatial-Intelligence Agency (NGA), which has provided topographic data for $80 \%$ of the Earth's land surface. This $90 \mathrm{~m}$ DEM was the digital elevation data available for Haiti. An attempt to create an ASTER- derived DEM, which would have a higher resolution failed due to software unreliability. 


\subsubsection{GPS Points Survey}

A GPS receiver Garmin 76 was used to collect field data in accessible areas of the Park Macaya. A total of 116 GPS points were acquired on the field trip undertaken during the period of December 28 to 30, 2007. A good rule of thumb would be to collect a minimum of 30 to 50 ground points per land cover class (Congalton and Green 1999), but due to limited access in the field, I was able to collect only 116 points. For each class, 5 to 19 ground control points were collected. A Relevé field form (Appendix C) was used to note and register information on the dominant type of land use/cover of the area. The ground truth data collected in the field were randomly divided and used as training and accuracy assessment.

\subsubsection{Software Packages Utilized}

ERDAS Imagine 9.1 was used for the image processing. ArcGIS 9.2 was utilized to map and quantify the rate of change. Derived hillshade and slope thematic layers were generated with ArcGIS 9.2. Microsoft Word and Excel 2007 were used to produce the report.

\subsection{Image Processing}

Preprocessing procedure was applied to the three TM and ETM+ bands 1, 2, 3, 4, 5 and 7 as well as ASTER VNIR bands 1,2,3 and SWIR bands 4, 5, 6, 7 were imported and layered stack with ERDAS Imagine 9.1 (Figure 3-8). 


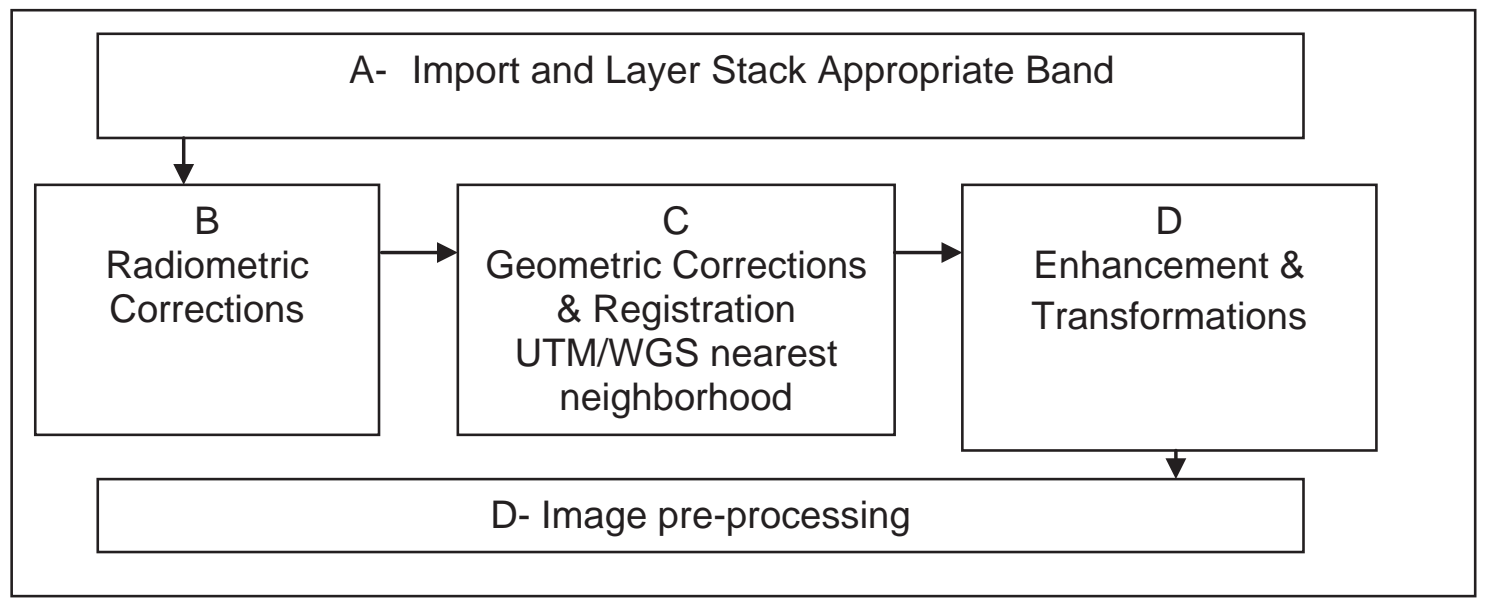

Figure 3-8. Preprocessing flowchart.

\subsubsection{Radiometric Corrections}

Using ERDAS Imagine model make, the DNs of each image was converted to surface reflectance using the modified dark object subtraction, an atmospheric correction that utilized the cosine of the solar zenith angle correction (COST)). Inputs into the model include the Earth-Sun Distance, the solar elevation, and the minimum DN values for each band (Chavez 1996).

\subsubsection{Geometric Correction}

Each individual satellite image was geo-rectified using a first order affine transformation and resampled to the Universal Transverse Mercator (UTM) coordinate system, zone 18 World Geodetic System (WGS 84) datum using a nearest neighbor interpolation algorithm (Jensen 2005). Nearest neighbor is a resampling method, which preserves the original reflectance value of the image data. Spatial resolutions of the two Landsat scenes were rectified from 28.5 to 30 m pixels. 
ASTER VNIR and SWIR bands (1, $23 \mathrm{~N}$ and 4 to 9$)$ were rectified to $30 \mathrm{~m}$ pixels also. All the image scenes were subset (Figure 3-9) to the following coordinates points:

Upper Left X: $\quad 590080 m$

Upper Left Y: 2038488m

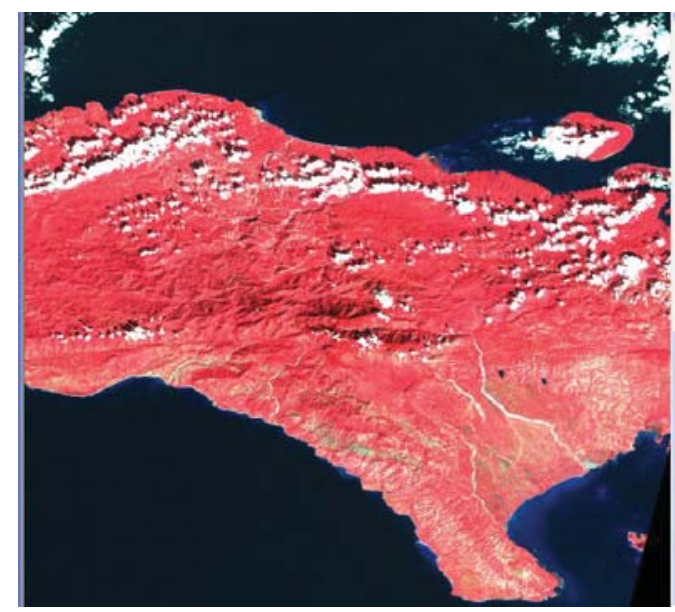

Lower Right X: 620920m

Lower Right Y: 2017818m

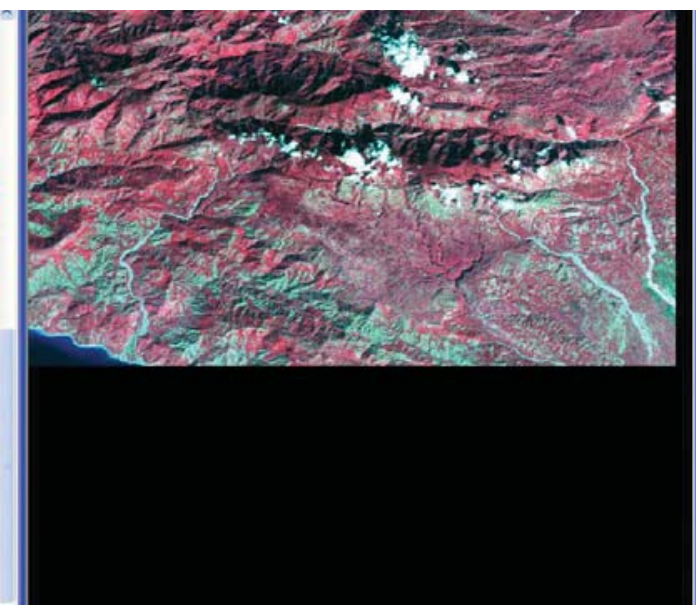

Figure 3-9. Original satellite imagery (left) without radiometric correction, subset of the Landsat $\mathrm{ETM}+$ after radiometric corrections (right).

\subsubsection{Enhancement and Transformations}

Image visualization enhancements and transformations were utilized to assist in the classification process. Scientific visualization is defined as:

"Visually exploring data and information in such a way as to gain understanding and insight into the data" (Brodlie et al. 1992).

There are different techniques to improve the visualization of digital imagery. Various band combinations displayed as red, green, blue (rgb), color composites were used to aid in visually interpreting the data. Principal component analyses reduced the redundancy in the data as well as improving image visualization (Jensen 2005). 
Digital imagery can be displayed using one gray scale band, a true color composite, or a false color (FC) composite in the RGB color display system. The standard false color composite $(4,3,2)$ helps to visualize land cover/use as vegetation is highly reflective in the near-IR (band4) and fairly reflective in the red (band 3) and green (band 2) (Lillesand et al. 2008).

The FC of 4,3,2 (Figure 3-10) shows pine forest in shades of dark red, broadleaved shrub in light red, barren land as shades of brown, karsts as light green and urbanization as blue-gray color.

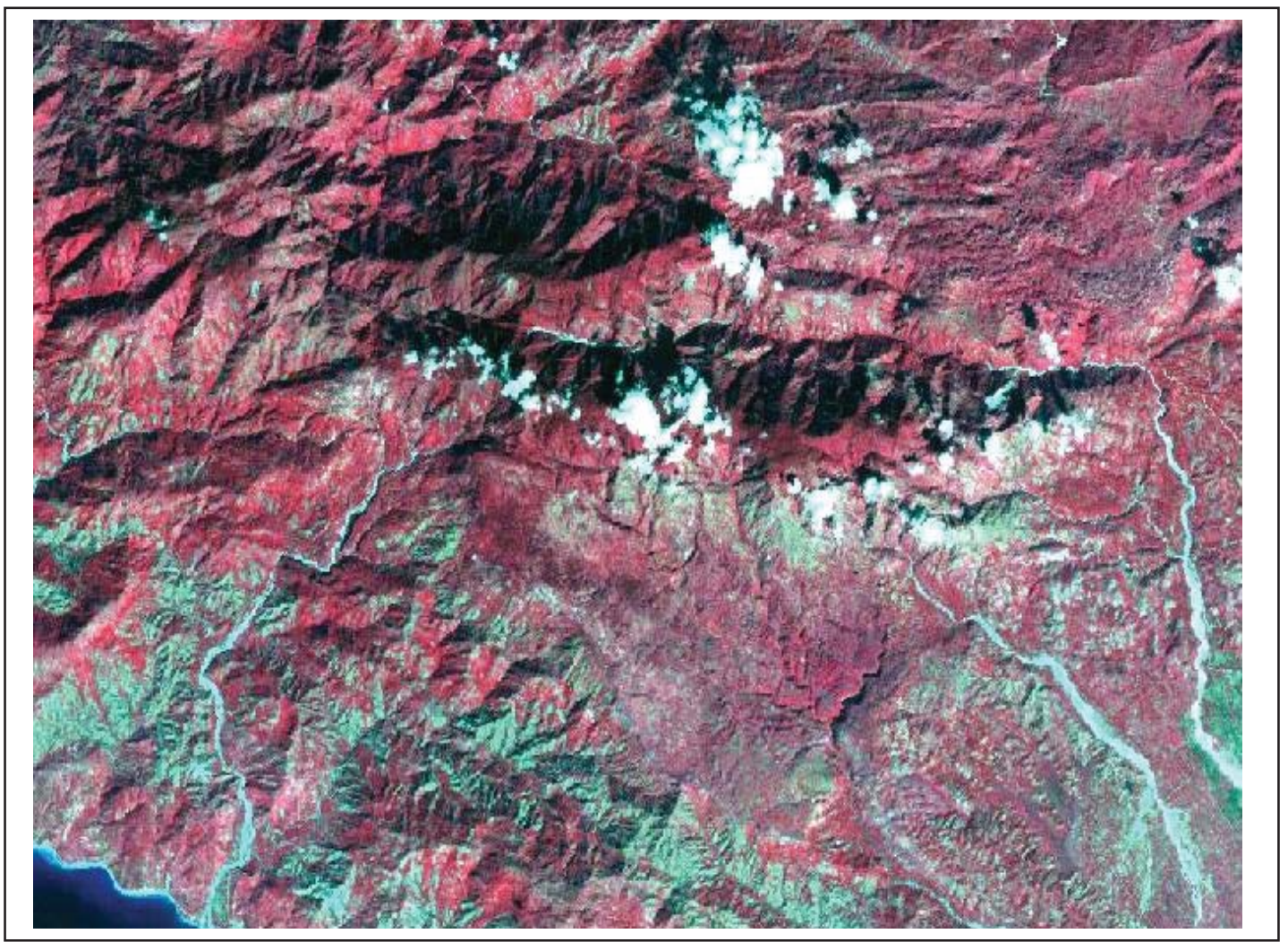

Figure 3-10. False color composite of bands 4, 3, 2 (rgb) of Landsat ETM+ 2000 scene. 
Band combinations 7, 4, and 2 in RGB (Figure 3-11) were used to gain more understanding of the geology (barren soils: karsts, and sediments), and distinguishing stream channels from erosion gullies. Pine forest appears as shades of olive-green. Grasslands appear as light green. Barren soil appears in pink shades and urbanization in different shades of magenta.

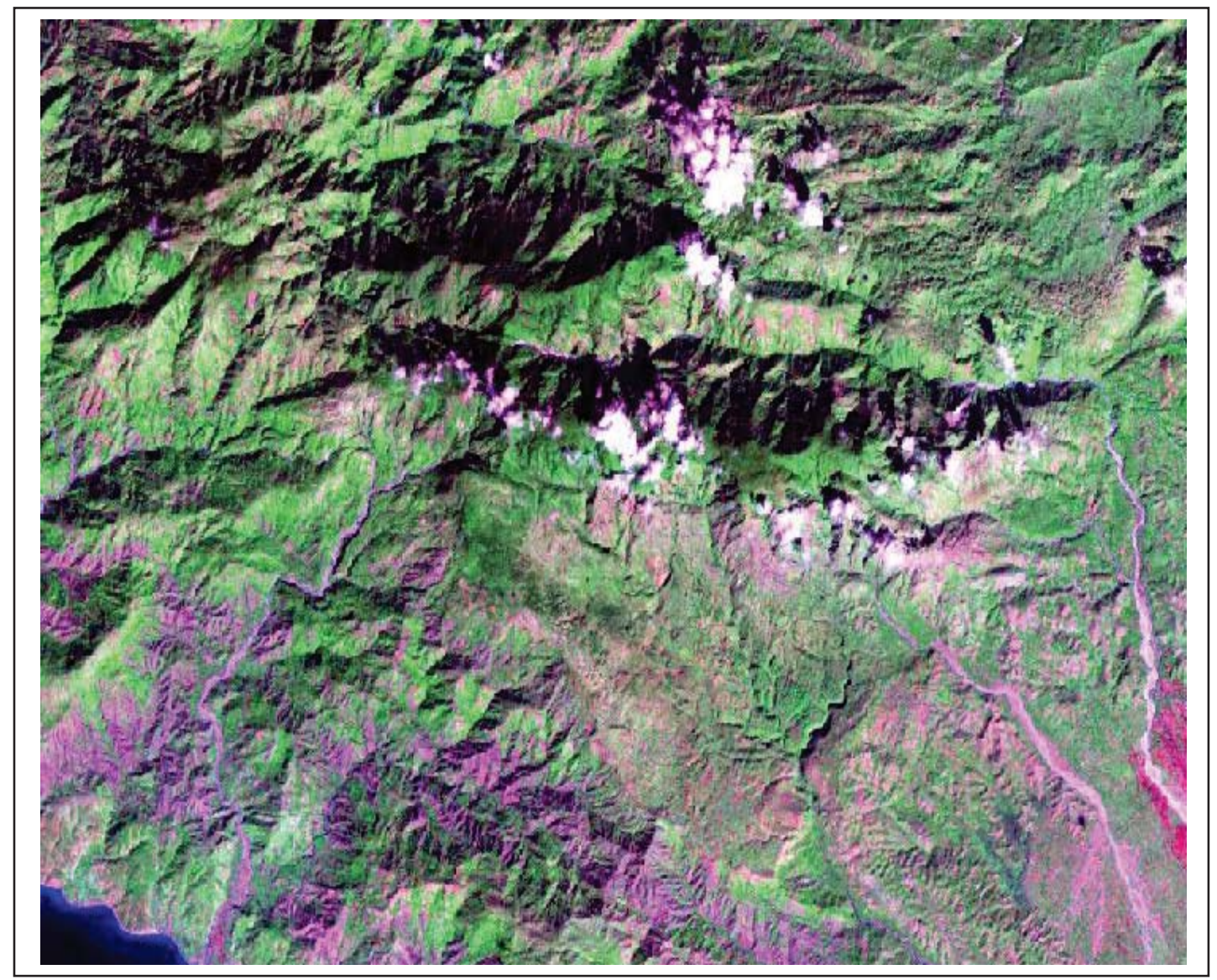

Figure 3-11: False color composite of bands 7, 4, and 2 (rgb) of Landsat ETM+ 2000 scene.

A true color composite (bands 3, 2, 1) was evaluated for each image. Resulted image shows ground features colors similar to what the human eye perceives. Clouds are white, water is blue, vegetation is green and cleared areas are light pink (Figure 3-12). 


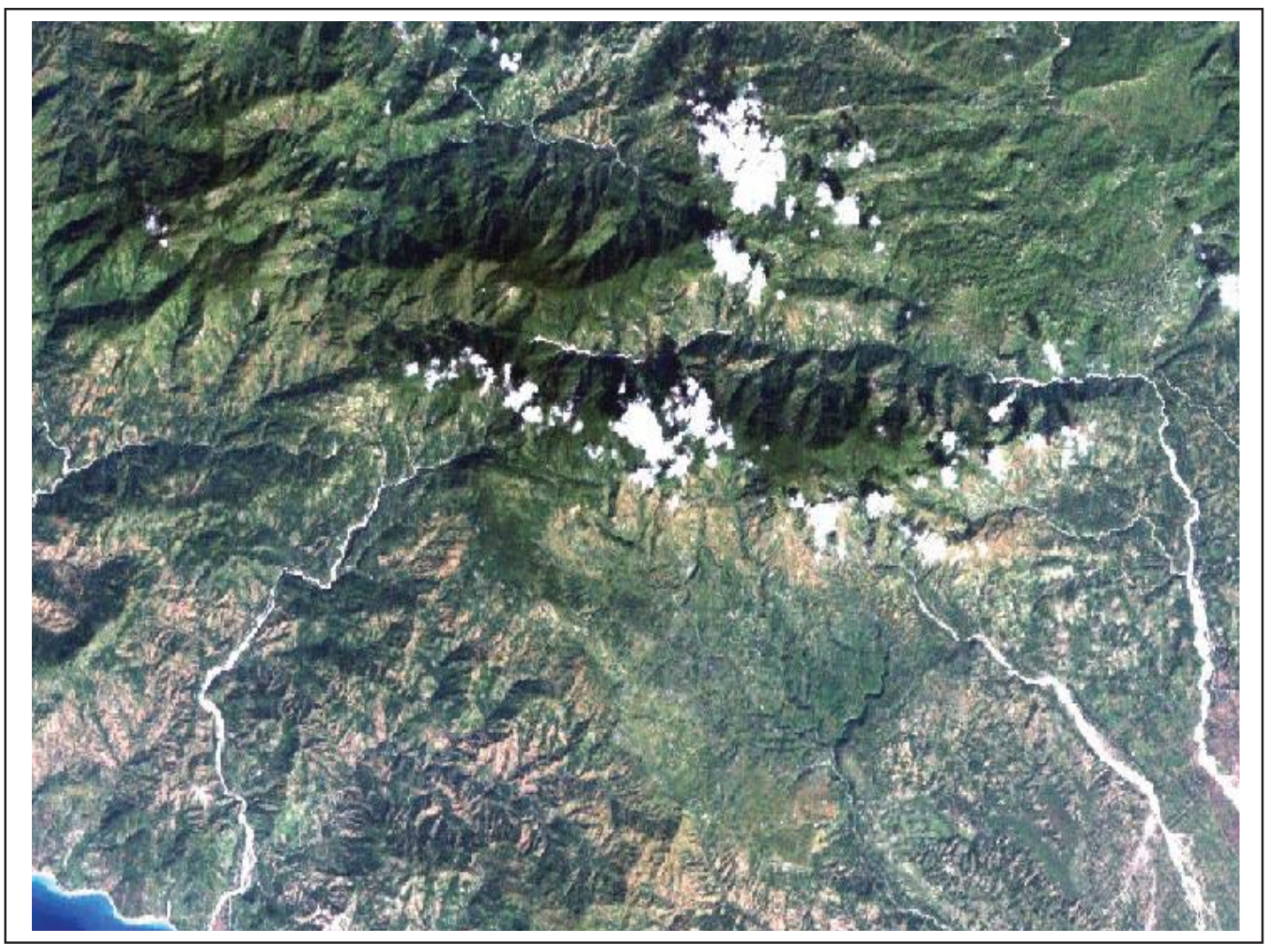

Figure 3-12. True color composite of bands 3, 2, 1 (rgb) of Landsat ETM+ 2000 scene.

Principal components were calculated for each of the 3 images. The transformation was applied to reduce the redundancy of information and compress the data into uncorrelated independent components that can be used for classification (Singh 1989). Eigenvalues were computed from each image's covariance matrix and determine the spectral length of each component's axis. Eigenvectors refer to the directional relationship between the principal components axes and imagery axes. A factor loadings matrix shows the information contributed by each band to the individual components (see Appendix) (Singh 1989; Jensen 2005). As a result of the transformation, a new image for each study was created. 
The first three PC components of the Landsat 1987 and 2000 scenes were stacked together to form a new image, since they accounted for $99.38 \%$ and $98.95 \%$ of the variance. The first PCA of the ASTER VNIR-SWIR was used since it accounted for $93 \%$ of the variance (APPENDIX A: Principal Components Statistics and Analysis). A subset of the Landsat ETM+ PC transformation is shown in Figure 3-13. The three PCA components combination greatly enhanced the visual interpretability and increased the separability between the land class covers (Jensen 2005).

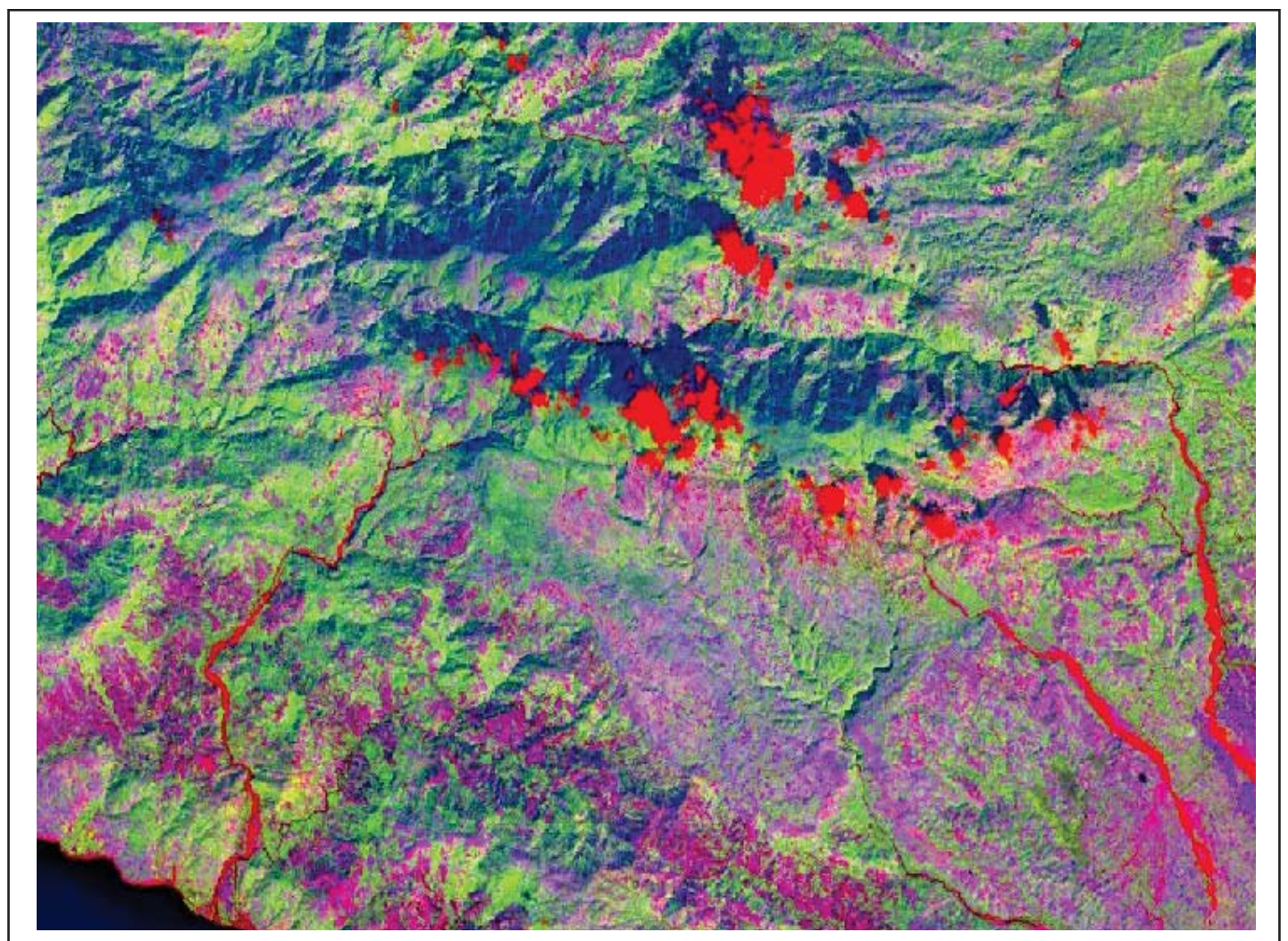

Figure 3-13. Landsat ETM+ PCs 1-2-3 displayed as red, green, blue. 


\subsection{Image Classification and Accuracy Assessment}

Figure 3-14 displays the steps to classify the land use/cover of each scene and asses the accuracy.

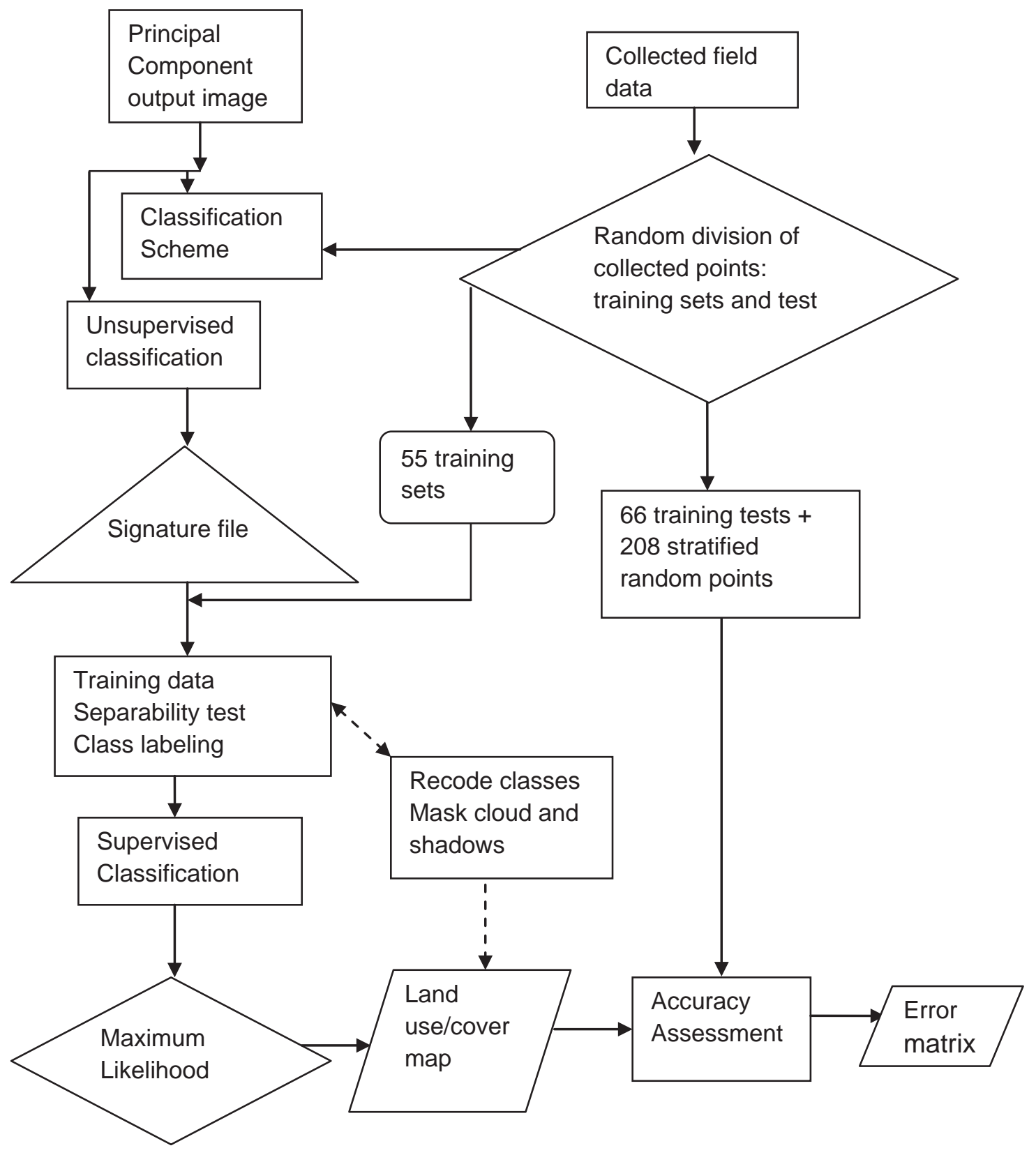

Figure 3-14. Flowchart of image classification and accuracy assessment. 


\subsubsection{Classification scheme and information classes' characteristics}

First, a classification scheme was developed. This scheme is based on the Anderson level II classification system (Table 3-2). However, an Anderson level III was also used to classify the open pine and mixed forests based on detailed ground truth information that were collected on the field. In addition, previous studies in the area were consulted to refine the classes. Six information classes were derived. 1) Built-up; 2) Agriculture; 3) Herbaceous; 4) Open pine forest; 5) Mixed forest; 6) Barren Land.

Table 3-2. Classification scheme designed for the study.

\begin{tabular}{|c|l|}
\hline Class Number & \multicolumn{1}{|c|}{ Class_Name } \\
\hline 1 & Built-up \\
\hline 2 & Agriculture \\
\hline 3 & Herbaceous \\
\hline 4 & Open pine forest \\
\hline 5 & Mixed forest \\
\hline 6 & Barren Land \\
\hline
\end{tabular}

\subsubsection{Information Class Description}

\section{Built-up}

Built-up areas are comprised of low residential areas of scattered housing, dense residential areas, and little road infrastructure. Dense residential areas are concentrated outside the park's boundary. Rural homes in and adjacent to the park area are dispersed in such a way they could not be classified into this class, except where deforestation was intense (Figure 3-15) 


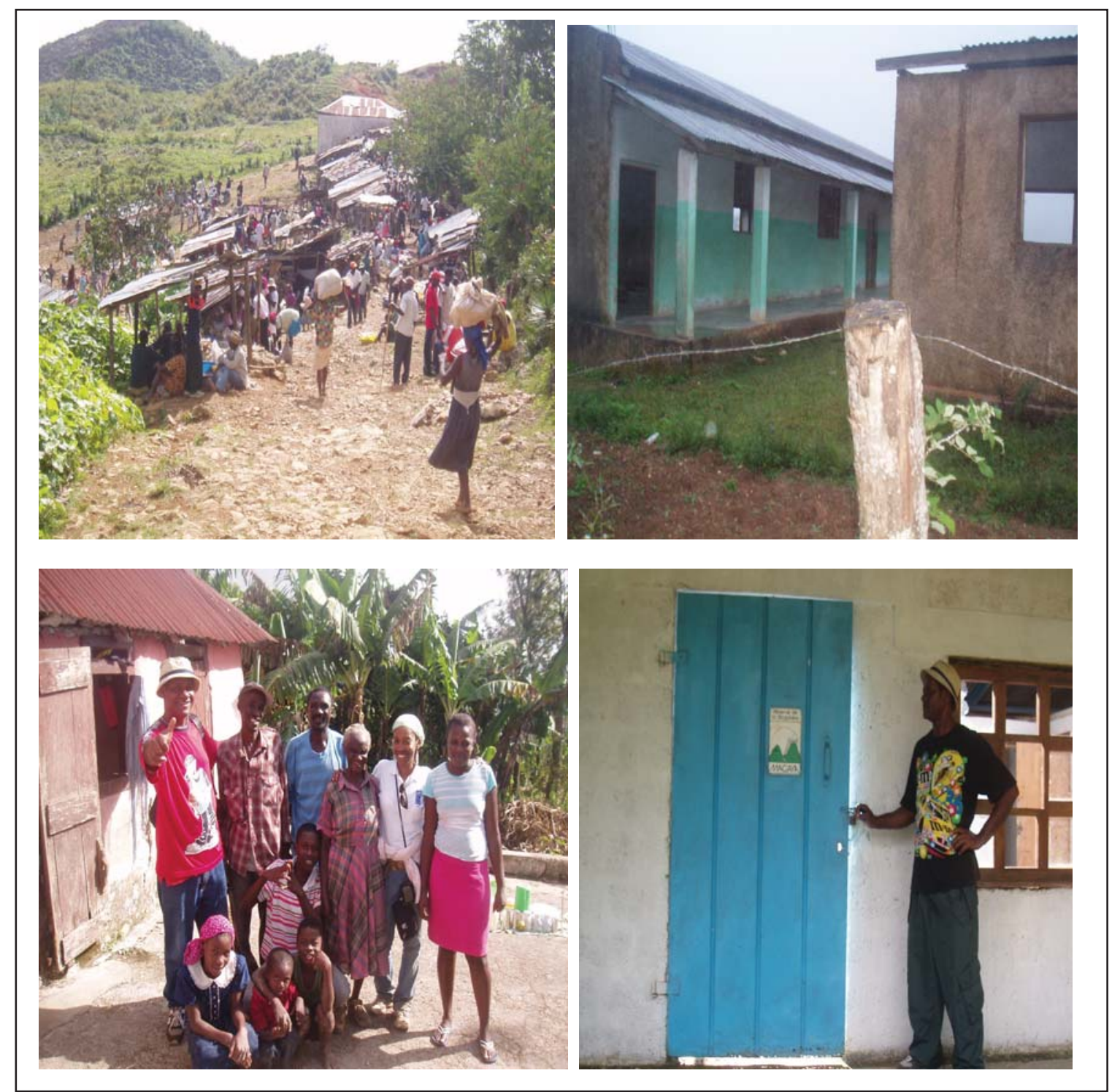

Figure 3-15. Illustrations of built-up areas. 


\section{Agriculture}

The agriculture class represents areas used for crop production and grazing (Figure 3-16). Based on field observations and the cropping calendar, it was observed that most of the agricultural land was fallow at the image acquisition dates. This contributed to confusion between agricultural areas and barren land composed of bare soil, rocks and unpaved roads. Hence, agricultural and barren land was evaluated with the use of ground truthing and texture analysis in order to decrease the possibility of misclassification.

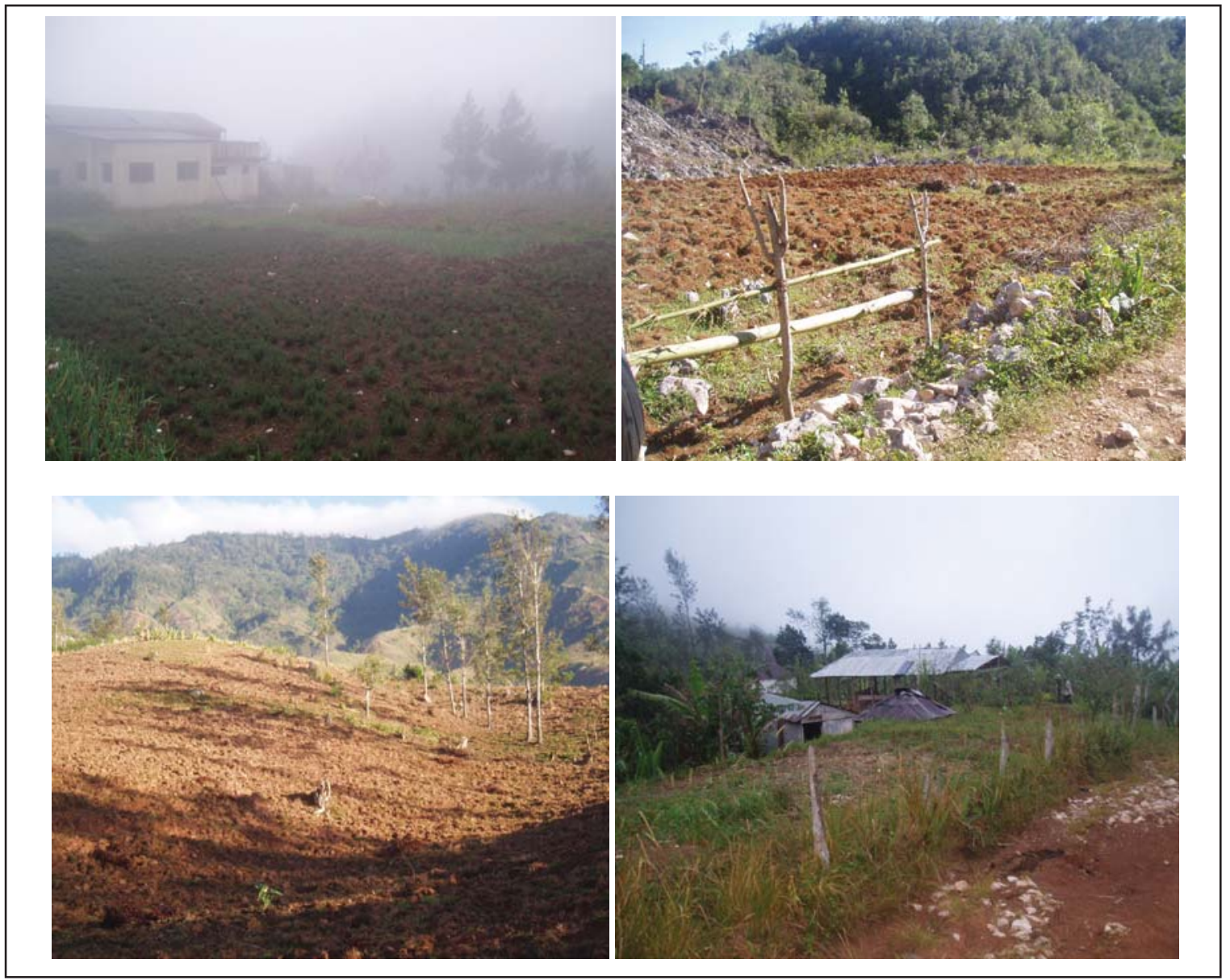

Figure 3-16. Illustrations of Agricultural land--active cropping and fallow lands. 


\section{Herbaceous}

The herbaceous class is composed of grasslands, forbs and ferns. When forests are cleared for agriculture, the land becomes less fertile as the agricultural practices are unsustainable. It is then abandoned for pasture, and grasses, forbs and ferns revegetate these sites (Figure 3-17).
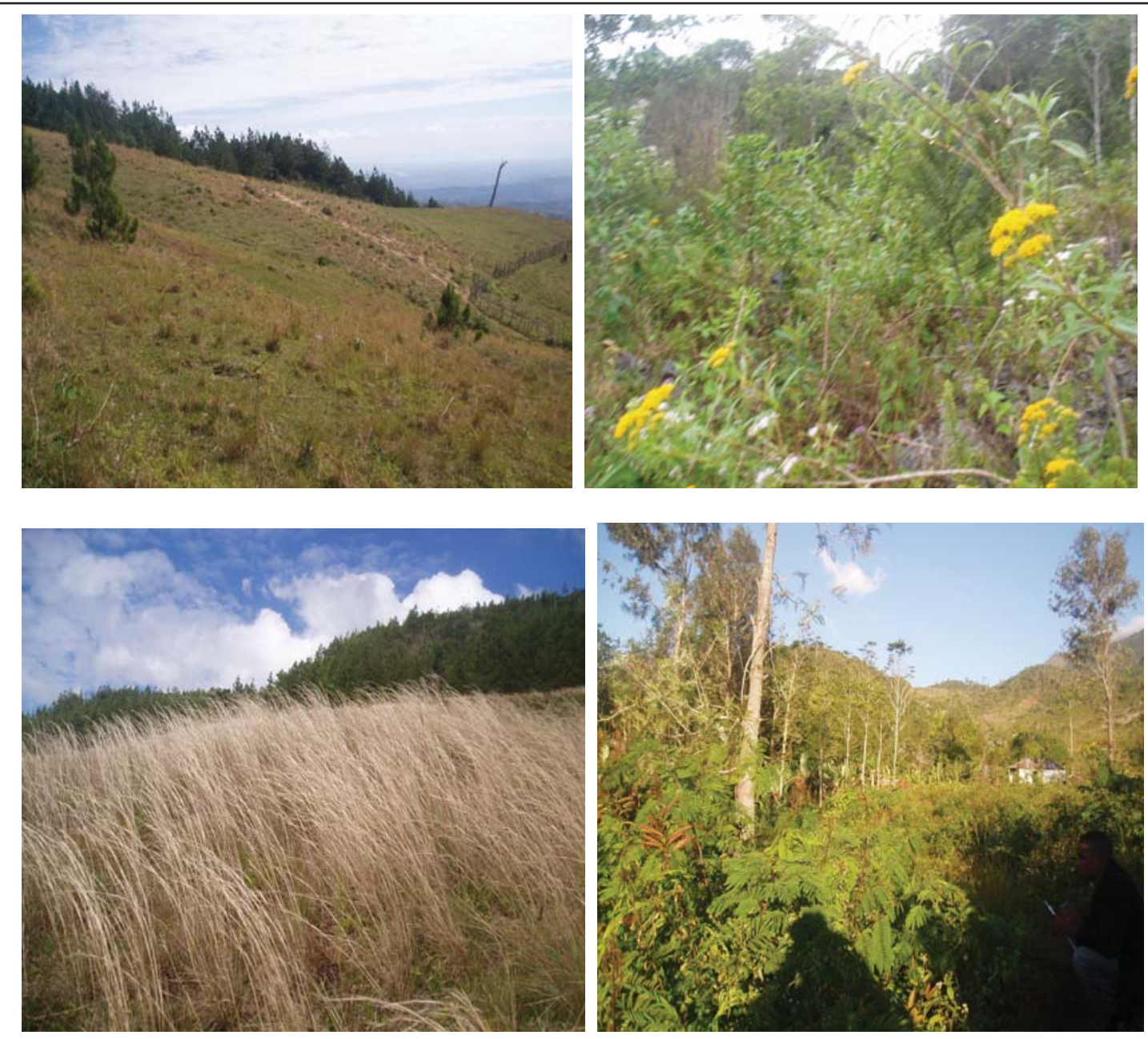

Figure 3-17. Illustrations of Herbaceous land types. 


\section{Open Pine Forest}

Judd (1986) divided the pine land into 4 categories 1) open rocky pinelands; 2) open pine savannas; 3) open pinelands with scattered shrubs; and 4) moist pinelands with a shrub understory. Open pine forest can be defined as a closed forest, which has turned into an open forest as a result of natural causes or human intervention. This class includes continuous vegetation cover in which tree crown cover exceeds 10 percent and a minimum of tree height of $5 \mathrm{~m}$ (FAO, 2006) at elevations between 850 and $1250 \mathrm{~m}$ (Figure 3-18).

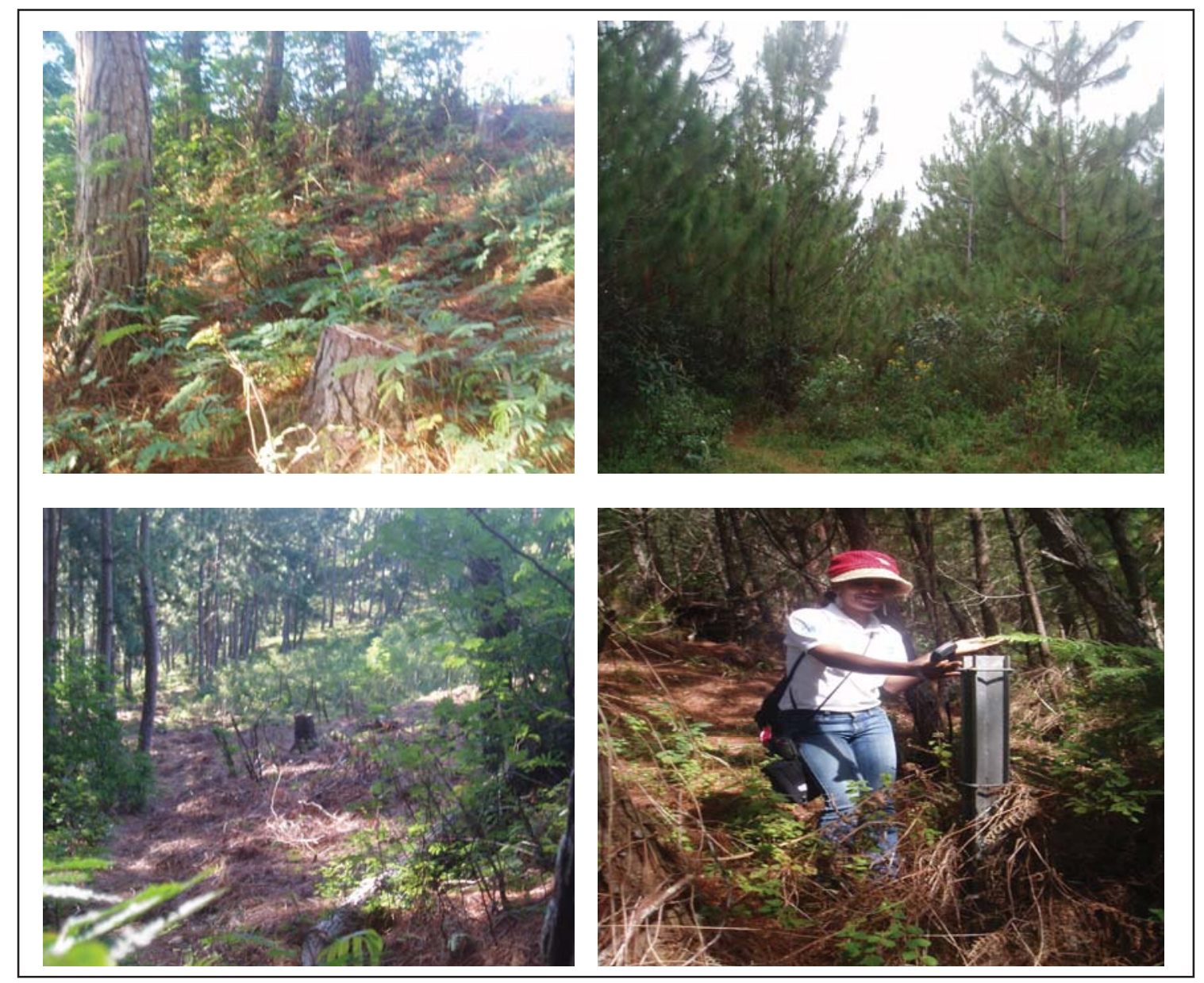

Figure 3-18. Illustrations of open pine forest in Pic Macaya National Park. 


\section{Mixed Forest}

The mixed forest in Macaya National Park is diverse with many endemic species. It is characterized by the absence of a dominant tree species. Instead many species such as pine, and different broad-leave trees (Didymopanax tremulum) are mixed with shrubs. However, based on field observations, there is an insignificant amount of broad-leave species such as the Bois Tremble and shrubs species. Instead small trees dominate the area (Figure 3-19).

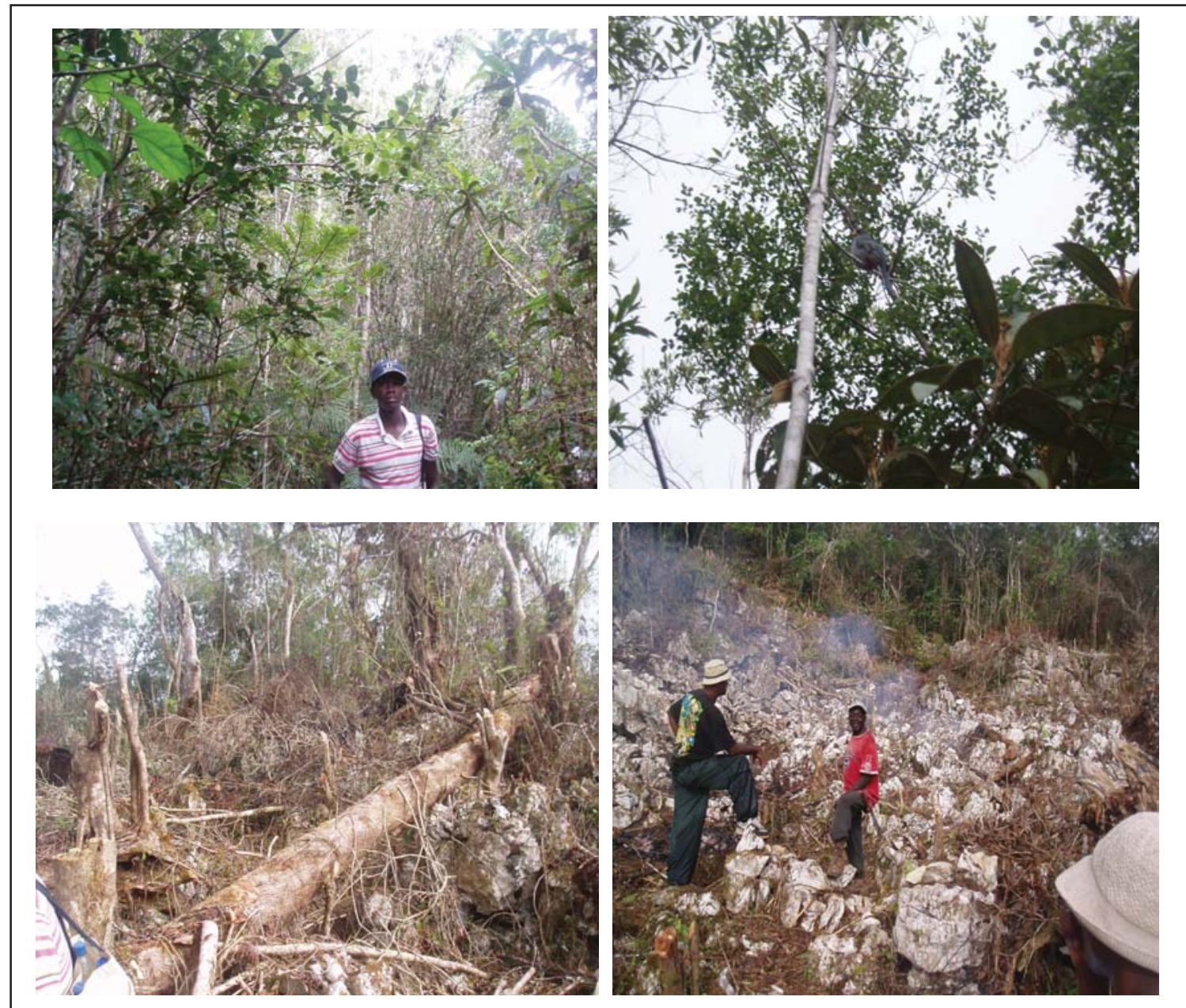

Figure 3-19. Varying compositions of mixed degraded forest. 


\section{Barren land}

Barren Land includes areas of bare soil, sand, and exposed rocks (Figure 3-20). In a barren area, less than one-third of the area has vegetation or other cover (Anderson et al, 1976).
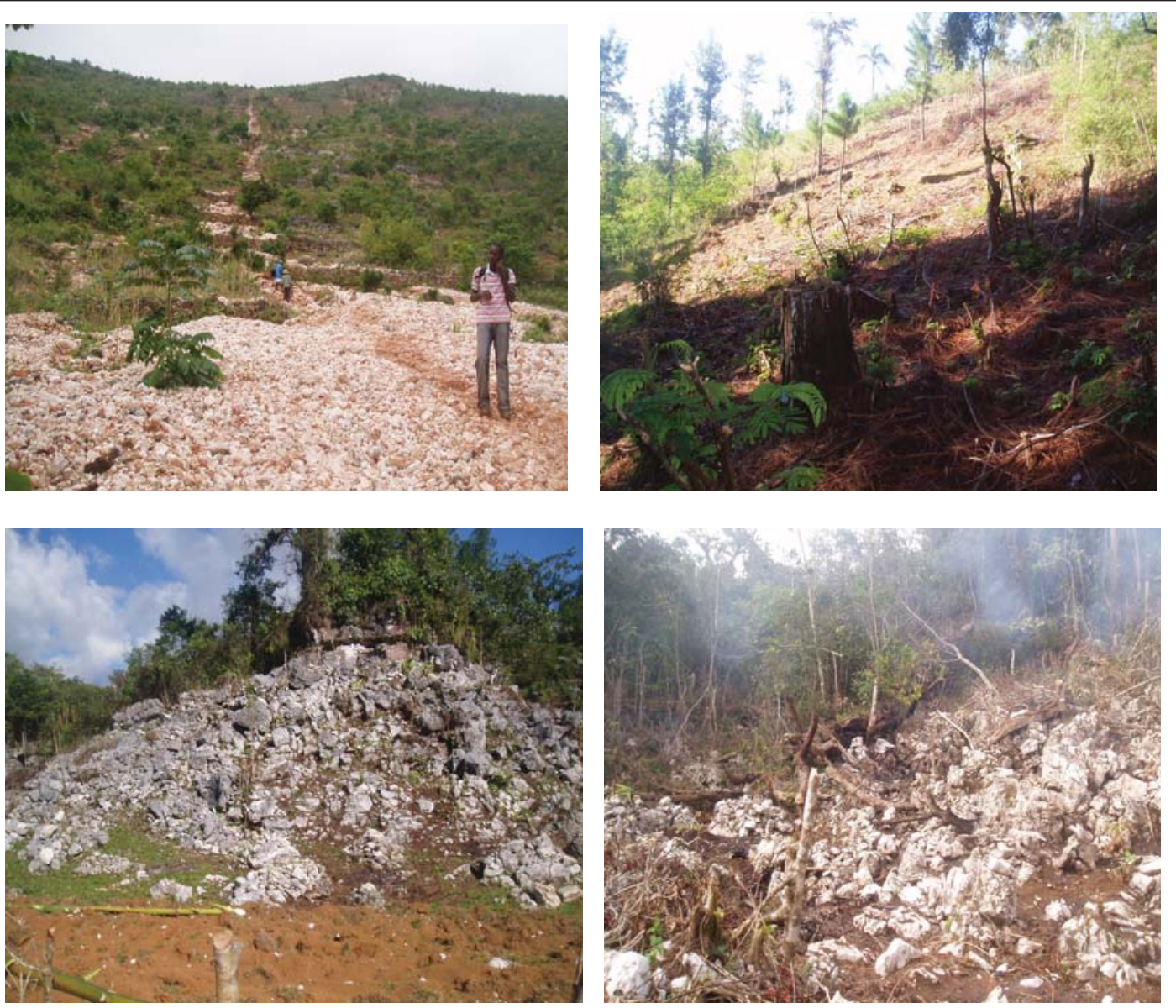

Figure 3-20. Illustrations of barren land class. 


\subsubsection{Hybrid classification and Accuracy Assessment processes}

The Hybrid classification approaches consisted of building spectral signature files derived from both unsupervised (ISODATA) techniques and supervised training sets, and were used together to classify every pixel within each scene. Unsupervised classification was performed on each of the three PC images to generate training data that were used to develop training sets for the supervised classifier. The clusters were grouped into classes with the help of visual interpretation and the available ancillary data. The results of unsupervised classification were verified from 55 training samples collected in the field to better understand the spectral signatures of the land use/cover classes. For each land use/cover class, 8 to 13 ground truth points, with the exception of built-up were used as training sites in the image classification.

Separability analysis of the signatures files were used to select the clusters or training sets with the best signatures and separability. Those selected were input into a maximum likelihood classifier (MLC). Ilustrations graphs are shown in the results section.

Recoding was done to merge the spectral classes into the six defined information classes. In addition, as noted, clouds and cloud shadows were not of interest. They were masked out using ArcMap GIS and the masking function in ERDAS/Imagine. Pixels classed as cloud shadow or cloud were clipped out by recoding them as 0 . Masking cloud shadows and clouds eliminated spectral confusion with barren soil. 
The last step of the image processing was accuracy assessment. Accuracy assessment was conducted independently on each classification. Two sources of information: the remote sensing-derived classification map and ground reference test information were used as inputs and compared to assess the accuracy of the classified map. A combination of training test information sources were used since the number of field collected samples was less than 20 per class. This limitation was due to site obstruction and inaccessibility. The only 116 ground verified points collected were divided randomly between training pixels and ground reference test pixels. 55 sites were used as sample to train the supervised classification and 61 sites were left as ground truth reference.

The number of reference pixels is an important factor to estimate the accuracy of each classified image. A good guide is to use a minimum of 30 sample points for each information class to obtain a statistically valid sample(Congalton and Green 1999). According to Congalton and Green (1999), more than 250 pixels are needed to estimate the mean accuracy of a class within plus or minus five percent.

Therefore, to obtain the ground reference test information, a sampling scheme using traditional and geostatistical techniques was designed. This sampling scheme made use of a higher spatial resolution remotely sensed data (the VNIR band ASTERpanchromatic image for the ETM+) to obtain the ground reference test information, which were added with the 61 ground verified points collected in the field to obtain $\mathrm{N}$ number of sample size.

The sample size was based on multinomial distribution. For more details see (Jensen 2005, page 501). The locations of the samples $(x, y)$ for each class were collected 
randomly using the equalized stratified random sampling model. An equal number of 30 samples were selected from each strata or land use/cover class by selecting 208 points that were added with the 61 reference points collected in the field. Strata are first created by extracting only pixels associated with a specific class found in the land use/cover map. Then, $(x, y)$ sample locations are randomly distributed throughout the geographic study area.

The reference image was overlaid with the 271 accuracy assessment points. In addition to the 61 ground verified points, several independent data were used as reference. The 1987 TM image was used as a backdrop. The 2000 ETM+ panchromatic band 8 and 2004 ASTER VNIR bands were also used to verify the accuracy points. Following this evaluation process, an accuracy report was generated. Error matrix with producer's and user's accuracies, overall accuracy and Kappa statistic was generated and analyzed. 


\section{RESULTS AND DISCUSSION}

\subsection{Spectral separability among the classes land use/cover $(1987,2000$, 2004)}

Separarability analyses were done on the signatures files using ERDAS to select the best statistical training signatures to use for the MLC classification. The spectral signature curves for the six land cover classes for each date showed the average reflectance responses. In most cases, barren land composed of unpaved, dry soil, limestone and built-up registered the highest reflectance from the visible band 1 (0.45$0.52 \mathrm{um})$ with a peak in the mid-infrared regions (1.55-1.75 um). The Figure 4-1, Figure 4-2, and Figure 4-3 illustrated the spectral signatures used for the classification.

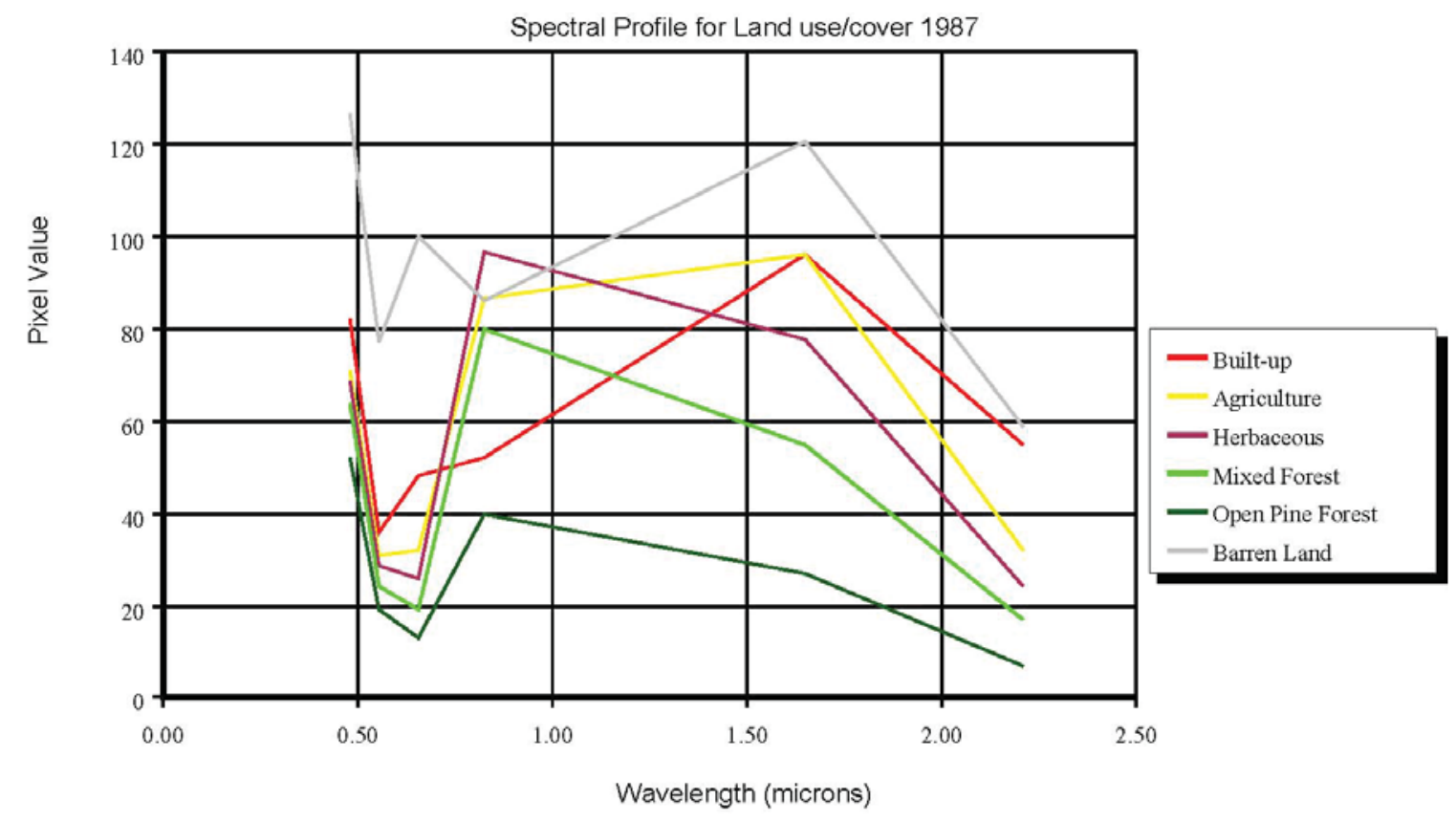

Figure 4-1. Spectral separability for land use/cover classes of the Landsat TM 1987. 


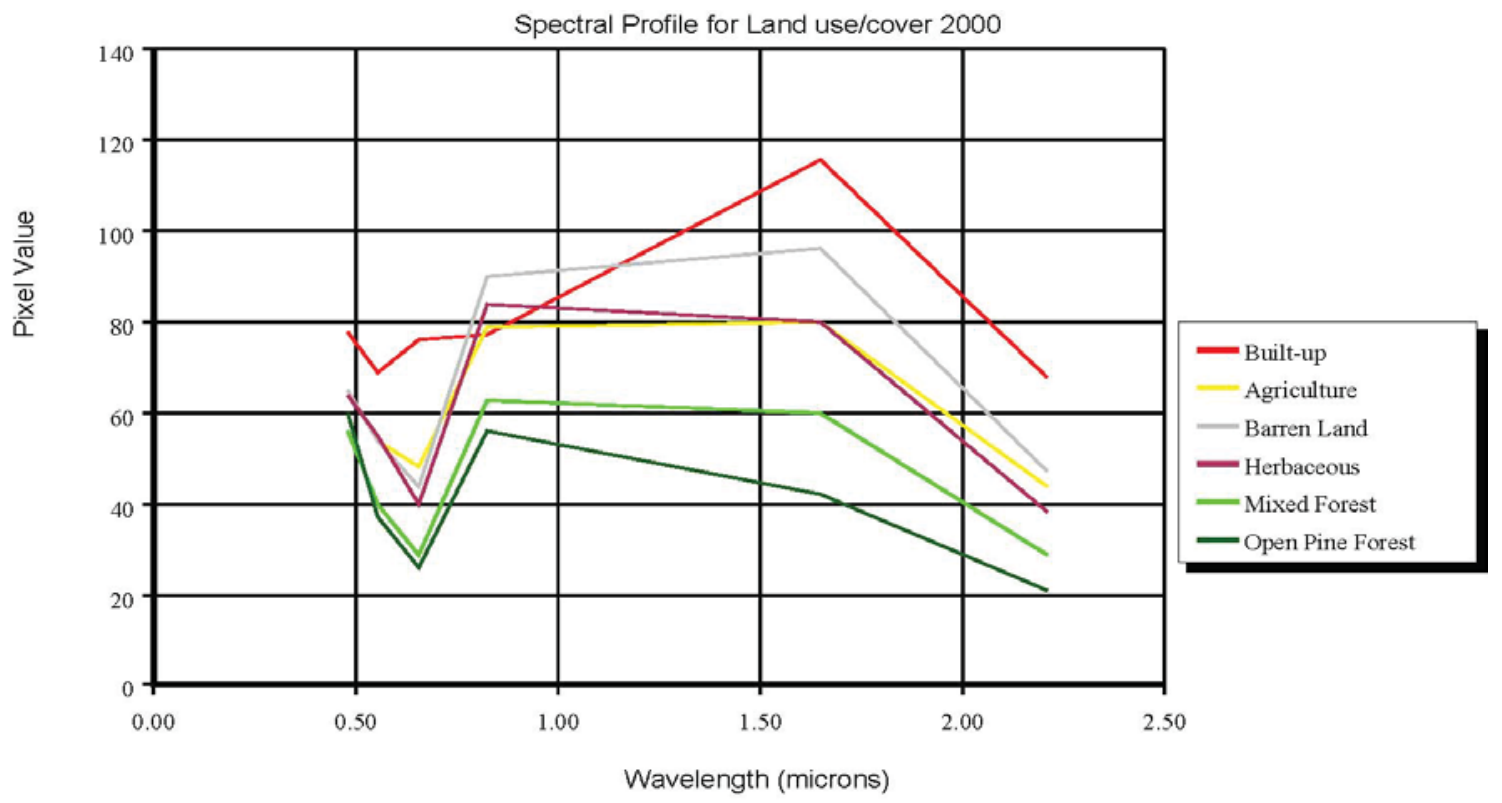

Figure 4-2. Spectral separability for land use/cover classes of the Landsat ETM+ 2000.

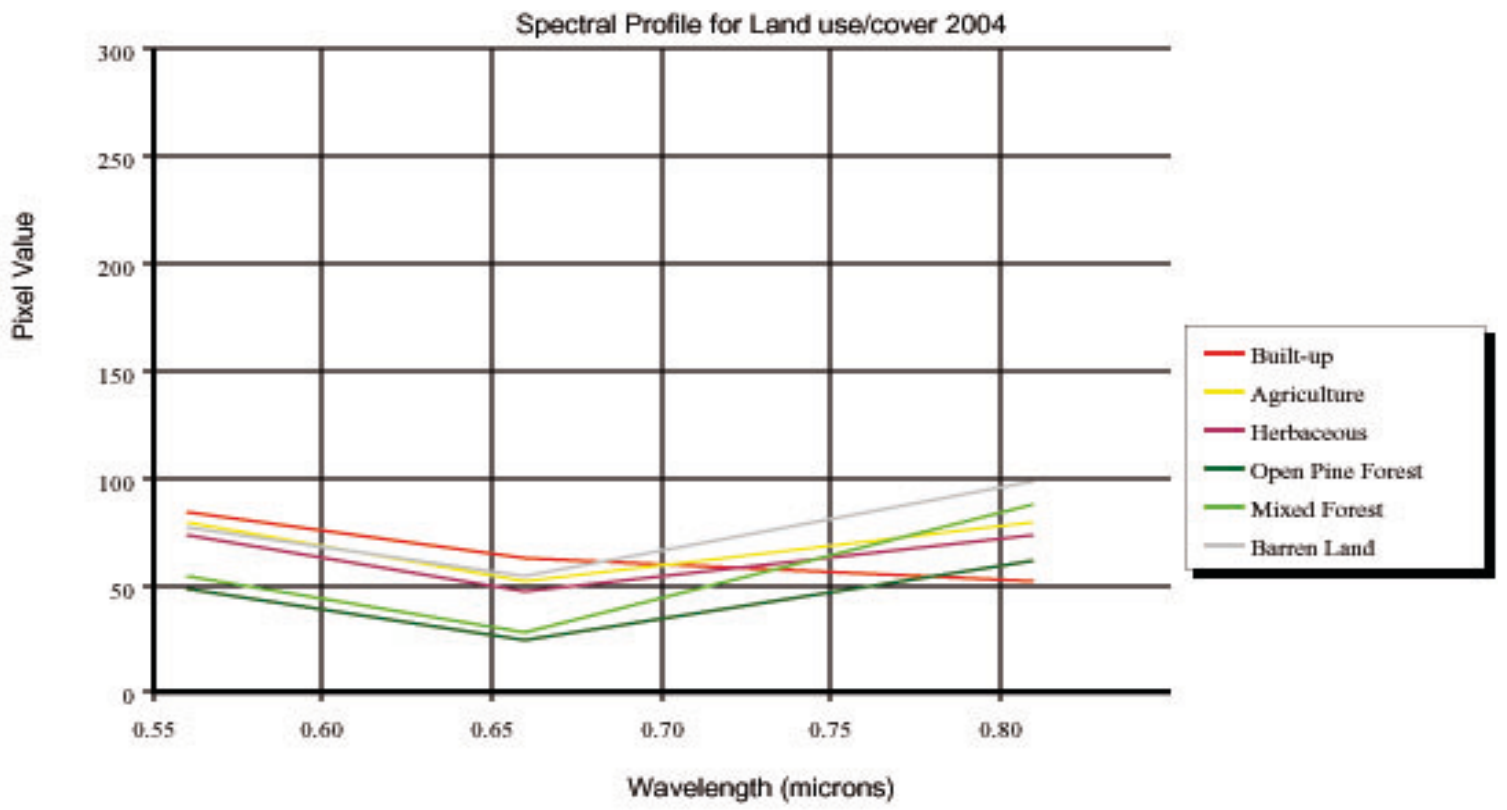

Figure 4-3. Spectral separability for land use/cover classes of the ASTER 2004. 
Agriculture registered a high reflectance in the mid-Infrared region due to low moisture and low organic matter in the soil. As soil moisture and organic matter decreased, the reflectance increased from the visible through the mid-infrared wavelengths. Open pine forest, mixed forest and herbaceous registered lower reflectance values, with its highest peak in the green and red bands. The decrease in reflectance is due to the chlorophyll and water absorption in the leaf. However, since bands 2 and 3 covers the green reflectance from the leaf, the highest reflectance peak increased in this visible region.

\subsection{Classification Maps and Accuracy Results of the Landsat TM, Landsat ETM+, and ASTER Images}

Error matrices were generated to evaluate each land use/cover class accuracies. The results are summarized and detailed in Table 4-1. The overall accuracies for 1987, 2000, and 2004 were respectively $82 \%, 82 \%$, and $87 \%$ with kappa statistics of $78 \%, 78 \%$, and $84 \%$. User's and producers' accuracies of each information class ranged from $75 \%$ to 97\% in most cases (Congalton and Green 1999).

Table 4-1. Summary of land use/cover accuracies (\%) for 1987, 2000, and 2004.

\begin{tabular}{|l|c|c|c|c|c|c|}
\hline \multirow{2}{*}{$\begin{array}{c}\text { Land use/cover } \\
\text { classes }\end{array}$} & \multicolumn{2}{|c|}{$\mathbf{1 9 8 7}$ - TM } & \multicolumn{2}{c|}{ 2000 - ETM+ } & \multicolumn{2}{c|}{ 2004 - ASTER } \\
\cline { 2 - 7 } & Producer's & User's & Producer's & User's & Producer's & User's \\
\hline Built-up & 91.0 & 87.0 & 90.0 & 71.0 & 87.0 & 84.0 \\
Agriculture & 84.0 & 75.0 & 88.0 & 89.0 & 80.0 & 84.0 \\
Herbaceous & 89.0 & 87.0 & 91.0 & 63.0 & 86.0 & 97.0 \\
Open Pine Forest & 83.0 & 71.0 & 83.0 & 87.0 & 92.0 & 89.0 \\
Mixed Forest & 71.0 & 80.0 & 78.0 & 77.0 & 95.0 & 91.0 \\
Barren Land & 77.0 & 90.0 & 71.0 & 94.0 & 85.0 & 79.0 \\
\hline Overall accuracy & $\mathbf{8 2 . 0}$ & & $\mathbf{8 2 . 0}$ & & $\mathbf{8 7 . 0}$ & \\
Kappa statistic & $\mathbf{7 8 . 0}$ & & $\mathbf{7 8 . 0}$ & & $\mathbf{8 4 . 0}$ & \\
\hline
\end{tabular}




\subsubsection{Accuracy Assessment and land use/cover Map of the Landsat TM (1987)}

A total of 271 pixels were selected and evaluated for accuracy and 222 were correctly classified, which resulted in an overall accuracy of $82 \%$ and a kappa statistic of $78 \%$. In terms of producer's accuracy, all classes were over $80 \%$ correct with the exception of mixed forest and barren land, which were $71 \%$ and $77 \%$ respectively (Table $4-2$ ).

Table 4-2. Results of the accuracy assessment of the 1987 land use/cover classification map produced from the Landsat TM data expressed as percentages.

\begin{tabular}{|c|c|c|c|c|c|c|c|c|c|c|}
\hline \multirow{11}{*}{ 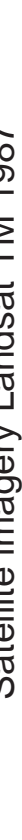 } & & \multicolumn{9}{|c|}{ Reference Data } \\
\hline & $\begin{array}{l}\text { Land use/cover } \\
\text { classes }\end{array}$ & $\begin{array}{l}\frac{0}{3} \\
\frac{1}{5} \\
\stackrel{5}{5}\end{array}$ & 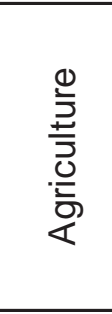 & 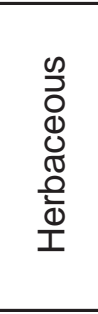 & 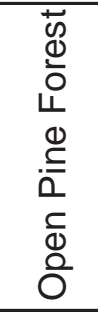 & 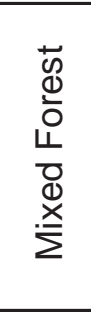 & 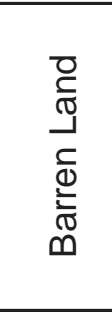 & 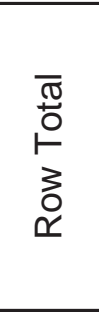 & 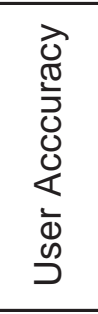 & 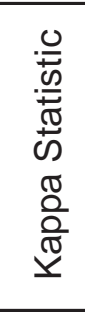 \\
\hline & Built-up & 40 & 1 & 0 & 2 & 0 & 3 & 46 & $87 \%$ & $84 \%$ \\
\hline & Agriculture & 1 & 36 & 4 & 0 & 5 & 2 & 48 & $75 \%$ & $70 \%$ \\
\hline & Herbaceous & 0 & 1 & 34 & 0 & 4 & 0 & 39 & $87 \%$ & $85 \%$ \\
\hline & Open Pine Forest & 1 & 0 & 0 & 30 & 4 & 7 & 42 & $71 \%$ & $67 \%$ \\
\hline & Mixed Forest & 0 & 3 & 0 & 4 & 35 & 2 & 44 & $80 \%$ & $75 \%$ \\
\hline & Barren Land & 2 & 2 & 0 & 0 & 1 & 47 & 52 & $90 \%$ & $88 \%$ \\
\hline & Column Total & 44 & 43 & 38 & 36 & 49 & 61 & 271 & & \\
\hline & Producer Accuracy & $91 \%$ & $84 \%$ & $89 \%$ & $83 \%$ & $71 \%$ & $77 \%$ & & & \\
\hline & $\begin{array}{l}\text { Number of pixels } \\
\text { correctly classified }\end{array}$ & 222 & \multicolumn{3}{|c|}{$\begin{array}{l}\text { Overall Classification } \\
\text { Accuracy }\end{array}$} & $82 \%$ & \multicolumn{3}{|c|}{$\begin{array}{l}\text { Overall Kappa } \\
\text { Statistic }\end{array}$} & $78 \%$ \\
\hline
\end{tabular}

Mixed forest has the largest source of omission error. Pixels labeled mixed forest should have been labeled agriculture, herbaceous, and/or open pine forest. In terms of user's accuracy, all classes were over $80 \%$ correct, except agriculture and open pine forest. Open pine forest pixels were often confused with barren land. This commission error 
could be due to clearing activities within the pine forest. The majority of each land use/cover type has a kappa statistic exceeding $75 \%$, except agriculture and open pine forest, which may be due to deforestation within the pine forest for agriculture or grazing.

Figure 4-4 shows the final classified map of the Landsat TM image (1987).

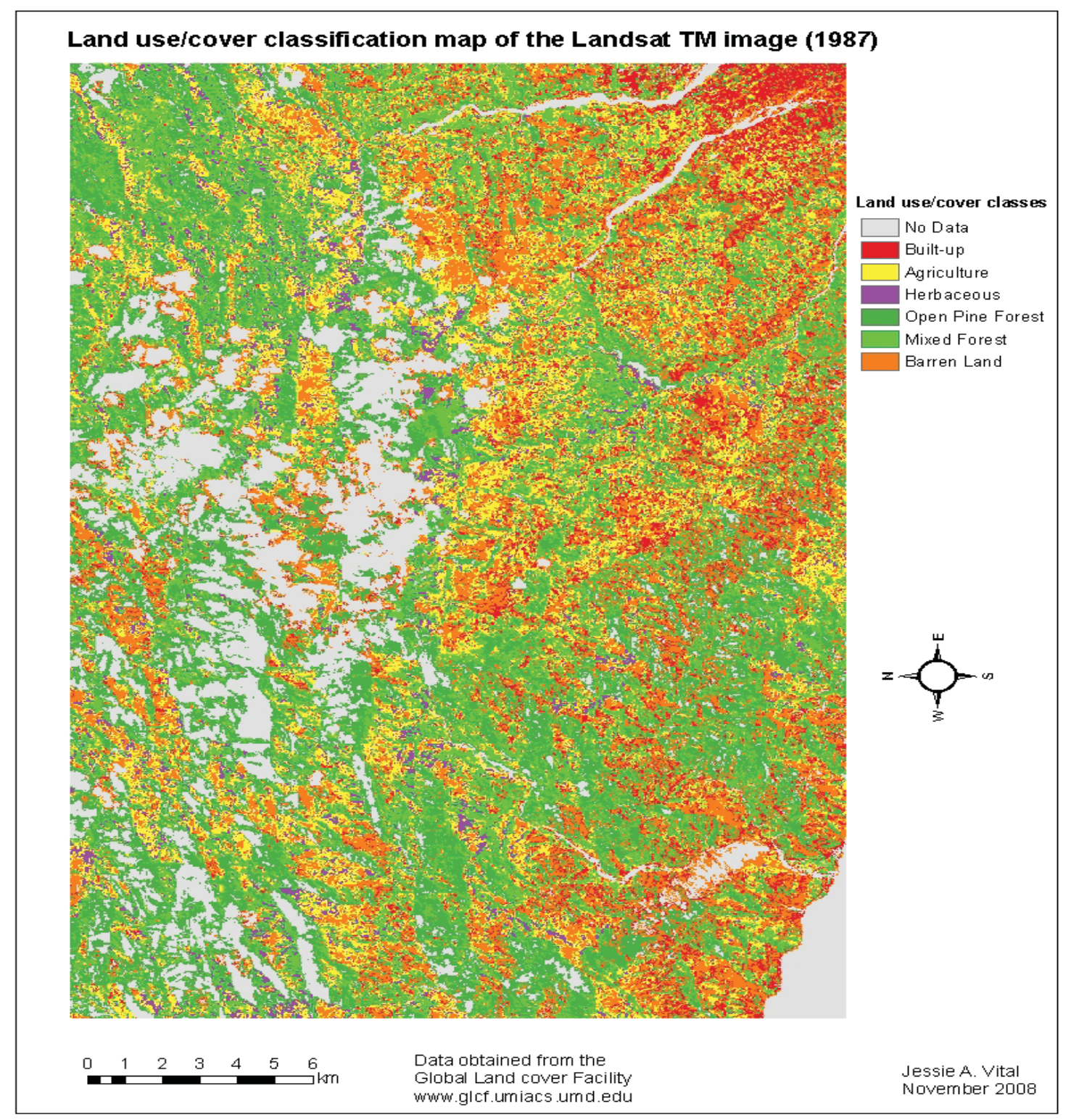

Figure 4-4. Land use/cover map of the Landsat TM (1987) image. 


\subsubsection{Landsat ETM+ 2000 scene}

Overall accuracy and kappa statistic follow a similar pattern as the Landsat TM 87 land use/cover classification. The overall accuracy is $82 \%$ and the kappa statistic is $78 \%$. In terms of producer's accuracy, all classes were over $80 \%$ with the exception of mixed forest and barren land, which were $78 \%$ and $71 \%$ respectively (Table $4-3$ ).

Table 4-3. Results of the accuracy assessment of the 2000 land use/cover classification map produced from the Landsat ETM+ data expressed as percentages.

\begin{tabular}{|c|c|c|c|c|c|c|c|c|c|c|}
\hline \multirow{2}{*}{\multicolumn{2}{|c|}{$\begin{array}{l}\text { Land } \\
\text { class }\end{array}$}} & \multicolumn{9}{|c|}{ Reference Data } \\
\hline & & $\begin{array}{l}\frac{0}{7} \\
\frac{1}{5} \\
0 \\
0\end{array}$ & $\begin{array}{l}\frac{0}{\grave{2}} \\
\frac{ \pm}{5} \\
\frac{0}{0} \\
\frac{0}{4}\end{array}$ & 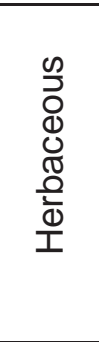 & 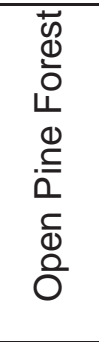 & 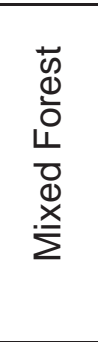 & 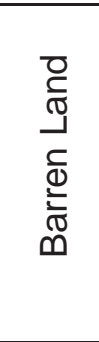 & 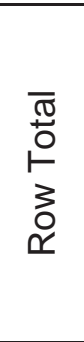 & 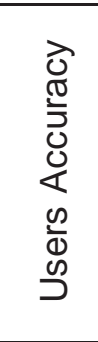 & 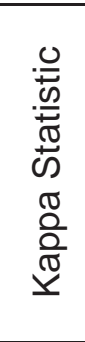 \\
\hline & Built-up & 27 & 2 & 0 & 0 & 0 & 9 & 38 & $71 \%$ & $67 \%$ \\
\hline & Agriculture & 0 & 58 & 1 & 1 & 1 & 4 & 65 & $89 \%$ & $86 \%$ \\
\hline & Herbaceous & 0 & 1 & 20 & 3 & 5 & 3 & 32 & $63 \%$ & $59 \%$ \\
\hline & Open Pine Forest & 0 & 0 & 1 & 34 & 4 & 0 & 39 & $87 \%$ & $85 \%$ \\
\hline & Mixed Forest & 2 & 3 & 0 & 3 & 36 & 3 & 47 & $77 \%$ & $72 \%$ \\
\hline & Barrren Land & 1 & 2 & 0 & 0 & 0 & 47 & 50 & $94 \%$ & $92 \%$ \\
\hline & Column Total & 30 & 66 & 22 & 41 & 46 & 66 & 271 & & \\
\hline & Producers Accuracy & $90 \%$ & $88 \%$ & $91 \%$ & $83 \%$ & $78 \%$ & $71 \%$ & & & \\
\hline & $\begin{array}{l}\text { Number of pixels } \\
\text { correctly classified }\end{array}$ & 223 & $\begin{array}{l}\text { Overa } \\
\text { Accur }\end{array}$ & $\begin{array}{l}\text { I Class } \\
\text { acy }\end{array}$ & ation & $82 \%$ & $\begin{array}{l}\text { Over } \\
\text { Statis }\end{array}$ & $\begin{array}{l}\text { I Ka } \\
\text { ic }\end{array}$ & & $78 \%$ \\
\hline
\end{tabular}

As shown in Table 4-3 barren land has the largest percentage of omission error. Some pixels were labeled barren land when they should have been classified as built-up or agriculture. This may be due to unpaved roads that are located within urban areas.

Furthermore, since the satellite imagery was acquired during the growing seasons, the 
majority of agricultural land was either fallow or harvested. In terms of user's accuracy all classes were over 77\%, except barren land and herbaceous.

The land use/cover classification of the Landsat ETM+ registered the most commission and omission error accuracy within the classes barren land and agriculture, open pine forest and built-up. Mixed forest has the largest source of omission error. Pixels labeled mixed forest should have been labeled agriculture, herbaceous, and/or open pine forest. The source of these errors might be caused by mixing pixels where clear-cut activities were frequent. Cleared areas are usually either used as agricultural land, or left behind for natural pine trees regeneration with the growing of grasses, which formed understory with small vegetation, barren land and grass. Conversion and transition of one class to another class played an important role in confusion occurring in the spectral properties of the pixels. Open pine forest pixels were often confused with barren land. This commission error may be due to the clearing within the pine forest. Also, since drought condition is common during winter season, grass is partially dead and is barely present in the land cover area. Herbaceous class registers also the lowest kappa statistics (59\%), which mean the agreement is poor. This might be caused by the conversion of large part of herbaceous area into fallow land.

In summary, the source of errors within pine and mixed forest with herbaceous, barren land, agricultural land may be caused by temporal transition. The energy reflected and measured by the Landsat TM and ETM+ sensors is based on the interaction of the electromagnetic radiation with plant components and bare soil. The density and the foliar 
coverage influence the reflectance response. Within a pine stand and mixed forest stand, where extensive clearing of the highest trees has occurred, some herbaceous and annual grasses, small plant and agriculture understory affect the electromagnetic response. Figure 4-5 illustrates the final land use/cover classification map for the Landsat ETM+ scene. 


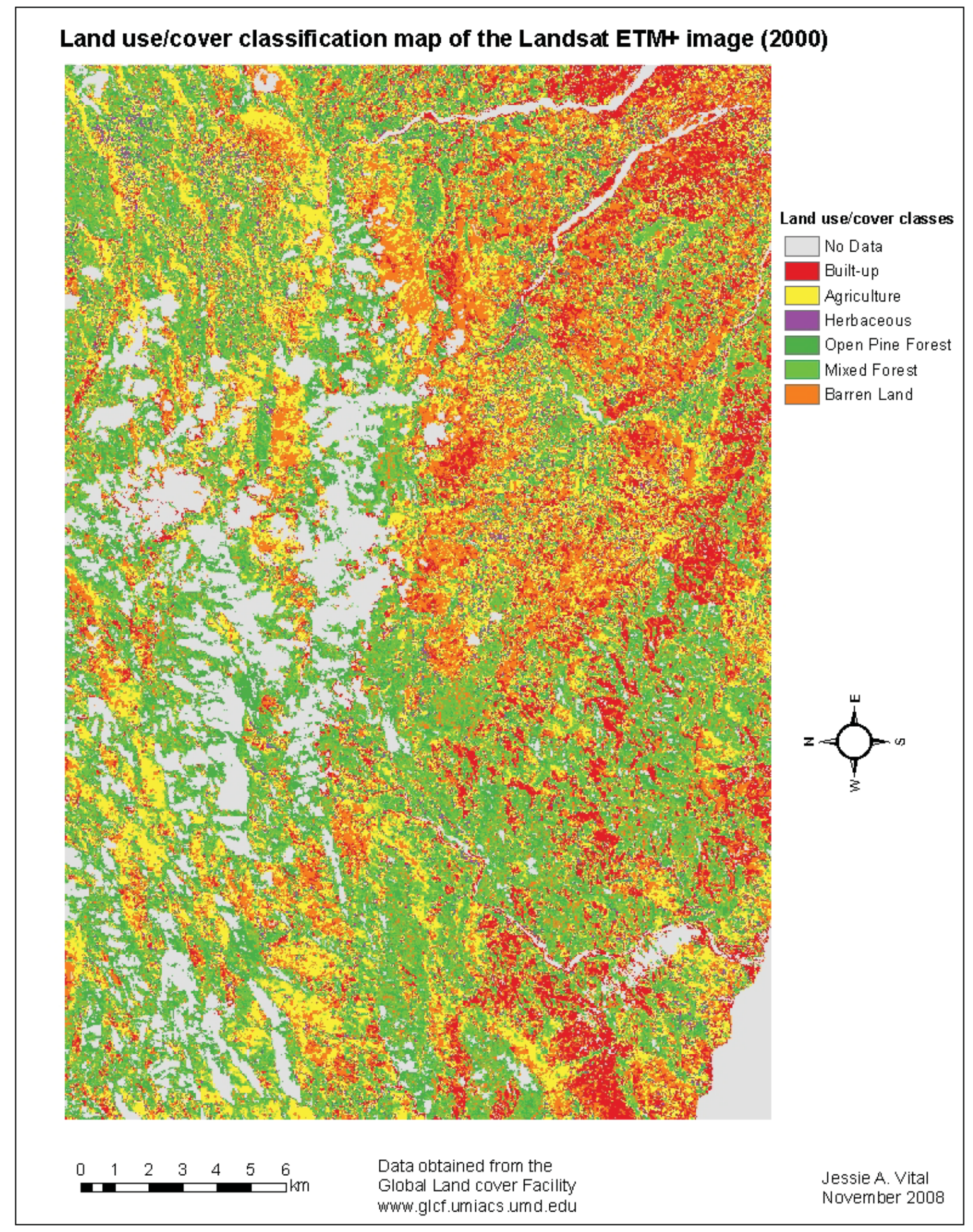

Figure 4-5. Land use/cover map of the Landsat ETM+ (2000) image. 


\subsubsection{ASTER 2004 image}

The geographic coverage of the 2004 scene was different from the two Landsat scenes. A total of 236 pixels were correctly classified (Table 4-4) and the results indicated a higher overall accuracy and kappa statistic when compared to the Landsat scenes.

Table 4-4. Results of the accuracy assessment of the 2004 land use/cover classification map produced from the ASTER SWIR+VNIR data expressed as percentages.

\begin{tabular}{|c|c|c|c|c|c|c|c|c|c|}
\hline \multirow[b]{2}{*}{\begin{tabular}{l|l}
2 & Land use/cover \\
+ & classes
\end{tabular}} & \multicolumn{9}{|c|}{ Reference Data } \\
\hline & 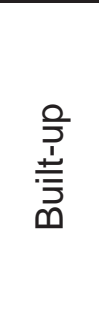 & $\begin{array}{l}\frac{0}{3} \\
\frac{1}{5} \\
\frac{0}{0} \\
\frac{0}{4}\end{array}$ & 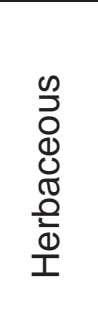 & 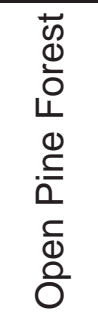 & 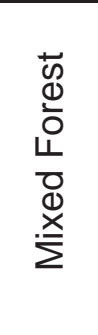 & 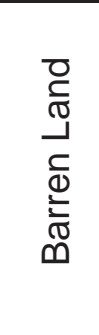 & $\begin{array}{l}\bar{\pi} \\
0 \\
0 \\
\vdots \\
0 \\
0 \\
\square\end{array}$ & 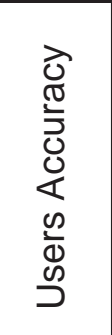 & 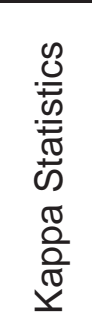 \\
\hline Built-up & 26 & 1 & 0 & 0 & 0 & 4 & 31 & $84 \%$ & $82 \%$ \\
\hline Agriculture & 3 & 43 & 2 & 0 & 0 & 3 & 51 & $84 \%$ & $87 \%$ \\
\hline Herbaceous & 0 & 1 & 36 & 0 & 0 & 0 & 37 & $97 \%$ & $97 \%$ \\
\hline Open Pine Forest & 0 & 0 & 0 & 33 & 3 & 1 & 37 & $89 \%$ & $88 \%$ \\
\hline Mixed Forest & 0 & 1 & 4 & 0 & 52 & 0 & 57 & $91 \%$ & $89 \%$ \\
\hline Barren Land & 1 & 8 & 0 & 3 & 0 & 46 & 58 & $79 \%$ & $81 \%$ \\
\hline Column Total & 30 & 54 & 42 & 36 & 55 & 54 & 271 & & \\
\hline Producers Accuracy & $87 \%$ & $80 \%$ & $86 \%$ & $92 \%$ & $95 \%$ & $85 \%$ & & & \\
\hline $\begin{array}{l}\text { Number of pixels } \\
\text { correctly classified }\end{array}$ & 236 & $\begin{array}{l}\text { Overa } \\
\text { Classi } \\
\text { Accur }\end{array}$ & $\begin{array}{l}\text { ficatio } \\
\text { acy }\end{array}$ & & $87 \%$ & $\begin{array}{l}\text { Over } \\
\text { Stati }\end{array}$ & $\begin{array}{l}\mathrm{Ka} \\
\mathrm{cs}\end{array}$ & & $84 \%$ \\
\hline
\end{tabular}

The overall accuracy results of the 2004 land use/cover classification are excellent. Each land use/cover class has a producer's accuracy higher than $85 \%$, except for agriculture. Spectral confusion also occurred between agriculture and barren land classes. User's accuracy exceeds $84 \%$, except barren land. The kappa statistics for all land use/cover class has an excellent agreement excelling $81 \%$. 
The highest overall accuracy was registered in the ASTER classification results. The 3 VNIR high spatial and broad spectral bands used as the reference data was able to pick up the high frequency of detail in the land use/cover. It was found that the classification accuracy increased by merging the VNIR and SWIR bands, which increased the level of details in terms of texture, shape and pattern of the classes. Figure 4-6 shows the classified map of the ASTER image.

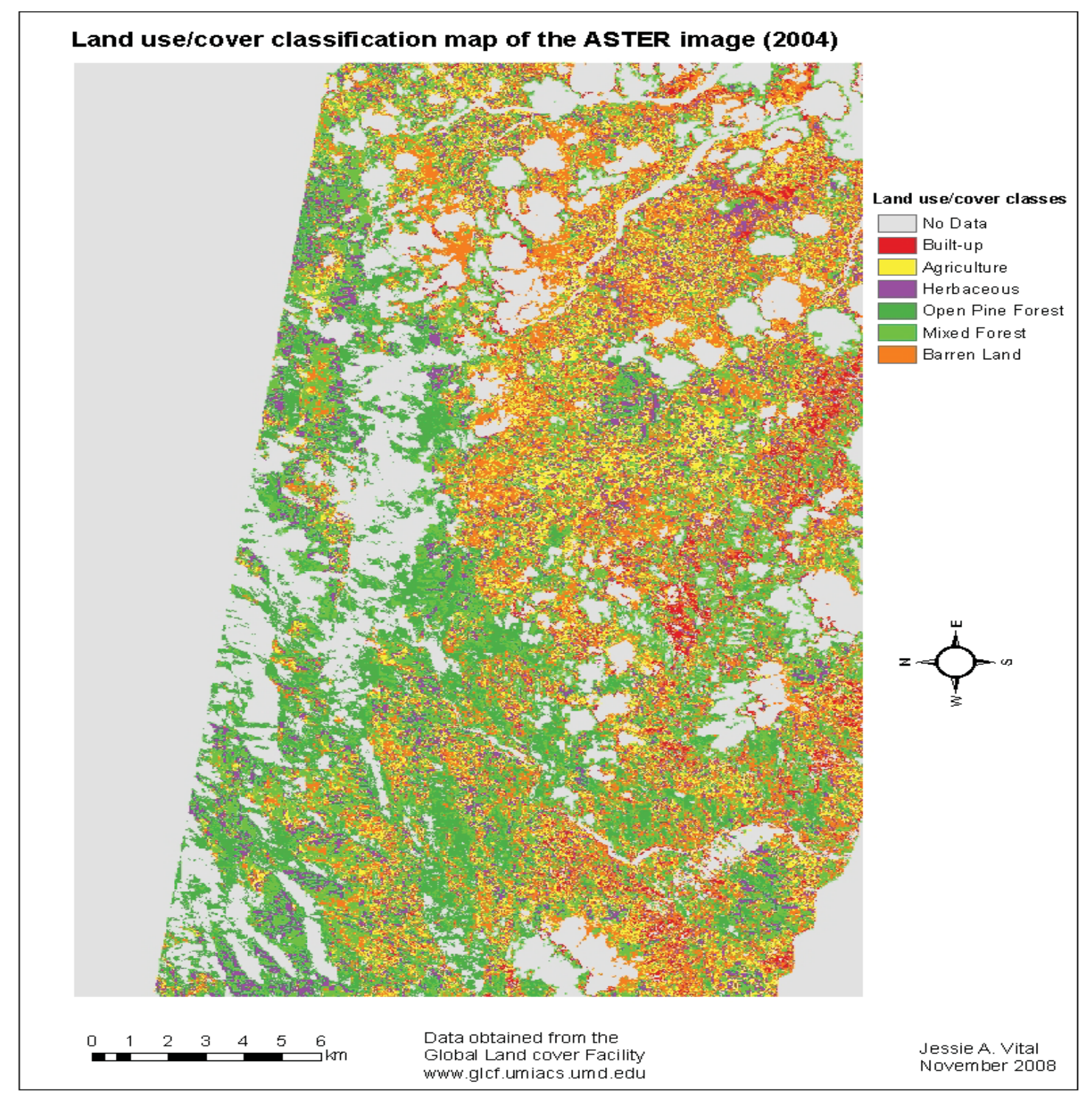

Figure 4-6. Land use/cover map of the ASTER (2004) image. 


\subsection{Land Use/Cover Change Detection Results}

Change detection matrices for 1987-2000, 2000-2004, and 1987-2004 were derived for the Landsat 5 TM 1987, Landsat ETM+ 2000, and ASTER 2004 land use/cover classifications. Change maps and statistics for each time frame are shown in the forms of a chart and a map. Due to the difference in geographic coverage for the 2004 scene, two different analyses based on the areal coverage were done.

\subsubsection{Change map between 1987 and 2000 classifications}

In 1987, open pine forest constituted the major type of land cover in the study area (Table 4-5). Accordingly, it accounted for about $26 \%$ of the total area followed by barren land (22\%), agriculture (19\%) and mixed forest (19\%). Built-up areas (8\%) and herbaceous (5\%) occupied the smallest area. During the 13 year time frame, open pine forest declined by $45 \%$ while mixed forest (19\%) remained the same. Agriculture and built-up areas increased by $29 \%$ and $53 \%$ (Figure 4-7 and Figure 4-8).

Table 4-5. Comparison of areas (ha) based on the six cover types and rates of change between 1987 and 2000.

\begin{tabular}{|c|c|c|c|c|c|c|c|c|}
\hline \multirow[t]{2}{*}{$\begin{array}{l}\text { Land use/cover } \\
\text { classes }\end{array}$} & \multicolumn{2}{|l|}{1987} & \multicolumn{2}{|l|}{2000} & \multicolumn{2}{|c|}{$\begin{array}{c}\text { Change } \\
\text { Between } \\
1987 \& 2000\end{array}$} & \multicolumn{2}{|c|}{$\begin{array}{l}\text { Average rate of } \\
\text { change 1987- } \\
2000\end{array}$} \\
\hline & Area (ha) & $\%$ & Area (ha) & $\%$ & Area (ha) & $\%$ & ha/year & $\%$ \\
\hline Built-up & 4,508 & 8 & 6,879 & 13 & $+2,372$ & +53 & +182 & +4.05 \\
\hline Agriculture & 10,270 & 19 & 13,259 & 24 & $+2,989$ & +29 & +230 & +2.24 \\
\hline Herbace & 2,853 & 5 & 3,263 & 6 & +410 & +14 & +32 & +1.11 \\
\hline Open Pine Forest & 14,272 & 26 & 7,861 & 14 & $-6,412$ & -45 & -493 & -3.46 \\
\hline Mixed Forest & 10,532 & 19 & 10,314 & 19 & -218 & -2 & -17 & -0.16 \\
\hline Barren Land & 12,003 & 22 & 12,862 & 24 & +859 & +7 & +66 & +0.55 \\
\hline Total & 54,438 & 100 & 54,438 & 100 & *** & *** & $* * *$ & *** \\
\hline
\end{tabular}




\section{Percentage of land cover types for 1987 and 2000 by total area $(54,438 \mathrm{ha})$}

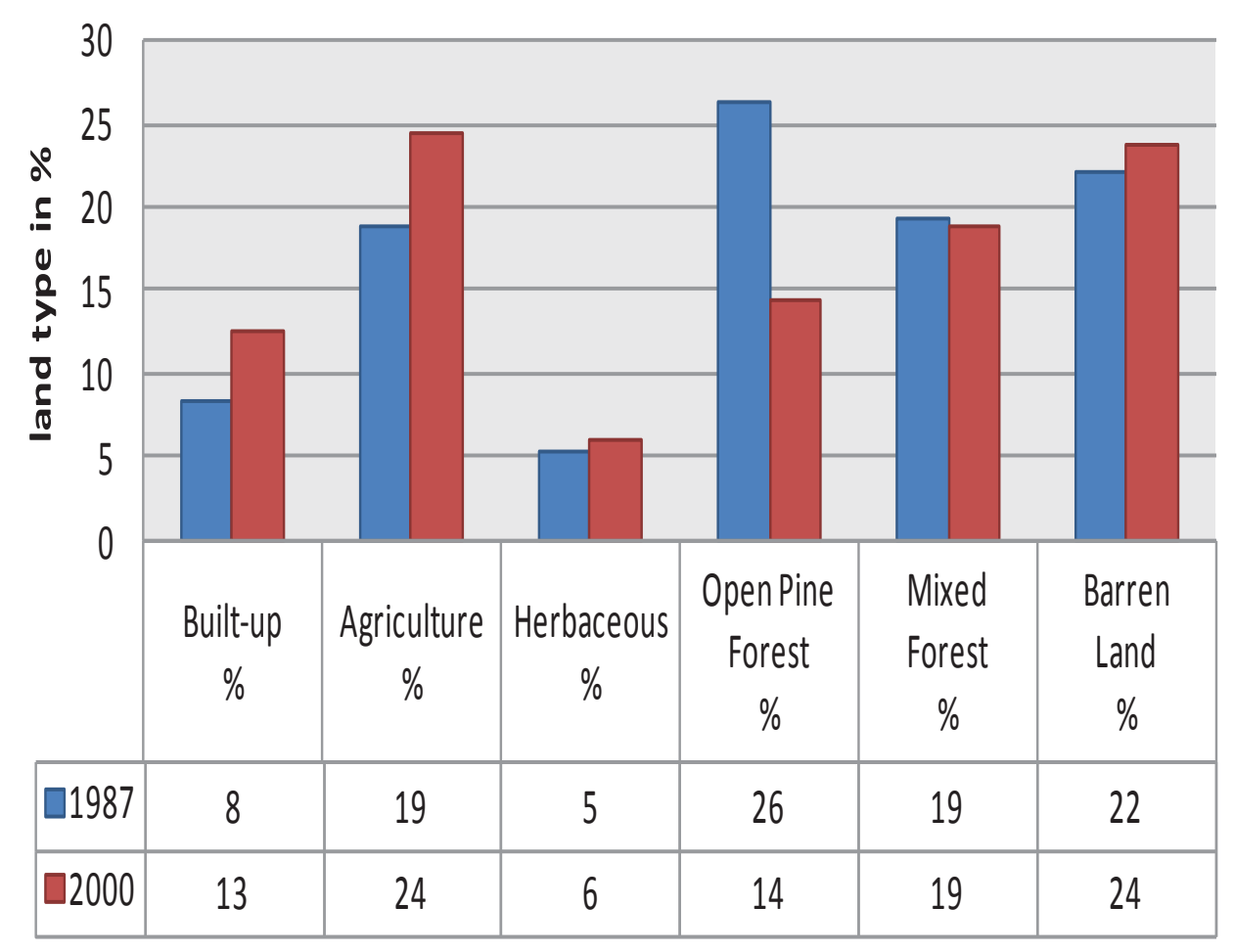

Figure 4-7. Comparison of the land use/cover changes between 1987 and 2004. 


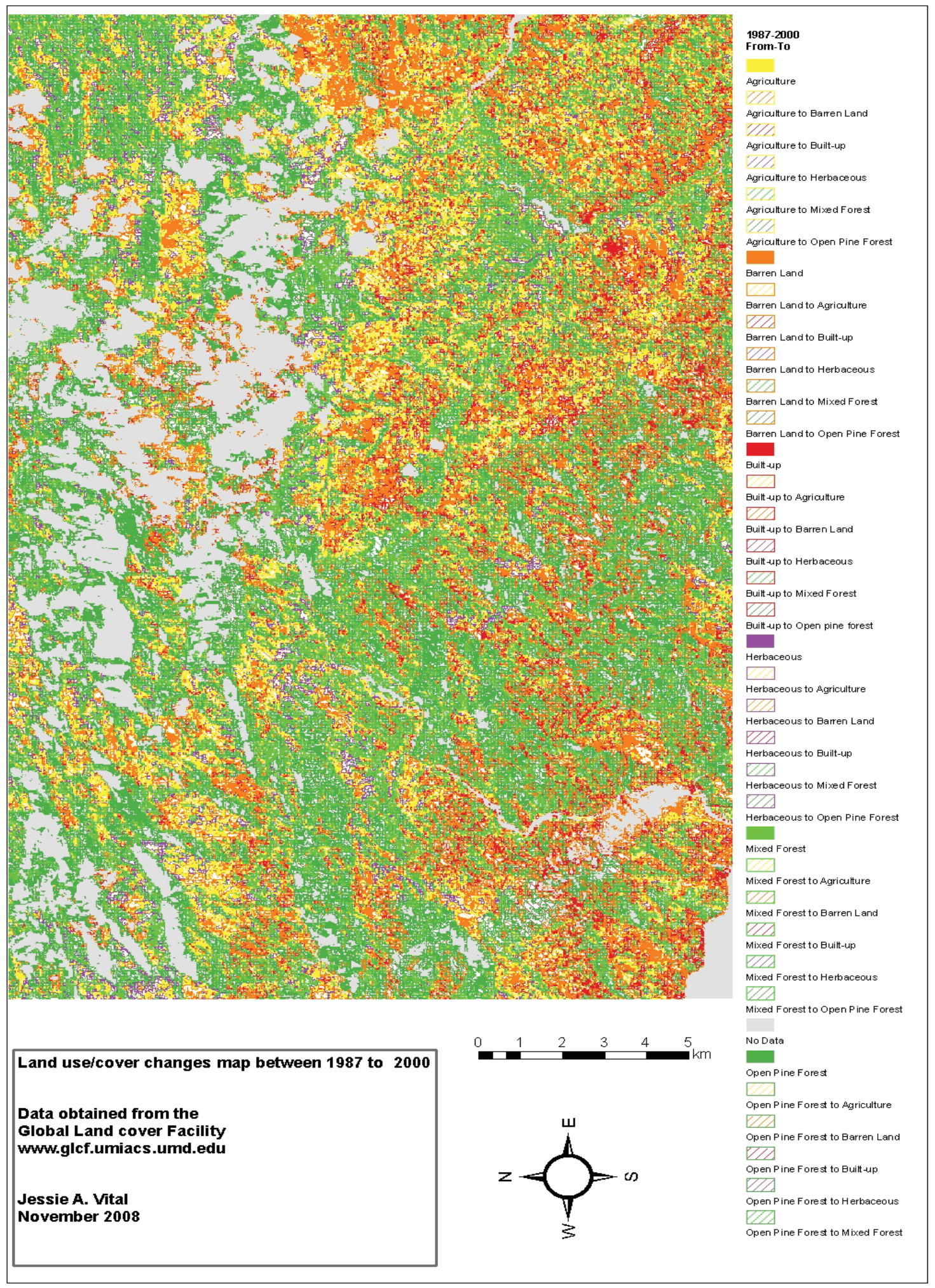

Figure 4-8. Land use/cover change map between 1987 and 2000. 


\subsubsection{Nature of change of 1987-2000}

Based on 54, 438 ha, the total size of the study for 1987-2000, open pine forest covered 14,273 ha in 1987 , but 7,861 ha in 2000 . Out of the 14,272 ha that was open pine forest in 1987 , only $4,037(28 \%)$ remained as open pine forest in 2000 . The remaining of $72 \%$ was either cleared or converted to other land use/cover types in 2000: built up (8\%), agriculture (13\%), herbaceous (3\%), mixed forest (29\%), and barren land $(17 \%)$. At the same time, at a greater extent, $1,931(18 \%)$ ha of mixed forest were converted to open pine forest in 2000 (Table 4-6).

Table 4-6. Matrix of land use/cover changes (ha) from 1987 to 2000. Diagonal cells (bold) represent no change in cover type.

\begin{tabular}{|c|c|c|c|c|c|c|c|}
\hline \multirow[b]{3}{*}{2000} & \multicolumn{7}{|c|}{ a. 1987 to 2000} \\
\hline & \multicolumn{6}{|c|}{1987} & \multirow[b]{2}{*}{ Total 2000} \\
\hline & 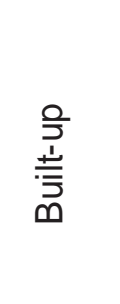 & 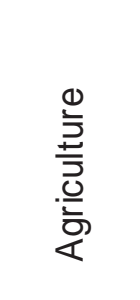 & 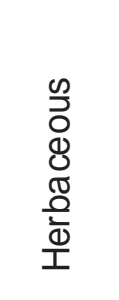 & 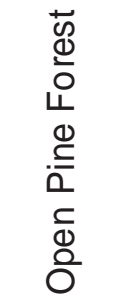 & 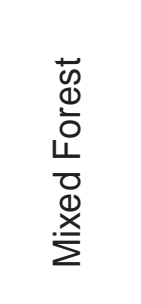 & 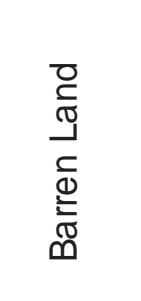 & \\
\hline Built-up & 1,435 & 1,116 & 109 & 1,189 & 618 & 2,412 & 6,879 \\
\hline Agriculture & 1,039 & 3,735 & 1,320 & 1,793 & 2,333 & 3,038 & 13,259 \\
\hline Herbaceous & 263 & 868 & 202 & 476 & 868 & 586 & 3,263 \\
\hline Open Pine Forest & 206 & 688 & 227 & 4,037 & 1,931 & 772 & 7,861 \\
\hline Mixed Forest & 312 & 1,150 & 560 & 4,097 & 3,027 & 1,169 & 10,314 \\
\hline Barren Land & 1,253 & 2,713 & 436 & 2,680 & 1,755 & 4,026 & 12,862 \\
\hline Total 1987 & 4,508 & 10,270 & 2,853 & 14,272 & 10,532 & 12,003 & 54,438 \\
\hline
\end{tabular}


The increase in pine forest represented a gain of $27 \%$ in 2000 . In summary, the results of Table 4-6 illustrated the types of land use/cover change between 1987 and 2000 . More land was converted to agriculture and built-up (low residential areas) at the expense of other land use/cover. Built-up and agriculture registered a net gain of $53 \%$ and $29 \%$ respectively, an average positive change of $4 \%$ and $2 \%$ per annum (Table 4-5). The areas under open pine forest and mixed forest declined significantly/slightly by $45 \%$ and $2 \%$, respectively. The results suggested that the areas covered with open pine forest and mixed forest were receding to the expansion of agricultural land and built-up areas.

\subsubsection{Change map between 1987 and 2004 classifications}

In 1987, barren land (26\%) followed by agriculture (21\%) and open pine forest $(20 \%)$ formed the major type of land cover in the study area. Mixed Forest covered a total of $18 \%$ of the total area. Built-up (10\%) and herbaceous areas (5\%) occupied the least cover (Table 4-7). Figure 4-10 illustrates the land use/cover change map (1987-2004)

Table 4-7. Comparison of areas (ha) based on the six cover types and rates of change between 1987 and 2004.

\begin{tabular}{|c|c|c|c|c|c|c|c|c|}
\hline \multirow[t]{2}{*}{$\begin{array}{l}\text { Land use/cover } \\
\text { classes }\end{array}$} & \multicolumn{2}{|l|}{1987} & \multicolumn{2}{|c|}{2004} & \multicolumn{2}{|c|}{$\begin{array}{c}\text { Change } \\
\text { Between } \\
\text { 1987\&2004 }\end{array}$} & \multicolumn{2}{|c|}{$\begin{array}{c}\text { Average rate of } \\
\text { change } 1987- \\
2004\end{array}$} \\
\hline & Area (ha) & $\%$ & Area (ha) & $\%$ & Area (ha) & $\%$ & ha/year & $\%$ \\
\hline Built-up & 3,400 & 10 & 5,668 & 17 & $+2,268$ & +67 & +133 & +3.92 \\
\hline Agriculture & 7,013 & 21 & 5,808 & 17 & $-1,205$ & -17 & -71 & -1.01 \\
\hline Herbaceous & 1,708 & 5 & 4,677 & 14 & +2969 & +174 & +175 & +10.23 \\
\hline Open Pine Forest & 6,865 & 20 & 4,735 & 14 & $-2,130$ & -31 & -125 & -1.83 \\
\hline Mixed Forest & 6,069 & 18 & 4,039 & 12 & $-2,029$ & -33 & -119 & -1.97 \\
\hline Barren Land & 8,612 & 26 & 8,738 & 26 & +127 & +1 & +7 & +0.09 \\
\hline Total & 33,666 & 100 & 33,666 & 100 & $* * *$ & $* * *$ & $* * *$ & $* * *$ \\
\hline
\end{tabular}


In 2004, however, agriculture, mixed forest and open pine forest declined by $17 \%$, 33\% and $31 \%$ respectively (Figure $4-9$ ). There are two principal causes for this drop in agriculture and increase in herbaceous: soil's infertility and exodus. The exhausted land in the region has lost its fertility and has been abandoned. The abandoned land then was reverted to herbaceous. In addition, the farming population, in hopes of a higher standard of living has moved into urban areas.

\section{Percentage of land use types for 1987 and 2004 by total area $(33,666 \mathrm{ha})$}

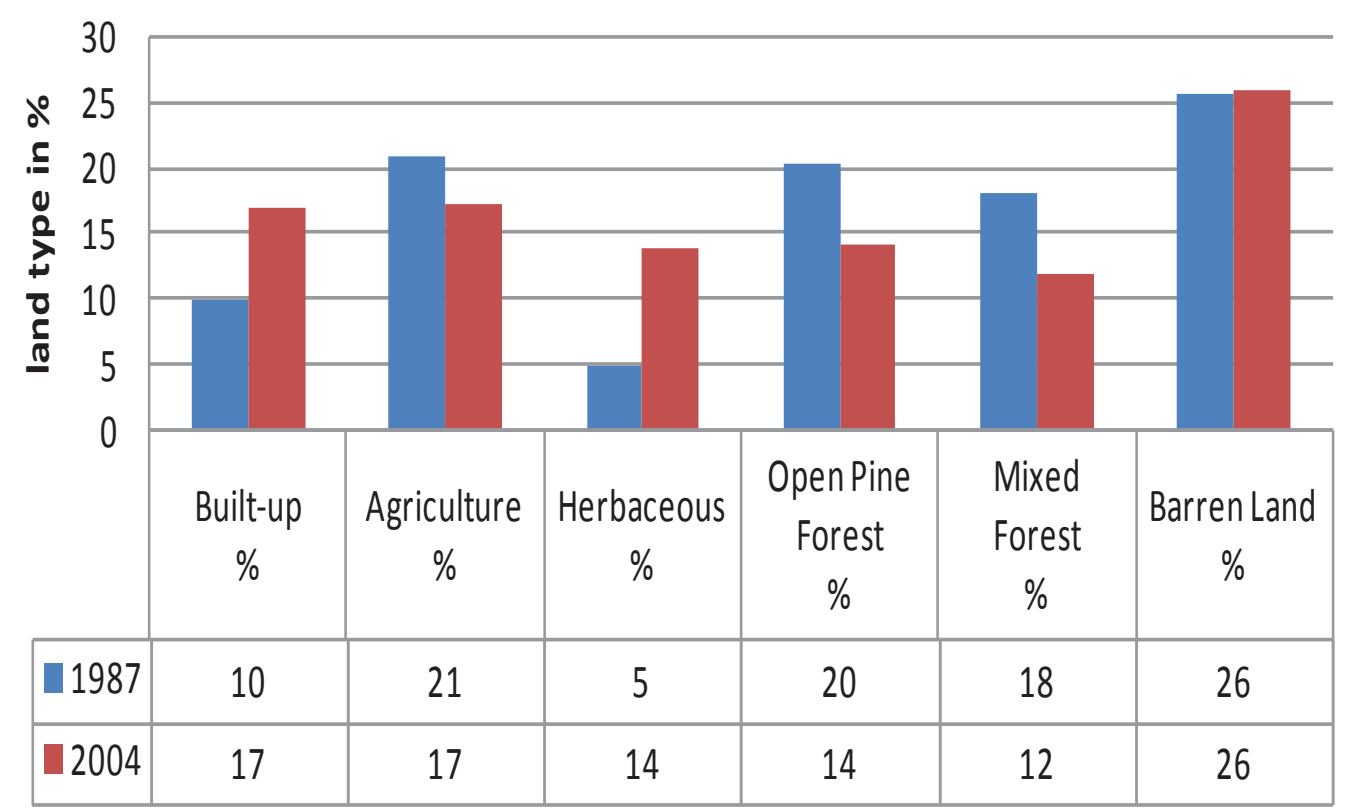

Figure 4-9. Comparison of the land use/cover changes between 1987 and 2004. 


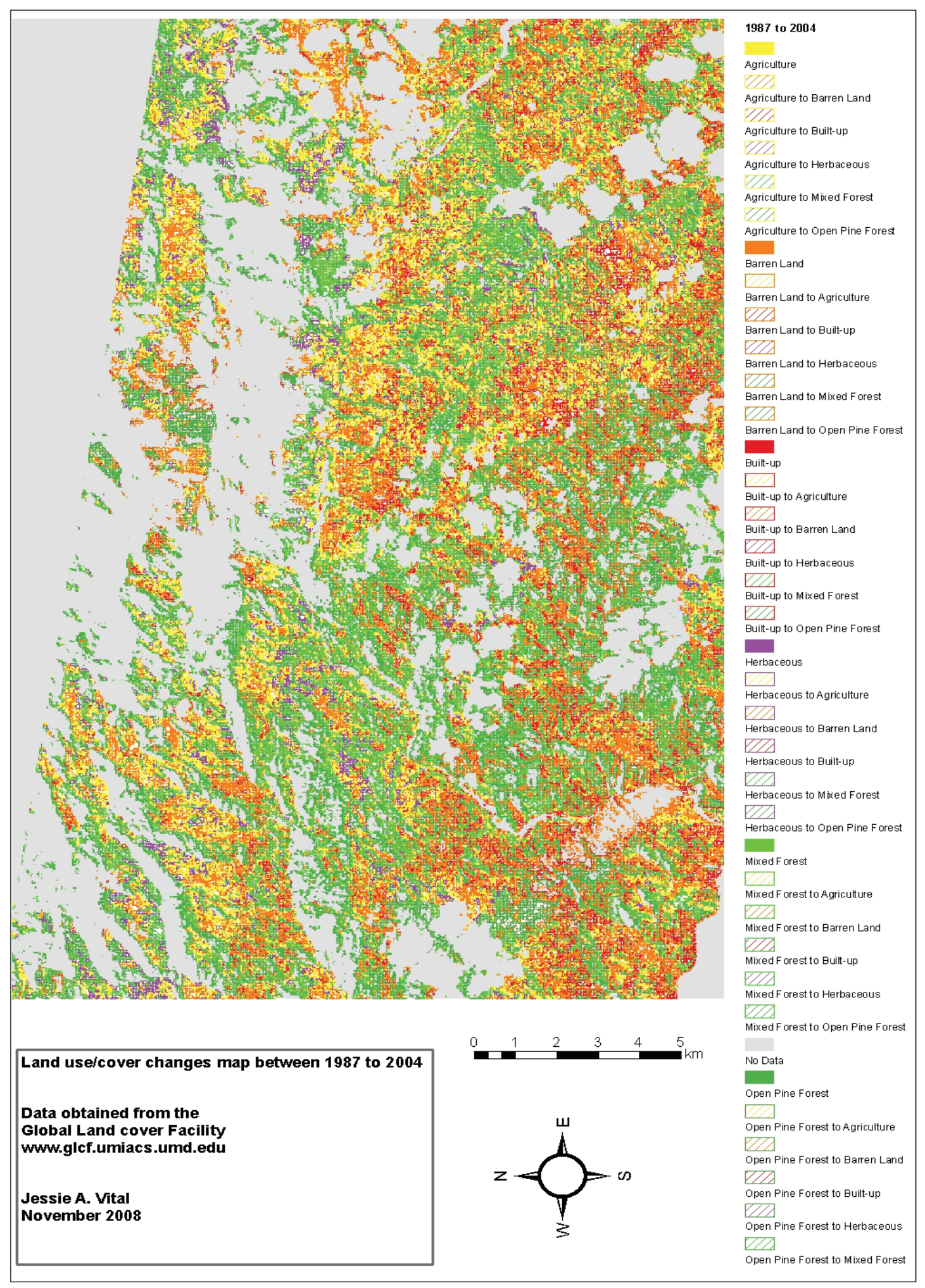

Figure 4-10. Land use/cover change map between 1987 and 2004 


\subsubsection{Nature of change of 1987-2004 classifications}

From 1987 to 2004 (Table 4-8), only 1734 ha $25 \%$ of the 6,865 ha remained as open pine forest in 2004. The remainder was converted to barren land (21\%), mixed forest (17\%), built up (14\%), agriculture (12\%), and herbaceous (11\%). The greatest transformation of open pine forest was to mixed forest (22\%) and barren land $(21 \%)$. Open pine forest, mixed forest and agriculture lost $31 \%, 33 \%$, and $17 \%$ of their areas to other land use/cover types.

Table 4-8. Matrix of land use/cover changes (ha) from 1987 to 2004. Diagonal cells (bold) represent no change in cover type.

\begin{tabular}{|c|c|c|c|c|c|c|c|}
\hline \multirow[b]{3}{*}{2004} & \multicolumn{7}{|c|}{ b. 1987 to 2004} \\
\hline & \multicolumn{6}{|c|}{1987} & \multirow[b]{2}{*}{ Total 2004} \\
\hline & 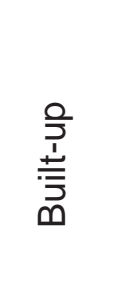 & $\begin{array}{l}\frac{0}{3} \\
\frac{2}{2} \\
.0 \\
\frac{0}{5} \\
\frac{0}{4}\end{array}$ & 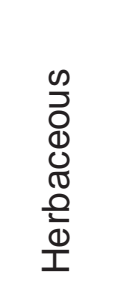 & 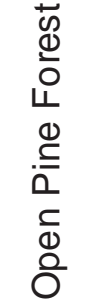 & 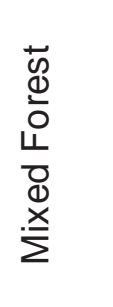 & 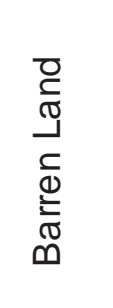 & \\
\hline Built-up & 647 & 1,230 & 287 & 959 & 921 & 1,625 & 5,668 \\
\hline Agriculture & 737 & 1,518 & 280 & 806 & 734 & 1,734 & 5,808 \\
\hline Herbaceous & 486 & 1,182 & 288 & 770 & 785 & 1,167 & 4,677 \\
\hline Open Pine Forest & 233 & 569 & 222 & 1,734 & 1,238 & 739 & 4,735 \\
\hline Mixed Forest & 236 & 640 & 245 & 1,138 & 1,074 & 707 & 4,039 \\
\hline Barren Land & 1,062 & 1,874 & 387 & 1,458 & 1,317 & 2,640 & 8,738 \\
\hline Total 1987 & 3,400 & 7,013 & 1,708 & 6,865 & 6,069 & 8,612 & 33,666 \\
\hline
\end{tabular}


The greatest change in terms of areas gained occurred in herbaceous (174\%) and builtup (67\%). Areas covered by herbaceous, for example, registered an average gain of $10.23 \%$ per annum from the conversion of all the other land use/cover types with the greatest from agriculture (17\%).

\subsubsection{Change map between 2000 and 2004}

Out of the 33,666 ha of land use/cover in 2000, agriculture and barren land occupied the largest area, $26 \%$ and $25 \%$ respectively, followed by mixed forest (17\%), built-up (15\%), open pine forest (10\%) and herbaceous (6\%). Meanwhile in 2004, agriculture occupied only $17 \%$ of the total land area, which represented in average a decline of $8.48 \%$ per annum. Accordingly, within 2000 to 2004, agriculture and mixed forest areas registered the greatest decline at a negative average rate of change of $8.48 \%$ and $6.96 \%$ respectively per annum. At the same time herbaceous land use/cover increased rapidly at an average rate of $28.76 \%$, followed by open pine forest $(9.96 \%)$, built-up $(2.27 \%)$ and barren land (0.63\%) (Table 4-9, Figure 4-11 and Figure 4-12).

Table 4-9. Comparison of areas (ha) based on the six cover types and rates of change between 2000 and 2004.

\begin{tabular}{|l|rc|rc|cc|cc|}
\hline \multirow{2}{*}{$\begin{array}{l}\text { Land use/cover } \\
\text { classes }\end{array}$} & $\mathbf{2 0 0 0}$ & $\mathbf{2 0 0 4}$ & \multicolumn{2}{|c|}{$\begin{array}{c}\text { Change } \\
\text { Between } \\
\text { 2000\&2004 }\end{array}$} & \multicolumn{2}{|c|}{$\begin{array}{c}\text { Average rate of } \\
\text { change 2000- } \\
\text { 2004 }\end{array}$} \\
\cline { 2 - 10 } & Area (ha) & \% & Area (ha) & \% & Area (ha) & \% & ha/year & $\%$ \\
\hline Built-up & 5,197 & 15 & 5,668 & 17 & +471 & +9 & +118 & +2.27 \\
Agriculture & 8,788 & 26 & 5,808 & 17 & $-2,980$ & -34 & -745 & -8.48 \\
Herbaceous & 2,175 & 6 & 4,677 & 14 & 2,502 & +115 & +626 & +28.76 \\
Open Pine Forest & 3,386 & 10 & 4,735 & 14 & $+1,349$ & +40 & 337 & 9.96 \\
Mixed Forest & 5,597 & 17 & 4,039 & 12 & $-1,557$ & -28 & -389 & -6.96 \\
Barren Land & 8,523 & 25 & 8,738 & 26 & +215 & +3 & +54 & +0.63 \\
Total & $\mathbf{3 3 , 6 6 6}$ & $\mathbf{1 0 0}$ & $\mathbf{3 3 , 6 6 6}$ & $\mathbf{1 0 0}$ & $* * *$ & $* * *$ & $* * *$ & $* * *$ \\
\hline
\end{tabular}




\section{Percentage of land use types for 2000 and 2004 by total area (33,666 ha)}

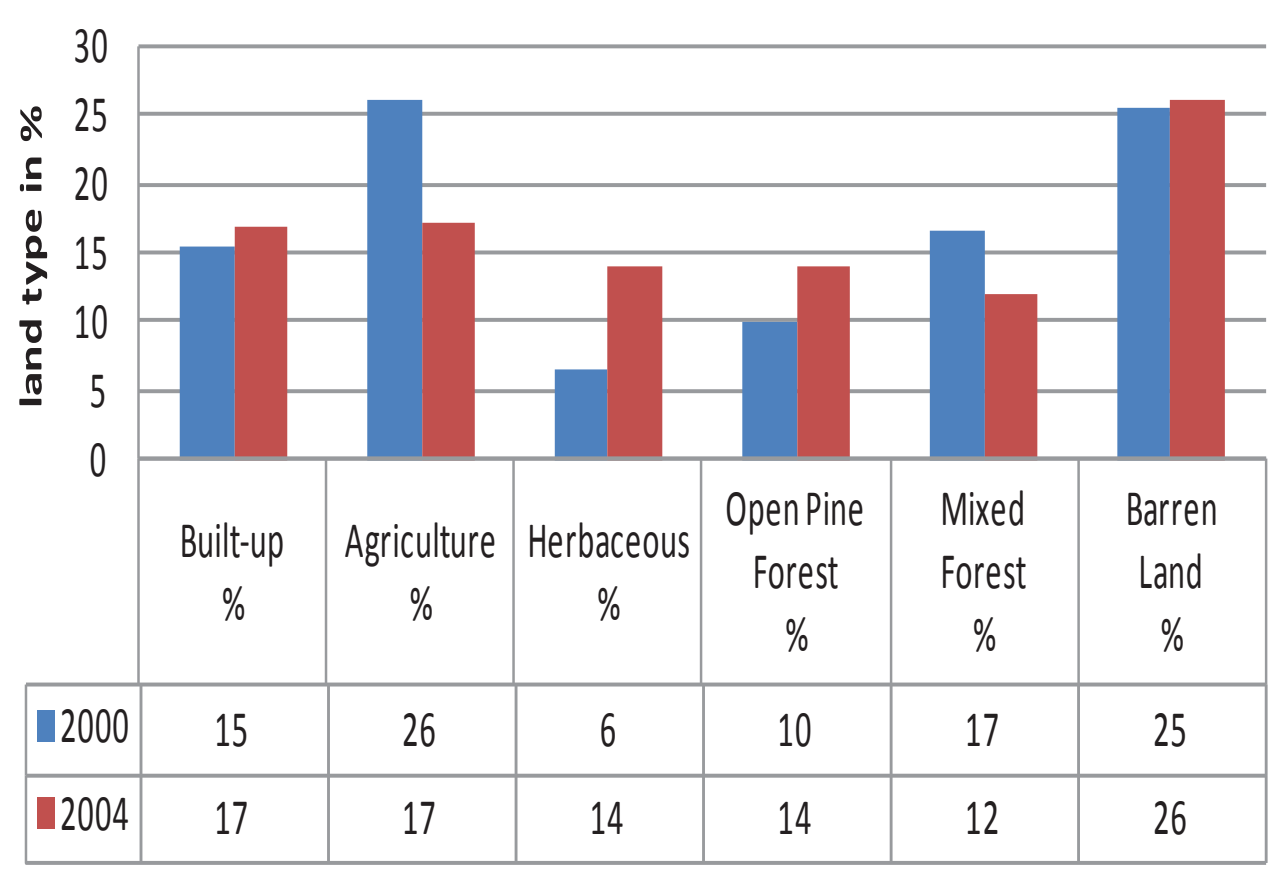

Figure 4-11. Comparison of the land use/cover changes between 2000 and 2004 classifications. 


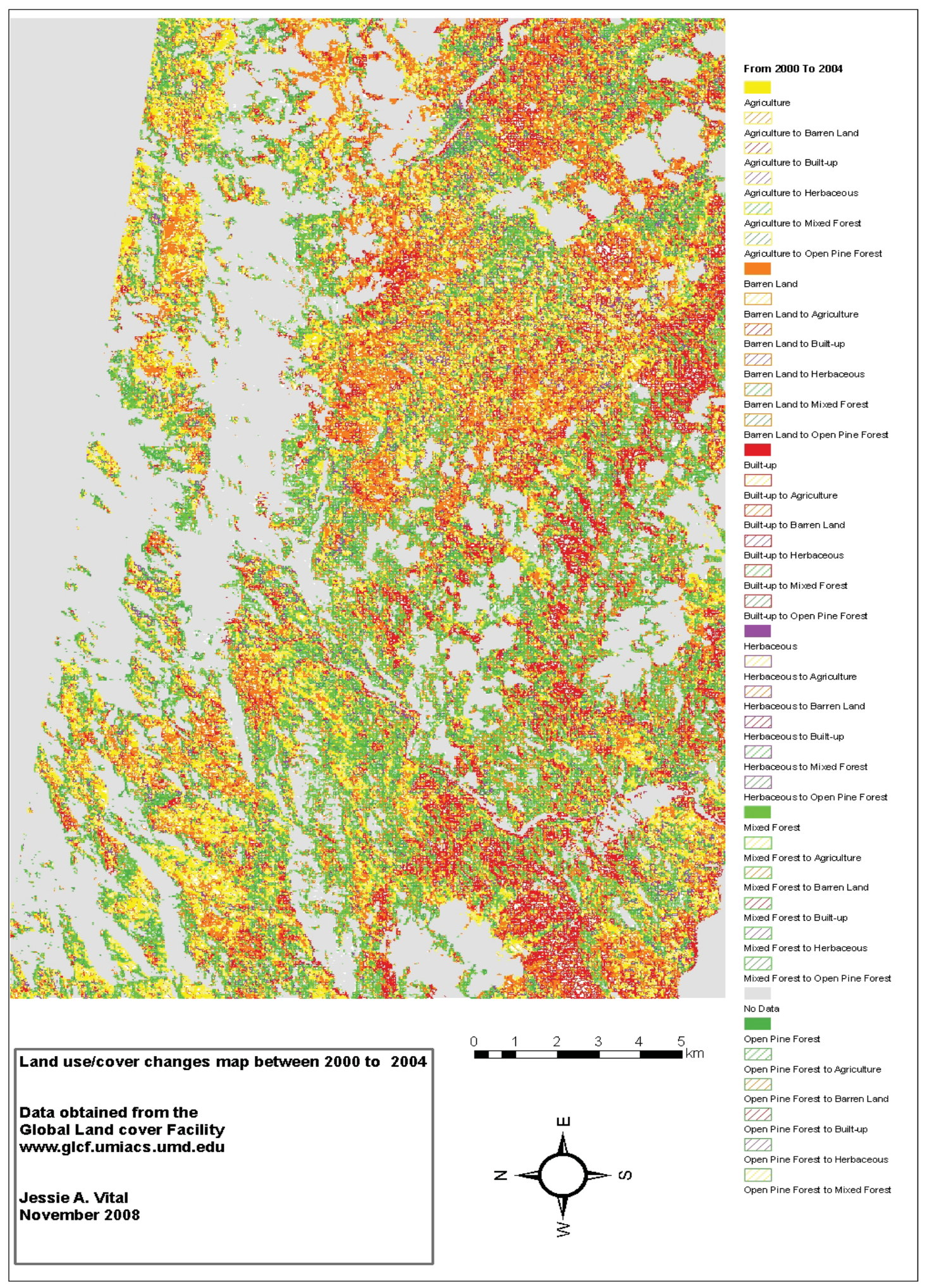

Figure 4-12. Map of land use/cover change between 2000 and 2004. 


\subsubsection{Nature of change of 2000-2004 classifications}

According to the matrix (Table 4-10), in $2000,8,788$ ha of land used for agriculture, only 1,817 ha $(21 \%)$ remained as agriculture. The balance of the agricultural area were either cleared or converted to other land use/cover types in 2004: built-up (17\%), herbaceous (18\%), mixed forest (21\%), and barren land (26\%). At the same time, in 2004, agriculture gained some land back from other land use/cover classes, with the greatest gain occurring from reverted built-up (22\%) followed by barren land $(20 \%)$.

Table 4-10. Matrix of land use/cover changes (ha) from 2000 to 2004. Diagonal cells (bold) represent no change in cover type

\begin{tabular}{|c|c|c|c|c|c|c|c|}
\hline \multirow[b]{3}{*}{2004} & \multicolumn{7}{|c|}{ b. 2000 to 2004} \\
\hline & \multicolumn{6}{|c|}{2000} & \multirow[b]{2}{*}{ Total 2004} \\
\hline & 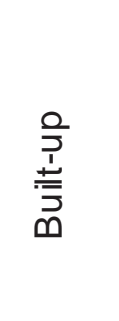 & $\begin{array}{l}\frac{0}{2} \\
\frac{2}{5} \\
\frac{0}{0} \\
\frac{0}{4}\end{array}$ & 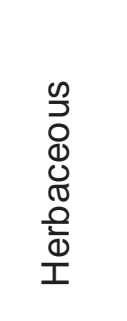 & 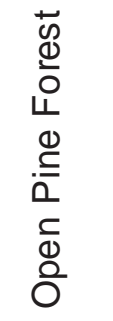 & 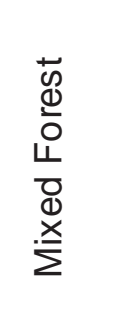 & 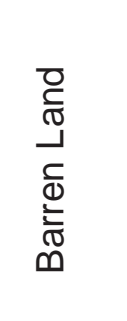 & \\
\hline Built-up & 1,033 & 1,534 & 396 & 427 & 745 & 1,534 & 5,668 \\
\hline Agriculture & 1,122 & 1,817 & 374 & 294 & 524 & 1,676 & 5,808 \\
\hline Herbaceous & 708 & 1,545 & 375 & 343 & 602 & 1,103 & 4,677 \\
\hline Open Pine Forest & 327 & 731 & 216 & 1,010 & 1,511 & 940 & 4,735 \\
\hline Mixed Forest & 359 & 887 & 285 & 680 & 1,104 & 724 & 4,039 \\
\hline Barren Land & 1,648 & 2,274 & 529 & 632 & 1,110 & 2,546 & 8,738 \\
\hline Total 2000 & 5,197 & 8,788 & 2,175 & 3,386 & 5,597 & 8,523 & 33,666 \\
\hline
\end{tabular}


In addition, $32 \%$ of built-up area was converted to barren land. The conversion of builtup to barren land and agriculture looks unrealistic. Commission and omission errors present between these classes in the 2000 land use/cover classification contributed to either an underestimate/overestimate of the changes. These errors are caused, in part, by the sensor's inability to pick up the small variations in certain classes, thus confusing agriculture, barren land, and built-up. It is important to note that the farming system in the area is based on subsistence agriculture, where parcel of lands are shared by households, gardens and livestock. Spatially the simultaneous location and patterns of certain classes composed of harvested agricultural plot, barren land, and unpaved road within the low residential areas change and vary inconsistently. These changes are either caused by anthropogenic or climatic variables such as a) soil infertility, which force the farmers to abandon the land, or b) landslide and floods, which destroyed houses and changed the road network.

In addition, the conversion of low residential area into barren land and agriculture is a consequence of political riots that happened in the area in 1994. Based on personal knowledge and discussion with the local people, the Pic Macaya National Park located in a very remote region, used to be a hidden refuge for paramilitary death squad members (FRAPH) from 1991 to 1994. In 1994, after a three year exile in the United States, the ex-president, Mr. Jean-Bertrand Aristide, who was overthrown by these paramilitary death squads (FRAPH), returned to Haiti to finish his presidential mandate. At the same time, riots were organized by the partisans of the ex-president and the people that were terrorized by the FRAPH against the paramilitary groups. Many of them hiding in the Pic Macaya region were caught and their houses were burnt. 
Lastly, the migration of the working force to the cities contributed to the decline of agricultural land. After the return of Aristide, considered as a symbol of hope to the peasant and vulnerable people, many young men and women moved to the cities to look for jobs, a better education and a higher standard of living as promised. The abandoned and exhausted agricultural land, then transitioned to herbaceous $(+115 \%)$, which in the future will revert naturally by succession into mixed forest or pine forest.

\subsubsection{Change map between 1987 and 2004 classifications}

Overall, from 1987 to 2004, open pine forest decreased from $20 \%$ to $14 \%$ with the greatest change occurring between 1987 and 2000. However, between 2000 and 2004, open pine forest increased at an average rate of $9.96 \%$ per annum. This increase in pine forest was an outcome of reforestation initiatives taken by USAID, ORE in the Macaya region in the 1990's.

Table 4-11. Comparison of areas (ha) based on the six cover types and rates of change between 1987, 2000, and 2004.

\begin{tabular}{|c|c|c|c|c|c|c|c|c|c|c|}
\hline \multirow{2}{*}{$\begin{array}{l}\text { Land } \\
\text { use/cover } \\
\text { classes }\end{array}$} & \multicolumn{2}{|c|}{1987} & \multicolumn{2}{|c|}{2000} & \multicolumn{2}{|c|}{2004} & \multicolumn{2}{|c|}{$\begin{array}{c}\text { Change } \\
\text { Between } \\
1987-2000\end{array}$} & \multicolumn{2}{|c|}{$\begin{array}{c}\text { Change } \\
\text { Between } 1987 \\
\text { to } 2004\end{array}$} \\
\hline & Area (ha) & $\%$ & Area (ha) & $\%$ & Area (ha) & $\%$ & Area (ha) & $\%$ & ha/year & $\%$ \\
\hline Built-up & 3,400 & 10 & 5,197 & 15 & 5,668 & 17 & $+1,797$ & +53 & +2268 & +67 \\
\hline Agriculture & 7,013 & 21 & 8,788 & 26 & 5,808 & 17 & $+1,775$ & +25 & $--1,205$ & -+17 \\
\hline Herbaceous & 1,708 & 5 & 2,175 & 6 & 4,677 & 14 & -467 & +27 & $+2,969$ & +174 \\
\hline $\begin{array}{l}\text { Open Pine } \\
\text { Forest }\end{array}$ & 6,865 & 20 & 3,386 & 10 & 4,735 & 14 & $--3,479$ & -51 & $--2,130$ & -+31 \\
\hline \begin{tabular}{|l|} 
Mixed \\
Forest \\
\end{tabular} & 6,069 & 18 & 5,597 & 17 & 4,039 & 12 & --472 & -+8 & $--2,029$ & -+33 \\
\hline $\begin{array}{l}\text { Barren } \\
\text { Land } \\
\end{array}$ & 8,612 & 26 & 8,523 & 25 & 8,738 & 26 & --88 & -+1 & +127 & +1 \\
\hline Total & 33,666 & 100 & 33,666 & 100 & 33,666 & 100 & & & & \\
\hline
\end{tabular}


Mixed forest also decreased at about $2 \%$ per annum, with the greatest decreased occurred from 2000 to 2004 . The rate of change in land use for agriculture varied. From 1987 to 2000 , land occupied by agriculture increased from 21 to $26 \%$, while from 2000 to 2004 , it decreased from $26 \%$ to $17 \%$, a loss of $1.01 \%$ in average per year. Built-up increased constantly year after year at a rate of $3.92 \%$. The most important change occurred in herbaceous land cover classes, with the greatest change occurred during 2000 and 2004, while at the same time agriculture decreased (Table 4-11 and Figure 4-13).

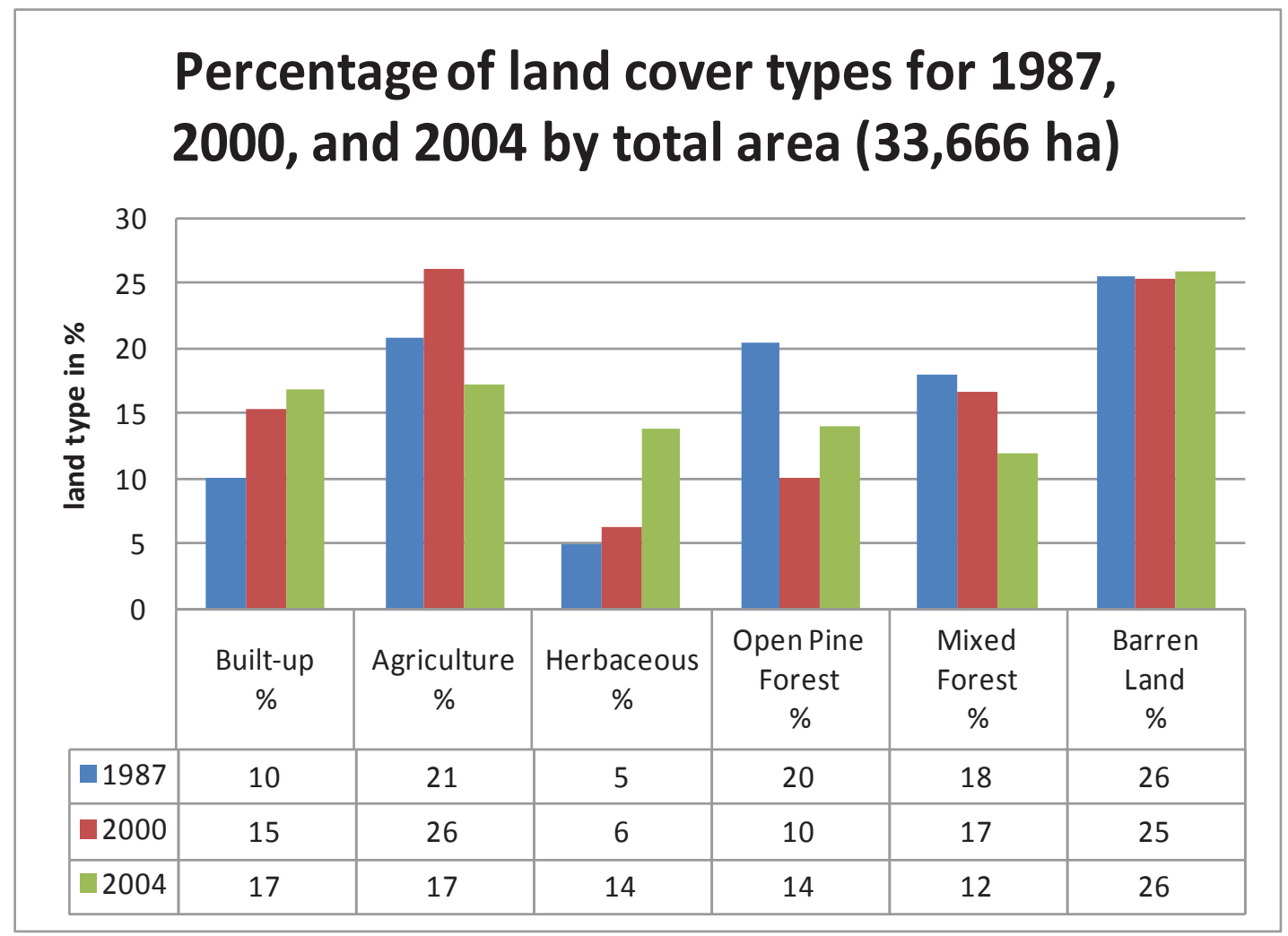

Figure 4-13. Comparison of the land use/cover changes between the 1987, 2000, and 2004 classifications. 


\subsection{Implications of the Study}

\subsubsection{Causes of land use/cover change in the Macaya area}

Based on the land use/cover results from 1987, it seems prior to 1987 the vegetation of the study area was already impacted by humans (Cohen 1984). The percentage of barren land (22\%) was quite high. Open pine forest and mixed forest represented $45 \%$ of the cover area in 1987, but in 2004 the areas under forest decreased greatly with increases in herbaceous, barren land, agriculture and built-up areas.

Many aspects based on the socio-economic conditions of the local population, the farming systems, the institutional settings, environmental policy and political instabilities influenced the type of changes that have occurred on the landscape. As many researchers indicated in Haiti, several factors have contributed to modify the original land cover in the region (Cohen 1984; Paryski et al. 1988; Sergile et al. 1992; Timyan 2000; Organization for the Rehabilitation of the Environment 2001 ; Dolisca et al. 2007a; Dolisca et al. 2007b). These include human activities such as agricultural colonization, evolution or not of rural road networks, which led to the migration of seasonal farmers for logging into the region and environmental policy.

The economy of the southern region of Haiti is based on agriculture, charcoal production, and fishing for those living near the coast. There is a lot of pressure on arable land, which led to the opening of natural forested area for cultivation. Forested areas are cleared and used for crop production, generating income and providing the basic food security for the local population (Organization for the Rehabilitation of the Environment 2001 ). In addition, high demand for charcoal, which is the main source of 
energy for cooking, and the need to build more houses based on the growing population have a major impact on the forest cover in the area. Population growth has an additive effect on the decreasing of open pine forests. When tree resources and crop productivity became insufficient, men or woman left their children to their grandmother and move to the city in search for jobs. At the same time, built-up area increased dramatically from 1987 to 2004. There are many new constructions and new houses in urban areas outside the park boundary, where roads are available. These houses are built by new retired Haitians that have migrated to the United States or Canada in the 70's. As they retired, they tend to spend half of the year in their mother land. Therefore, in the future, I suggest integrating socio-economic surveys to show the relation and correlation between changes in the landscape and the socio-economic aspects of the region.

Poor ecological policy formulation on the local scale to manage and protect the natural resources of the region has also influenced land use/cover changes (Pierre-Louis 1989; Pellek 1990). Policy is a plan of course of action intended to influence and to determine decisions and actions to achieve some objectives. Pierre-Louis (1989), looking at Haitian forest policy from 1915 to 1984 , stated that the laws and decrees were strongly influenced by punitive measures against the peasants. Also policy formulation was based on top-down-decision making. International experts hired to formulate those policies were constrained by barriers such as languages, roads, and institutionalize social stratification that would not allowed them to include and involve in the decision making process the local communities impacted by such decisions. 
The Pic Macaya National Park was established by Presidential Decree in 1983 to protect the biodiversity of the region (Paryski et al. 1988; Sergile et al. 1992; Timyan 2000). Park rangers were hired to protect the reserve from illegal logging and land exploitation for agriculture. Unfortunately, these measures have not been sufficient to protect the park for many reasons. The park rangers were not paid as promised and abused the resources in the park to obtain income to replace unpaid government wages. The community living in the area has always felt forgotten. Living in an abject poverty, the local people found it natural to use the natural resources nearby in order to survive on a daily basis.

Based on personal communication, the local community acknowledged that the only way to protect the biodiversity in the region is by giving them economic alternatives. They praised the initiatives of job creation through reforestation projects and soil conservation training, the construction of an unpaved road up to Formon, a primary school and a health care center brought by many organizations (USAID, ORE, and The Societé Audubon). However, once the project expired, the lack of governmental monitoring with programs to enhance and reinforce these initiatives taken by international organizations in the region undermine the continuity of sustainable land use practices and natural resources management in the region. Chronic socioeconomic hardships and political instability have hindered efforts to implement an effective, sustainable conservation plan in Pic Macaya National Park.

In addition to the above human and socio-economic factors, climate change has significant impact on land use/cover changes observed in the study area. The south 
region is the scene of yearly flood, landslide, and falling trees mainly caused by frequent tropical depressions, bigger storms and hurricanes. Since the mountainous region is undergoing strong deforestation, the soil is becomes less able to slowly absorb the rain water. Thus, the mountainous rain water accompanied with sediment and rocks flow downslope to the plains region, taking in its path the arable land to the sea, destroying crop plantations, and livestock production making the local people more vulnerable to economic loss.

\subsubsection{Consequences of land use/cover change in the Macaya area}

The vegetation of the Pic Macaya National Park is composed mainly of pine forest and many endemic plants, which protect the environment in many ways. The forest regulates the soil water of the region that receives more than $3,000 \mathrm{~mm}$ of annual precipitation. It also protects habitat for wildlife such as neo-tropical migratory birds and mammals. Many researchers have mentioned the importance of the region's rich biodiversity (Cohen 1984; Judd 1987; Paryski et al. 1988; Sergile et al. 1992; Organization for the Rehabilitation of the Environment 2001).

The continuous degradation of the forest has major effects on the environment and other segments of the population. Land degradation, soil erosion, avian habitat destruction, leading to the loss of biodiversity, plant species and birds endangerments, stream degradation of the five rivers are among the negative impacts of deforestation in the region (Judd 1987). Soil degradation in the study area is a combination of deforestation and unsustainable agricultural system. Where the density of the population is also high such as in Formond and Cavalier, the forest land cleared is over cultivated and not allowed to regenerate into mature secondary forest (Sergile et al. 1992). 
In addition, according to a report publish by ORE and based on personal observations, deforestation in the park has contributed to the sedimentation of the irrigation canals in the plains areas. This represents a major problem for farmers located in Camp-Perrin. Camp-Perrin, and many cities in the plains are constantly in danger of flooding as a result of deforestation in the Macaya National Park (Organization for the Rehabilitation of the Environment 2001 ). Generally, land degradation in Haiti is both a part and consequence of environmental changes caused by the socio-economic conditions of the people and unpractical environmental policies, which fail to sustainably manage its natural resources. There is a need, therefore, to minimize the negative ecological consequences of land use/cover change in the study area for the protection of the biodiversity, the well being of the people and the environment.

\subsubsection{Limitations of the Study}

The lack of an earliest map of the region with detailed information, the lack of socioeconomic data and the difficulty to access the whole study area presented some drawbacks to the study. We also had to limit the range of the study based on the quality and extent of the satellite imagery. The satellite data available for the study area were all acquired in consecutive months (November, December, and January). Although, the temporal differences were not large, some spatial variability in the land use changes sun angle and altitude and cloud cover and their shadows contributed to additional processing. We would recommend using radar imagery to overcome the cloud problem, since radar can penetrate cloud and shadow. 


\section{CONCLUSIONS}

This research was carried out in the National Macaya Park region from 1987 to 2004. The objectives were to demonstrate the usefulness of using satellite digital image processing coupled with GIS technology to map land use/cover and detect changes in land use/cover. The potential of using multi-sensor remotely sensed data, particularly, ASTER in conjunction with Landsat-5 TM, and Landsat ETM+ was also evaluated.

A hybrid classification approach was used to classify the image, given that this approach takes advantages of both supervised and unsupervised classification to improve the accuracy of the derived maps. The general trends observed were a decrease in open pine forest and mixed forest land cover types and a corresponding increase in built-up areas and herbaceous land. The study showed that:

1. Between 1987 and 2000, land areas covered with open pine forest and mixed compounded forest receded by $45 \%$ and $2 \%$ respectively. This represents a negative rate of change of $3.5 \%$ and $0.2 \%$ per annum. Agriculture and built-up area expanded at rates of $2 \%$ and $4 \%$ respectively; representing a net gain of $53 \%$ and $29 \%$. The conversion of forest to agriculture and development illustrate the impact of human activities on the dynamics of landscape change.

2. Between 2000 and 2004 , agriculture areas registered the greatest decline (an average 34\% per annum); while at the same time herbaceous land cover had a net gain of $115 \%$. This gain came mainly from agriculture $(18 \%)$. The results suggest that the soil was exhausted, so land used for agriculture was abandoned and herbaceous land cover type was expanding at the expense of agriculture. Open pine forest increased at an average rate of $9.96 \%$ due to intensive reforestation projects promoted by USAID, ORE in the 1990's. 
3. Between 1987 and 2004, built up areas (94\%) and herbaceous (89\%) increased significantly in 17 years. The increase of herbaceous was mostly caused by the conversion of agriculture. At the same time, open pine forest and mixed forest areas lost $(75 \%)$ and $(83 \%)$ of their areas to other land use/cover types. Open pine forest and mixed forest were transformed into barren land at a greater extent. This shows there was a trend of widespread illegal logging and clearing.

The results show the Macaya region is facing continuing land degradation, particularly deforestation and soil erosion. The whole park including areas outside the park boundary needs substantial reforestation and soil conservation intervention. There is a strong association between the estimation of change by land use/cover classes and the local population living nearby. The majority of the people earn a living from farming or from illegal logging. They form a class of deprived farmers, illiterate, forgotten in a remote area with no basic infrastructure.

A successful approach of promoting effective land use regulation, reforestation and biodiversity protection must also address the socio-economic situation of the farmers. Environmental and ecological programs and policies, which contribute to the empowerment of the local population and raise small farmer productivity, would have high success expectancy. Raising farmers self sufficiency, giving them an education and technical assistance on how to enhance and sustain the land and its natural resources will not only be beneficial to the environment and the farmer's welfare, but the whole economy, with a direct impact on achieving a high quality and quantity of agricultural productions to maintain a beneficial balance between the import and export rate. 
In addition, Haiti needs to implement strong and focused policies and laws following a participatory approach to reverse the trend of its chaotic environmental degradation. It is possible if state institutions, stakeholders, donors, Haitian people are willing to commit in a long-term sustainable reforestation and land use management process. For instance, the Dominican Republic and Costa Rica represent a model of successful forest management during the last three decades (Diamond 2005; Rodríguez 2005). There is also a need for strong and transparent institutions that are able to be open to the public and fulfill their mission as expected. Conflict resolutions regarding land use, forest exploitation, conflict of interest should be defined within the policies and laws and coordination among the various institutions involved in the process. In addition it is important to develop human capacities, trainers and training programs that take into account the people with their cultural beliefs and values (Babbie 1994; Kusel and Adler 2003; Creighton 2005). I also recommend the institutionalization of RS and GIS technologies to manage and monitor efficiently land use/cover resources. Maps of land use/cover, soil, species location, watersheds, and population statistics for each Department must be publicized, stored in a geospatial database and updated regularly for adopted planning and policy decision. 


\section{APPENDIX A: Principal Components Statistics and Analysis}

Multivariate Statistics derived from the PCA transformation for the Landsat TM image (1987)

\begin{tabular}{|lrrrrrr|}
\hline & \multicolumn{7}{c|}{ EIGENVALUES } & $\mathbf{5}$ & $\mathbf{7}$ \\
Component & $\mathbf{1}$ & $\mathbf{2}$ & $\mathbf{3}$ & $\mathbf{4}$ & $\mathbf{5}$ & $\mathbf{0}$ \\
Eigen values & 2132.808 & 244.207 & 105.0387 & 12.80839 & 2.426055 & 0.260781 \\
Differences & 1888.601 & 139.1683 & 92.23031 & 10.38233 & 2.165274 & 0 \\
Total Variance & 2497.549 & & & & & \\
Percentage & 85.39605 & 9.777864 & 4.205671 & 0.512838 & 0.097137 & 0.010441 \\
Cumulative & 85.39605 & 95.17391 & $\mathbf{9 9 . 3 7 9 5 8}$ & 99.89242 & 99.98956 & 100 \\
\hline
\end{tabular}

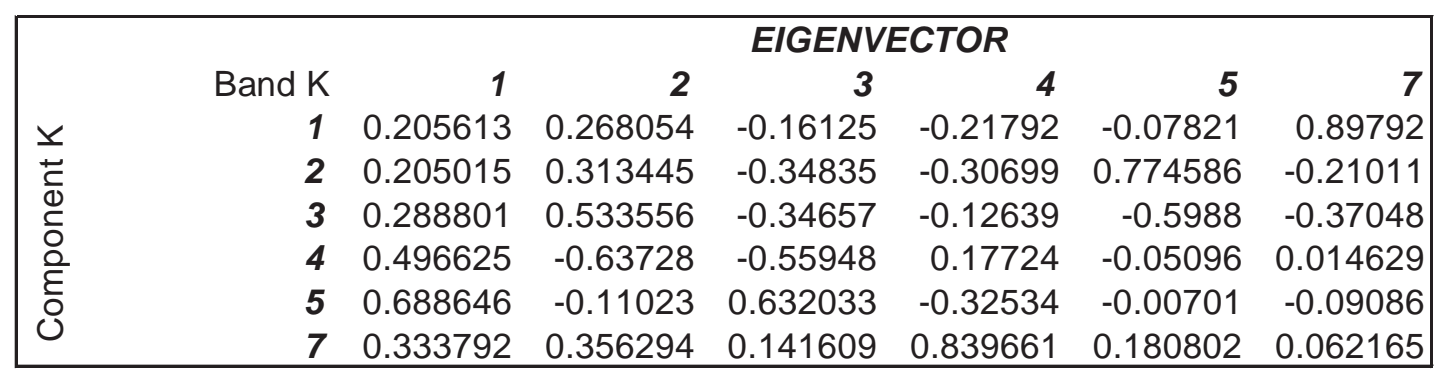

\begin{tabular}{|c|c|c|c|c|c|c|c|}
\hline \multirow{8}{*}{ 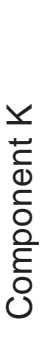 } & & \multicolumn{6}{|c|}{ COVARIANCE } \\
\hline & Band $\mathrm{K}$ & 1 & 2 & 3 & 4 & 5 & 7 \\
\hline & 1 & 111.2797 & 116.9853 & 167.8255 & 185.0644 & 284.9617 & 9401 \\
\hline & 2 & 116.9853 & 129.0581 & 179.1952 & 188.0511 & 270.8236 & 792 \\
\hline & 3 & 167.8255 & 179.1952 & 261.137 & 243.0161 & 387.3507 & 245.2425 \\
\hline & 4 & 185.0644 & 188.0511 & 243.0161 & 658.4929 & 708.6912 & 291.6669 \\
\hline & 5 & 284.9617 & 270.8236 & 387.3507 & 708.6912 & 1057.733 & 486.5631 \\
\hline & 7 & 164.9401 & 165.0792 & 245.2425 & 291.6669 & 486.5631 & 279.8487 \\
\hline
\end{tabular}

\begin{tabular}{|c|c|c|c|c|c|c|c|}
\hline & & & & ACTOR L & IDINGS & & \\
\hline & Band K & 1 & 2 & 3 & 4 & 5 & 7 \\
\hline$צ$ & 1 & 0.900158 & 0.397094 & -0.15666 & -0.07393 & -0.01155 & 0.009954 \\
\hline$\rightleftarrows$ & 2 & 0.833432 & 0.431169 & -0.31427 & -0.09671 & 0.106201 & 0944 \\
\hline$\stackrel{\oplus}{\check{D}}$ & 3 & 0.825353 & 0.515971 & -0.2198 & -0.02799 & -0.05772 & -0.01171 \\
\hline$\stackrel{0}{2}$ & 4 & 0.893776 & -0.38809 & -0.22345 & 0.024719 & -0.00309 & 0.000291 \\
\hline हิ & 5 & 0.977876 & -0.05296 & 0.199171 & -0.0358 & -0.0 & -0.00143 \\
\hline 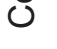 & 7 & 0.921488 & 0.332832 & 0.086757 & 0.179634 & 0.016834 & 0.001898 \\
\hline
\end{tabular}


Multivariate Statistics derived from the PCA transformation for the Landsat ETM+ image (2000)

\begin{tabular}{|lcccccc|}
\hline & \multicolumn{7}{c|}{ EIGENVALUES } \\
\hline & $\mathbf{1}$ & $\mathbf{2}$ & $\mathbf{3}$ & $\mathbf{4}$ & $\mathbf{5}$ & $\mathbf{7}$ \\
Eigen values & 3280.129 & 610.1729 & 173.4309 & 28.54379 & 10.1184 & 4.054727 \\
Differences & 2669.956 & 436.742 & 144.8871 & 18.42539 & 6.063671 & \\
Total Variance & 4106.45 & & & & & \\
Percentage & 79.87749 & 14.85889 & 4.223379 & 0.695097 & 0.246403 & 0.09874 \\
Cumulative & 79.87749 & 94.73638 & $\mathbf{9 8 . 9 5 9 7 6}$ & 99.65486 & 99.90126 & 100 \\
\hline
\end{tabular}

\begin{tabular}{|c|c|c|c|c|c|c|c|}
\hline & & & & EIGENI & ECTOR & & \\
\hline & Band $k$ & 1 & 2 & 3 & 4 & 5 & 7 \\
\hline 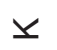 & 1 & 0.070586 & -0.52898 & -0.33453 & 0.616052 & -0.06808 & -0.468119 \\
\hline$\tilde{c}$ & 2 & 0.175095 & -0.4286 & -0.30543 & 0.079886 & 0.186134 & 0.807051 \\
\hline$\stackrel{0}{\check{2}}$ & 3 & 0.286888 & -0.45997 & -0.16198 & -0.7474 & 0.128802 & -0.323543 \\
\hline 을 & 4 & 0.601562 & 0.530727 & -0.58086 & 0.025756 & -0.12919 & -0.041244 \\
\hline ㄷํㅇ & 5 & 0.619941 & 0.002767 & 0.002767 & 0.233938 & 0.507534 & -0.066317 \\
\hline & 7 & 0.368579 & -0.20792 & 0.363621 & -0.00969 & -0.81844 & 0.136948 \\
\hline
\end{tabular}

\begin{tabular}{|c|c|c|c|c|c|c|c|}
\hline \multirow{8}{*}{ 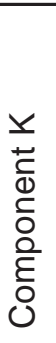 } & & \multicolumn{6}{|c|}{ COVARIANCE MATRIX } \\
\hline & Band $\mathrm{K}$ & 1 & 2 & 3 & 4 & 5 & 7 \\
\hline & 1 & 218.2579 & 196.3423 & 211.6686 & 0.297891 & 114.8106 & 131.4856 \\
\hline & 2 & 196.3423 & 232.0008 & 291.1199 & 237.1517 & 327.6387 & 245.686 \\
\hline & 3 & 211.6686 & 291.1199 & 420.1548 & 432.7852 & 563.0046 & 393.9461 \\
\hline & 4 & 2.297891 & 237.1517 & 432.7852 & 1417.58 & 1168.604 & 624.3576 \\
\hline & 5 & 114.8106 & 327.6387 & 563.0046 & 1168.604 & 1316.682 & 779.3268 \\
\hline & 7 & 131.4856 & 245.686 & 393.9461 & 624.3576 & 779.3268 & 501.7748 \\
\hline
\end{tabular}

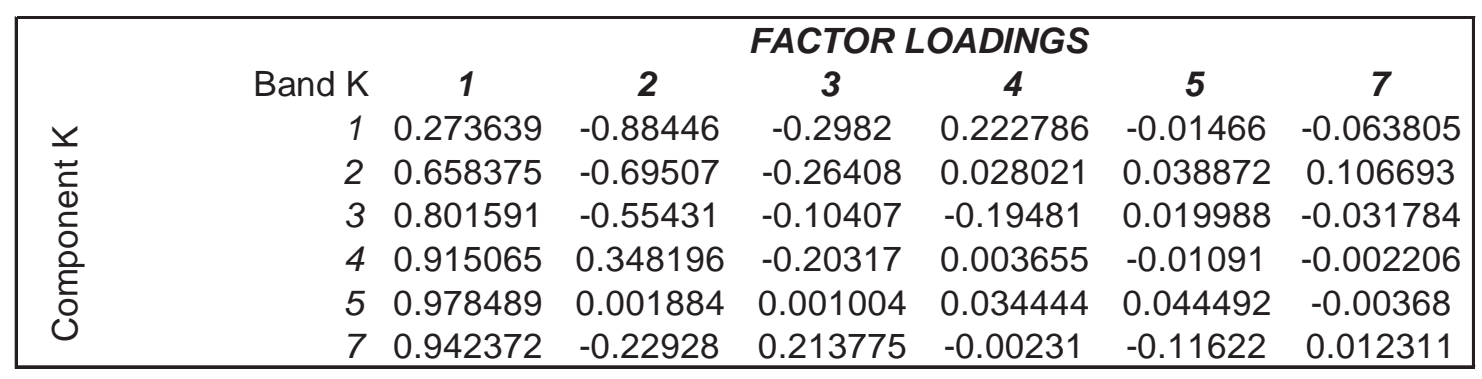


Multivariate Statistics derived from the PCA transformation for the ASTER VNIr+SWIR image (2004)

\begin{tabular}{|lrrrrrrrrr|}
\hline & & \multicolumn{9}{c|}{ EIGENVALUES } & $\mathbf{6}$ & $\mathbf{7}$ & $\mathbf{8}$ & $\mathbf{9}$ \\
& $\mathbf{1}$ & $\mathbf{2}$ & $\mathbf{3}$ & $\mathbf{4}$ & $\mathbf{5}$ & $\mathbf{6}$ & 1.94 & 1.20 & 0.67 \\
Eigen values & 7994.89 & 478.06 & 73.31 & 28.97 & 11.86 & 3.11 & 1.94 & \\
Differences & 7516.83 & 404.75 & 44.34 & 17.11 & 8.75 & 1.17 & 0.74 & 0.53 & \\
Total Variance & 8594.01 & & & & & & & & \\
Percentage & 93.03 & 5.56 & 0.85 & 0.34 & 0.14 & 0.04 & 0.02 & 0.01 & 0.01 \\
Cumulative & $\mathbf{9 3 . 0 3}$ & 98.59 & 99.44 & 99.78 & 99.92 & 99.96 & 99.98 & 99.99 & 100.00 \\
\hline
\end{tabular}

\begin{tabular}{|c|c|c|c|c|c|c|c|c|c|c|}
\hline & & & & & EIGL & VVECTC & & & & \\
\hline & Band K & 1 & 2 & 3 & 4 & 5 & 6 & 7 & 8 & 9 \\
\hline & 1 & 0.438 & -0.519 & 0.247 & 0.689 & 0.020 & 0.025 & -0.043 & 0.013 & -0.002 \\
\hline & 2 & 0.440 & -0.488 & 0.155 & -0.685 & -0.231 & -0.092 & 0.113 & -0.020 & 0.005 \\
\hline$\underline{x}$ & 3 & 0.439 & 0.595 & 0.639 & -0.069 & 0.176 & -0.009 & -0.087 & -0.030 & 0.013 \\
\hline$\frac{\bar{\sigma}}{0}$ & 4 & 0.328 & 0.329 & -0.266 & 0.170 & -0.638 & 0.210 & 0.434 & 0.148 & -0.148 \\
\hline ᄃ็ & 5 & 0.248 & 0.128 & -0.323 & 0.082 & 0.033 & -0.744 & -0.071 & -0.401 & -0.301 \\
\hline$\stackrel{2}{2}$ & 6 & 0.283 & 0.100 & -0.331 & -0.021 & -0.073 & -0.156 & -0.553 & 0.532 & 0.426 \\
\hline O & 7 & 0.254 & 0.056 & -0.301 & -0.016 & 0.117 & 0.371 & -0.023 & -0.649 & 0.519 \\
\hline & 8 & 0.253 & -0.012 & -0.281 & -0.118 & 0.305 & 0.471 & -0.325 & 0.049 & -0.648 \\
\hline & 9 & 0.208 & 0.005 & -0.230 & -0.029 & 0.628 & -0.095 & 0.610 & 0.331 & 0.131 \\
\hline
\end{tabular}

\begin{tabular}{|c|c|c|c|c|c|c|c|c|c|c|}
\hline & & & & & $C O$ & IIAN & & & & \\
\hline & Band $\mathrm{K}$ & 1 & 2 & 3 & 4 & 5 & 6 & 7 & 8 & 9 \\
\hline & 1 & 1679 & 1652 & 1400 & 1066 & 832 & 961 & 870 & 880 & 723 \\
\hline & 2 & 1652 & 1681 & 1416 & 1075 & 838 & 972 & 878 & 891 & 728 \\
\hline$y$ & 3 & 1400 & 1416 & 1742 & 1233 & 892 & 1008 & 895 & 871 & 723 \\
\hline Ф) & 4 & 1066 & 1075 & 1233 & 926 & 677 & 767 & 681 & 664 & 547 \\
\hline 동 & 5 & 832 & 838 & 892 & 677 & 509 & 576 & 514 & 505 & 418 \\
\hline है & 6 & 961 & 972 & 1008 & 767 & 224 & 657 & 585 & 579 & 477 \\
\hline O & 7 & 870 & 878 & 895 & 681 & 514 & 585 & 526 & 520 & 429 \\
\hline & 8 & 880 & 891 & 871 & 664 & 505 & 579 & 520 & 519 & 427 \\
\hline & 9 & 723 & 728 & 723 & 547 & 418 & 477 & 429 & 427 & 356 \\
\hline
\end{tabular}

\begin{tabular}{|c|c|c|c|c|c|c|c|c|c|c|}
\hline \multirow{2}{*}{\multicolumn{2}{|c|}{$d$}} & \multicolumn{9}{|c|}{ FACTORLOADINGS } \\
\hline & & 1 & 2 & 3 & 4 & 5 & 6 & 7 & 8 & 9 \\
\hline \multirow{9}{*}{ 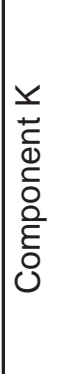 } & 1 & 0.955 & -0.277 & 0.052 & 0.091 & 0.002 & 0.001 & -0.001 & 0.000 & 0.000 \\
\hline & 2 & 0.961 & -0.260 & 0.032 & -0.090 & -0.019 & -0.004 & 0.004 & -0.001 & 0.000 \\
\hline & 3 & 0.941 & 0.312 & 0.131 & -0.009 & 0.015 & 0.000 & -0.003 & -0.001 & 0.000 \\
\hline & 4 & 0.965 & 0.237 & -0.075 & 0.030 & -0.072 & 0.012 & 0.020 & 0.005 & -0.004 \\
\hline & 5 & 0.982 & 0.124 & -0.123 & 0.020 & 0.005 & -0.058 & -0.004 & -0.019 & -0.011 \\
\hline & 6 & 0.989 & 0.085 & -0.111 & -0.004 & -0.010 & -0.011 & -0.030 & 0.023 & 0.014 \\
\hline & 7 & 0.991 & 0.054 & -0.124 & -0.004 & 0.018 & 0.029 & -0.001 & -0.031 & 0.018 \\
\hline & 8 & 0.992 & -0.012 & -0.106 & -0.028 & 0.046 & 0.037 & -0.020 & 0.002 & -0.023 \\
\hline & 9 & 0.987 & 0.006 & -0.104 & -0.008 & 0.115 & -0.009 & 0.045 & 0.019 & 0.006 \\
\hline
\end{tabular}




\section{APPENDIX B: Copyrights}

Jessie,

By all means use these two images for your thesis!!!

Keep in mind that amphibians would also be high on your list-as I recall $93 \%$ of Haiti's amphibians are in some category of threat (IUCN red List). Also keep in mind that reptiles are in the process of being evaluated for Red Listing as well and La Hotte has a few that will surely make it in. In addition, orchids-especially from the genera Lepanthes, Lepanthopsis, Pleurethalis, Tomzanonia, etc. are not classified under the Red List either. The forest around Formond is a place of high endemism of these orchids, whch are rapidly disappearing.

If you need more pics, let me know.

Eladio Fernandez

Caribbean Nature Photography

www.eladiofernandez.com

tel 809-224-3665

Dominican Republic

> Date: Thu, 16 Oct 2008 11:50:31 -0400

$>$ From: javital@mtu.edu

> To: eladio 809@hotmail.com; eladiof@mac.com

> Subject: Copyright permission pictures

$>$ Dear Mr. Fernandez,

My name is Jessie Vital. I am a Haitian Master's Graduate student at Michigan

Technological University. I am currently writing my thesis on land use/cover change within and adjacent the Pic Macaya National Park, Haiti. To describe the area of study in term of its fauna, I was looking for some pictures of the endangered species within the Macaya region in the web. Fortunately, I found these two interesting pictures taken by you: 1 . Hispaniolan Solenodon 2. White winged Warbler. I would appreciate that you grant me permission to use these picture in my thesis. The Graduate School (Forest and Ecology Management) would need a message, either a form or e-mail from the author of the pictures, which said I was allowed to use the pictures in my document.

I am hopeful that you will say yes and I am available for any information you required.

Mesi ampil, muchas gracias!

Jessie Vital

Master's Candidate Forest Ecology and Management

Michigan Technological University 
Image:Pterodroma hasitataPCCA20070623-3608B.jpg

From Wikispecies

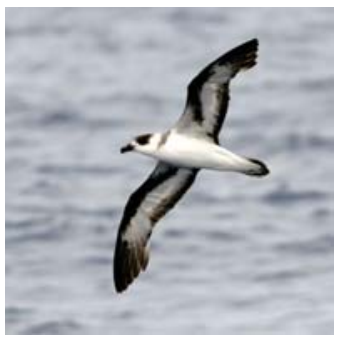

No higher resolution available.

Pterodroma hasitataPCCA20070623-3608B.jpg (499 $\times 512$ pixel, file size: $46 \mathrm{~KB}$, MIME type: image/jpeg)

This is a file from the Wikimedia Commons. The description on its description page there is shown below.

The description on its file description page on the shared repository is shown below.

Description Black-capped Petrel, Pterodroma hasitata, Location: Gulf Stream off of Hatteras, North Carolina, United States

Source Photograph taken by Patrick Coin

Date created 2007-06-23

Author Patrick Coin (Patrick Coin)

Permission cc-by-sa-2.5

(Reusing

$\underline{\text { this }}$

image)

Other none

versions

[edit]

Licensing

Ce SOME RUGHTS RESERVED

This file is licensed under the Creative Commons Attribution ShareAlike 2.5 License. In short: you are free to share and make derivative works of the file under the conditions that you appropriately attribute it, and that you distribute it only (1)(2) under a license identical to this one. Official license 


\section{APPENDIX C: Relevé Field Form}

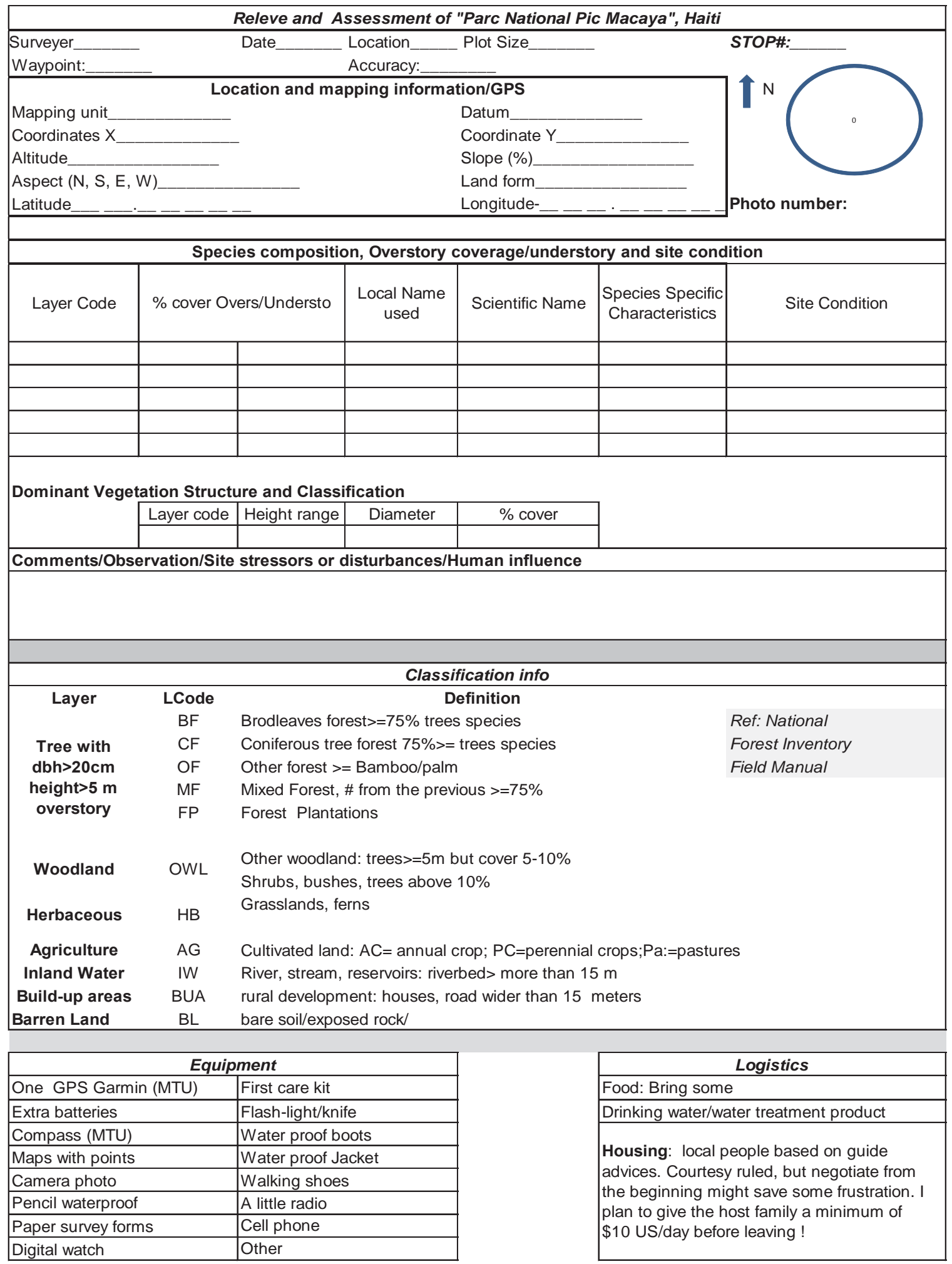




\section{LITERATURE CITED}

Abrams, M., S. Hook and B. Ramachandran 2004. ASTER User Handbook, Version 2 (Available at http://asterweb.jpl.nasa.gov/content/03_data/04_Documents/ aster_user_guide_v2.pdf [Access 11/20/2007]).

Allen, J.C. and D.F. Barnes 1985. The Causes of Deforestation in Developing Countries. Annals of the Association of American Geographers, 75(2): 163-184.

Anderson, J.R., E.E. Hardy, J.T. Roach and R.E. Witmer. 1976. A Land Use and Land Cover Classification System for Use with Remote Sensor Data. In., Washington, DC:US Geological Survey, U. S. Geological Survey Professional Paper 964 p28.

Anderson, R.P. and E. Martinez-Meyer 2004. Modeling species' geographic distributions for preliminary conservation assessments: an implementation with the spiny pocket mice (Heteromys) of Ecuador. Biological Conservation, 116(2): 167-179.

Areces-Mallea, A.E., A.S. Weakley, X. Li, R.G. Sayre, J.D. Parrish, C.V. Tipton and T. Boucher 1999. A Guide to Caribbean Vegetation Types:Preliminary Classification System and Descriptions The Nature Conservancy, pp157.

Babbie, E.R. 1994. The sociological spirit : critical essays in a critical science. Wadsworth Pub. Co., Belmont, California.

Brodlie, K., L. Carpenter, R. Earnshaw, J. Gallop, R. Hubbold, A. Mumford, C. Osland and P. Quarendon. 1992. Scientific Visualization: Techniques and Applications Springer Verlag, Berlin; New York.

Bruzzone, L., R. Cossu and G. Vernazza 2002. Combining parametric and nonparametric algorithms for a partially unsupervised classification of multitemporal remotesensing images. Information Fusion, 3(4): 289-297.

Bruzzone, L., R. Cossu and G. Vernazza 2004. Detection of land-cover transitions by combining multidate classifiers. Pattern Recognition Letters, 25(13): 1491-1500.

Bruzzone, L. and F. Prieto 2000. Automatic Analysis of the Difference Image for Unsupervised Change Detection. IEE Transactions on Geoscience and Remote Sensing, 38(3): 1171-1182.

Campbell, J.B. 2007. Introduction to Remote Sensing. 3rd edition Guildford Press, New York.

Castellana, L., A. D'Addabbo and G. Pasquariello 2007. A composed supervised/unsupervised approach to improve change detection from remote sensing. Pattern Recognition Letters, 28(4): 405-413. 
Chang, K.T. 2006. Introduction to Geographic Information Systems. 4th edition. McGraw-Hill Education, New York, NY p459.

Chavez, P.S. 1988. An improved dark-object subtraction technique for atmospheric scattering correction of multispectral data. Remote Sensing of Environment, 24(3): 459479.

Chavez, P.S. 1996. Image-based atmospheric corrections - Revisited and Improved Photogrammetric Engineering and Remote Sensing, 62(9): 1025-1036.

Civco, D.L., J.D. Hurd, E.H. Wilson, M. Song and Z. Zhang. 2002. A Comparison of Land Use and Land Cover Change Detection Methods. In. Proceedings ASPRS-ACSM Annual Conference and FIG XXII Congress, April 22-26, Bethesda, MD. American Society for Photogrammetry and Remote Sensing p22-26.

Cohen, W.B. 1984. Environmental Degradation in Haiti: An Analysis of Aerial Photography. United States Agency For International Development, Port-au-Prince pp48.

Cohen, W.B. and S.N. Goward 2004. Landsat's role in ecological applications of remote sensing. BioScience, 54(6): 535-545.

Congalton, R.G. and K. Green. 1999. Assessing the Accuracy of Remotely Sensed Data: Principles and Practices. Lewis CRC Press.

Creighton, J.L. 2005. The Public Participation Handbook: Making better decisons through citizen involvement. Jossey-Bass A Willey Imprint, San Francisco, CA.

Currit, N. 2005. Development of a remotely sensed, historical land-cover change database for rural Chihuahua, Mexico. International Journal of Applied Earth Observation and Geoinformation, 7(3): 232-247.

Diamond, J.M. 2005. Collapse : How societies choose to fail or succeed. The Penguin Group Viking, New York p592.

Dolisca, F., J.M. McDaniel and L.D. Teeter 2007a. Farmers' perceptions towards forests: A case study from Haiti. Forest Policy and Economics, 9(6): 704-712.

Dolisca, F., J.M. McDaniel, L.D. Teeter and C.M. Jolly 2007b. Land tenure, population pressure, and deforestation in Haiti: The case of Foret des Pins Reserve. Journal of Forest Economics, 13(4): 277-289.

Duda, R.O., P.E. Hart and D.G. Stork. 2001. Pattern Classification. John Wiley \& Sons, New York.

Feldpausch, T.R., A.J. McDonald, C.A.M. Passos, J. Lehmann and S.J. Riha 2006. Biomass, harvestable area, and forest structure estimated from commercial timber 
inventories and remotely sensed imagery in southern Amazonia. Forest Ecology and Management, 233(2006): 121-132.

Foody, G.M. 2002. Status of Land Cover Classification Accuracy Assessment. Remote Sensing of Environment, 80: 185-201.

Franklin, S.E. and M.A. Wulder 2001. Remote sensing methods in medium spatial resolution satellite data land cover classification of large areas. Progress in Physical Geography, 26: 173-205.

Gillespie, A., M. Abrams and Y. Yamaguchi 2005. Scientific results from ASTER. Remote Sensing of Environment, 99(1-2): 1.

Gong, P. and B. Xu 2003. Remote Sensing of forest over time: Change types, methods and opportunities. In: Wulder, M. A. and S. E. Franklin (Eds.). Remote sensing of forest environments: Concepts and case studies (pp:301-333). Kluwer Press Amsterdam, Netherlands pp519.

Güler, M., T. Yomralıoglu and S. Reıs 2006. Using Landsat data to determine land use/land cover changes in Samsun, Turkey. Environmental Monitoring Assessment, 127(1-3): 155-167.

Haklay, M.E. 2003. Public access to environmental information: past, present and future. Computers, Environment and Urban Systems, 27(2): 163-180.

Hartter, J., C. Lucas, A.E. Gaughan and L. Lizama Aranda 2008. Detecting tropical dry forest succession in a shifting cultivation mosaic of the Yucatán Peninsula, Mexico. Applied Geography, 28(2): 134-149.

Hayes, D.J. and W.B. Cohen 2007. Spatial, spectral and temporal patterns of tropical forest cover change as observed with multiple scales of optical satellite data. Remote Sensing of Environment, 106(1): 1-16.

Heiskanen, J. 2006. Estimating aboveground tree biomass and leaf area index in a mountain birch forest using ASTER satellite data. International Journal of Remote Sensing, 27(6): 1135-1158.

Helmer, E.H., O. Ramos, T.d. Lopez, M, M. Quiñones and W. Dıáz 2002. Mapping the forest type and land cover of Puerto Rico, a component of the Caribbean biodiversity hotspot. Caribbean Journal of Science, 38((3-4)): 165-183.

Holdridge, L.R. 1942. The pine forest of Haiti. Caribbean Forest, 4(1): 16-22.

Holdridge, L.R. 1947. The pine forest and adjacent mountain vegetation in Haiti considered from the standpoint of a new climatic classification of plants formations. Ph. D. dissertation. University of Michigan, Ann Arbor, p187. 
Howard, R.A. 1973. The vegetation of the Antilles. In: Graham, A. (Ed.). Vegetation and Vegetational History of Northern Latin America. Elsevier, New York pp1-38.

IHSI 2003. Résultats préliminaires: 4ème recensement général de la population et de I'habitat. Institut Haitien de Statistique et d'Informatique (IHSI), Port-au-Prince.

International Union for Conservation of Nature 2008. The IUCN Red List of Threatened Species. (Available at http://www.iucnredlist.org/ [Access 10/21/2008]).

Jensen, J.R. 2000. Remote Sensing of The Environment. Prentice Hall, Upper Saddler River, NJ p526.

Jensen, J.R. 2005. Introductory Digital Image Processing: A Remote Sensing Perspective. 3rd Prentice Hall, Upper Saddle River, New Jersey.

Judd, W.S. 1987. Floristic study of Morne la Visite and Pic Macaya National Parks, Haiti. Bull. Florida St. Mus. Biological Sience, 32(1): 1-136.

Kaufmann, R.K. and K.C. Seto 2001. Change detection, accuracy, and bias in a sequential analysis of Landsat imagery in the Pearl River Delta, China: econometric techniques. Agriculture, Ecosystems \& Environment, 85(1-3): 95-105.

Kusel, J. and E. Adler. 2003. Forest communities, community forests. Rowman \& Littlefield Publishers, Lanham, Md.

Laurance, W.F., C.A. Peres, P.A. Jansen and L. D'Croz 2006. Emerging Threats to Tropical Forests: What We Know and What We Don't Know. In: Laurance, W. F. and C. A. Peres (Eds.). Emerging Threats to Tropical Forests. University of Chicago Press, Chicago pp437-462.

Leica Geospatial Imaging. 2005. ERDAS Field Guide. Leica Geospatial Imaging, LLC Norcross, GA p770.

Lillesand, T.M., R.W. Kiefer and J.W. Chipman. 2008. Remote Sensing and Image Interpretation 6th edition Wiley.

Lo, C.P. and J. Choi 2004. A hybrid calssification approach to urban land use/cover mapping using Landsat 7 Enhanced Thematic Mapper Plus (ETM+) images. International Journal of Remote Sensing, 25(14): 2687-2700.

Macleod, R.D. and R.G. Congalton 1998. Quantitative Comparison of Change-Detection Algorithms for Monitoring Eelgrass from Remotely-Sensed Data. Photogrammetric Engineering and Remote Sensing, 64(3): 207-216.

Meyer, W.B. 1995. Past and Present Land Use and Land Cover in the USA. Consequences, 1(1): 24-33. 
Moran, M.S., R.D. Jackson, P.N. Slater and P.M. Teillet 1992. Evaluation of simplified procedures for retrieval of land surface reflectance factors from satellite sensor output. Remote Sensing of Environment, 41(2-3): 169-184.

Munasinghe, M. 1993. Environmental economics and biodiversity management in developing countries. Ambio, 22(2-3): 126-135.

Myers, N., R.A. Mittermeier, C.G. Mittermeier, G. Fonseca and J. Kent 2000. Biodiversity hotspots for conservation priorities. Nature, 403: 853-858.

Nangendo, G., A.K. Skidmore and H. van Oosten 2007. Mapping East African tropical forests and woodlands -- A comparison of classifiers. ISPRS Journal of Photogrammetry and Remote Sensing, 61(6): 393-404.

NASA Landsat 7 2004. Landsat 7 Science Data Users Handbook (Available at http://landsathandbook.gsfc.nasa.gov/handbook/handbook toc.html [Access January 8, 2008]).

National Aeronautics and Space Administration (NASA) 1999. Advanced Spaceborne Thermal Emission and Reflection Radiometer (ASTER). (Available at http://asterweb.jpl.nasa.gov/ [Access June 3,2008]).

Olson, D., E, E. Dinerstein, G. Castro and E. Maravi 1996. Identifying gaps in botanical infromation for biodiversity conservation in Latin America and the Caribbean (Available at $[$ Access.

Organization for the Rehabilitation of the Environment 2001 A wake-up call for CampPerrin and the Canal d'Avezac (Available at http://www.oreworld.org/laprise.htm [Access 21 June, 2008]).

Paryski, P., C.A. Woods and F. Sergile 1988. Conservation Strategies and the Preservation of Biological Diversity in Haiti. United Nations Development Programme, Port-au-Prince, Haiti pp23.

Pellek, R. 1990. Combating Tropical Deforestation in Haiti: Implementing an action plan requires a more stable political environment. Journal of Forestry, 88(9): 15-19.

Pierre-Louis, R. 1989. Forest policy and deforestation in Haiti: the case of the Forêt des Pins (1915-1985). Ministere de l'Agriculture, des Ressources Naturelles et du Developpement Rural (MARNDR), Port-au-Prince, Haiti, p151.

Read, J.M. and N.S.N. Lam 2002. Spatial methods for characterizing land cover and detecting land-cover changes for the tropics. International Journal of Remote Sensing, 23(12): 2457-2474.

Richards, J.A. and J. Xiuping 2006. Clustering and Unsupervised Classification. In. Remote Sensing Digital Image Analysis. Springer, pp249-266. 
Riebsame, W.E., W.B. Meyer and B.L. Turner II 1994. Modeling land use and cover as part of global environmental change. Climatic Change, 28: 45-64.

Rodríguez, C.M. 2005. The Environmental Services Payment Program: A Success Story of Sustainable Development Implementation in Costa Rica (Available at http://www.imfn.net/en/ev-91178-201-1-DO TOPIC.html [Access 11/18/2008]).

Sergile, F., C.A. Woods and P. Paryski 1992. Final Report Macaya Biosphere Reserve Project. Gainesville, FI pp130.

Shalaby, A. and R. Tateishi 2007. Remote sensing and GIS for mapping and monitoring land cover and land-use changes in the Northwestern coastal zone of Egypt. Applied Geography, 27(1): 28-41.

Shrivastava, R.J. and J.L. Gebelein 2007. Land cover classification and economic assessment of citrus groves using remote sensing. ISPRS Journal of Photogrammetry and Remote Sensing, 61(5): 341-353.

Sieber, R.E. 2003. Public participation geographic information systems across borders. The Canadian Geographer, 47(1): 50-61.

Singh, A. 1989. Digital change detection techniques using remotely sensed data International Journal of Remote Sensing, 10(6): 989-1003.

Song, C., C.E. Woodcock, K.C. Seto, M.P. Lenney and S.A. Macomber 2001. Classification and Change Detection Using Landsat TM Data: When and How to Correct Atmospheric Effects. Remote Sensing of Environment, 75(2): 230-244.

Stein, T.V., D.H. Anderson and T. Kelly 1999. Using stakeholders' values to apply ecosyste management in the upper Midwest landscape. Environmental Management, 24(3): 399-413.

Strauss, V. 2000. Wood has become a scarce commodity (Available at http://www.eoearth.org/article/Hispaniolan moist forests [Access 02/22/2008]).

Tasaico, H. 1967. Ecología (zonas de vida de la República Dominicana). . In: I., T. (Ed.). Organización de los Estados Americanos (OEA). Reconocimiento y evaluación de los recursos naturales de la República Dominicana,. OEA, Washington, D.C. (mapa).

Timyan, C.J. 2000. GIS Analysis of the Endemic Flora of Pic Macaya National Park, Haiti. New York Botanical Garden pp21.

UNEP-WCMC 1997. United Nations List of Protected Areas (Available at http://www.unep-wcmc.org/cgi-bin/pa un97 [Access 10/09/2007]).

UNEP 2007. Activities of UNEP/ROLAC (Available at http://www.pnuma.org/ informacion_ing/penumanuevasing/index_i.php [Access 08/20/2008]). 
Van Lynden, G., W. J. and S. Mantel 2001. The role of GIS and remote sensing in land degradation assessment and conservation mapping: some user experiences and expectations. International Journal of Applied Earth Observation and Geoinformation, 3(1): 61-68.

Vincent, R.K. 1972. An ERTS multispectral scanner experiment for mapping iron compounds In. Proceedings 8th International Symposium on Remote Sensing of Environment, Ann Arbor, MI, p1239-1247.

Wulder, M.A., J.C. White, S.N. Goward, J.G. Masek, J.R. Irons, M. Herold, W.B. Cohen, T.R. Loveland and C.E. Woodcock 2008. Landsat continuity: Issues and opportunities for land cover monitoring. Remote Sensing of Environment, 112(3): 955-969.

Zurick, D.N. 1995. Preserving paradise. The Geographical Review, 85(2): 157-172. 